\author{
Universidade de SÃo Paulo \\ Instituto DE FÍsicA
}

\title{
Estudo do mecanismo de deposição de filmes finos de nitreto de carbono preparados com o sistema de deposição assistida por feixe de íons
}

\author{
Wilmer Alexe Sucasaire Mamani \\ Orientador: Prof. Dr. Masao Matsuoka \\ Tese de doutorado apresentada ao Instituto de Física \\ para a obtenção do título de Doutor em Ciências
}

Comissão Examinadora:

Prof. Dr. Masao Matsuoka (IFUSP)

Profa. Dra. Márcia Carvalho de Abreu Fantini (IFUSP)

Profa. Dra. Lucy Vitória Credidio Assali (IFUSP)

Prof. Dr. Luis da Silva Zambom (FATEC/SP)

Prof. Dr. Pedro Augusto de Paula Nascente (UFScar)

\section{São Paulo}


A mi esposa Miriam y a mis hijitos Wilmer Rodrigo,

Patricia Valentina y Juan Diego, y a mamá Lady que con amor e dedicación me apoyaron y me incentivaron en la obtención de este título.

A mis padres Avelino y Silveria, y a mis hermanos Yané, Rossel, Marleny y René, por el apoyo moral que siempre me mostraron. 


\section{Agradecimentos}

Quero, primeiramente, agradecer a Deus por conceber-me a vida e por conseguinte a capacidade de vencer os obstáculos.

Quero agradecer a minha familia por todo o apoio demonstrado durante toda a minha vida, pelo grande estímulo constante, por ensinar-me que sempre há um lugar onde posso voltar.

Ao Prof. Dr. Masao Matsuoka, pela orientação, incansável apoio, estímulo e paciência durante a realização deste trabalho.

Ao Dr. Leônidas Mello, pela colaboração e brindar todo o apoio na realização das medidas da espectroscospia de Raman.

Ao Prof. Dr. José F. D. Chubaci, pela colaboração das medidas de ERDA e da espectroscopia Raman, e a Dra. Roseli Guennari, pela colaboração das medidas de espectroscopia do IR e pelas correções do texto.

Agradecer a Ricardo, Edgar, Javier, Henry e Walter Cárdenas; pessoas que me ajudaram em algo muito importante: a realização deste trabalho! E isso é uma felicidade inexplicável, e quero manifestar todo meu apreço por eles.

Agradecer a Karina, Walter Feria, Manuel, Edna, Nilo, Thiago, Luiz e Rene companheiros do grupo de LACIFID. Eles são exemplo de paciência e de simpatia.

Quero agradecer à entidade CAPES pelo auxilio financeiro sem a qual nada disto teria sido possível.

A todos que diretamente ou indiretamente colaboram na execução deste trabalho e que involuntariamente foram omitidos. 


\section{Resumo}

Filmes finos de $\mathrm{CN}_{x}$ foram depositados em temperatura ambiente, $350,400,500^{\circ} \mathrm{C}$, por deposição a vapor de carbono sobre os substratos de $\operatorname{Si}(100)$ ou $\operatorname{Si}(111)$ com irradiação simultânea por íons derivado de gás $\mathrm{N}_{2}$ ou de mistura gasosa $A r-\mathrm{N}_{2}$. A energia de íons variou de 150 a 600 eV e a razão de chegada, $\mathrm{R}(\mathrm{I} / \mathrm{A})$, definida pela razão do fluxo de íons de nitrogênio incidentes relativa ao fluxo de átomos de carbono transportados ao substrato, foi de 1,0-2,5. A pressão de gás na câmara de vácuo foi mantida a $1,6 \times$ $10^{-2} \mathrm{~Pa}$ durante o processo de deposição. A taxa de deposição dos filmes foi governada pelo sputtering químico. O rendimento de sputtering químico por íons de nitrogênio foi practicamente independente da energia de íons utilizada, enquanto que o rendimento de sputtering químico por íons de Ar e nitrogênio foi dependente da energia de íons devido ao efeito multiplicativo dos íons. Os espectros Raman medidos mostraram dois picos em torno de 1350 e $1560 \mathrm{~cm}^{-1}$, chamados do pico D e do G, respectivamente, e foram analisados em termos de: posição e largura do pico $\mathrm{G}$, e razão das intensidades $\mathrm{I}_{D} / \mathrm{I}_{G}$.

Os comportamentos destes parâmetros obtidos em função de R(I/A) foram explicados razoavelmente através do modelo de três estágios, sugerido por Ferrari et al., levando em consideração uma transição da fase característica de grafite à de fulereno, na qual a incorporação suficiente de nitrogênio em camadas grafíticas promove a formação de anéis pentagonais que pode induzir o enrugamento em camadas, facilitando ligações entre as camadas através de átomos de carbono hibridizados de $s p^{3}$. Um indício da ocorrência desta transição pode ser visto nos difratogramas de raios X dos filmes correspondentes. Neste contexto, os espectros Raman e de XPS dos filmes de $\mathrm{CN}_{x}$ depositados previamente com o método RF magnetron sputtering reativo foram analisados e explicados consistentemente, levando-se em consideração a concentração de nitrogênio nos filmes. 


\section{Abstract}

Thin $\mathrm{CN}_{x}$ films were deposited at room temperature, $350,400,500^{\circ} \mathrm{C}$, by carbon vapor deposition on $\mathrm{Si}(100)$ or $\mathrm{Si}(111)$ substrates with simultaneous irradiation by ions derived from $\mathrm{N}_{2}$ gas or from a gas mixture of $\mathrm{Ar}-\mathrm{N}_{2}$. The ion energy varied from 150 to $600 \mathrm{eV}$ and the arrival rate ratio, $\mathrm{R}(\mathrm{I} / \mathrm{A})$, defined as the ratio of the flux of incident nitrogen ions relative to flux of carbon atoms transported to the substrate, was in the range of 1.02.5. The gas pressure in the vacuum chamber was maintained at $1.6 \times 10^{-2} \mathrm{~Pa}$ during the deposition. The deposition rate of the films was governed by chemical sputtering. The chemical sputtering yield by nitrogen ions was practically independent of the ion energy used, while the chemical sputtering yield by Ar and nitrogen ions was dependent on it due to the multiplicative effect of the ions. Raman spectra measured showed two peaks around 1350 and $1560 \mathrm{~cm}^{-1}$, called D and G peaks, respectively, and were analyzed in terms of: the $\mathrm{G}$ peak position and width, and the peak intensity ratio $\mathrm{I}_{D} / \mathrm{I}_{G}$. The behaviors of these parameters as a function of $\mathrm{R}(\mathrm{I} / \mathrm{A})$ were explained reasonably through the three-stage model, suggested by Ferrari et al., taking into account a transition from a graphitelike phase to a fullerenlike phase, in which a sufficient incorporation of nitrogen into graphitic planes promotes a formation of pentagonal rings which can induce buckling of graphitic planes, facilitating cross-linking between the planes through $s p^{3}$-hybridized carbon atoms. Evidence for this transition could be seen in X-ray diffratograms of the corresponding

films. In this context, Raman and XPS spectra of $\mathrm{CN}_{x}$ films previously deposited with the reactive $\mathrm{RF}$ magnetron sputtering method were analyzed and explained consistently, considering the nitrogen concentration in the films. 


\section{Conteúdo}

1 Introdução 1

1.1 Considerações gerais $\ldots \ldots \ldots \ldots \ldots$

1.2 Hibridização do átomo de carbono . . . . . . . . . . . . . . . . . . . 4

1.2 .1 Hibridização $s p \ldots \ldots \ldots \ldots \ldots \ldots \ldots \ldots \ldots$

$1.2 .2 \quad$ Hibridização $s p^{2} \ldots \ldots \ldots \ldots \ldots \ldots \ldots \ldots \ldots \ldots$

$1.2 .3 \quad$ Hibridização $s p^{3} \ldots \ldots \ldots \ldots \ldots \ldots$

1.3 Nitrogênio na matriz carbonada . . . . . . . . . . . . . . . . . . 9

1.4 Métodos de deposição . . . . . . . . . . . . . . . . . . . . . . . . . . . . . . 12

1.4.1 CVD assistida por plasma $\ldots \ldots \ldots \ldots \ldots \ldots$

1.4 .2 Deposição por sputtering . . . . . . . . . . . . . . . 13

1.4 .3 Laser ablation . . . . . . . . . . . . . . . . . . . . . 14

1.4.4 Deposição assistida por feixe de íons . . . . . . . . . . . . . 14

1.5 Motivações e objetivos do trabalho . . . . . . . . . . . . . . . . 15

2 Sistema IBAD $\quad 17$

$2.1 \quad$ Sistema IBAD . . . . . . . . . . . . . . . . . . . . . . . . . 17

2.2 Fonte de íns . . . . . . . . . . . . . . . . . . . . . . . 20

2.3 Características da fonte de íons . . . . . . . . . . . . . . . . . . 21 


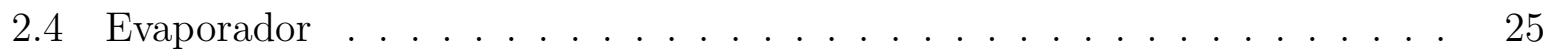

2.5 Preparação dos filmes de $\mathrm{CN}_{x}$. . . . . . . . . . . . . . . . . . 27

3 Técnicas de caracterização $\quad 29$

3.1 Perfilometria . . . . . . . . . . . . . . . . . 29

3.2 Espalhamento de partículas em recuo elástico . . . . . . . . . . . . 30

3.3 Espectroscopia Raman . . . . . . . . . . . . . . . . . . . 32

3.4 Espectroscopia do infravermelho . . . . . . . . . . . . . . . 43

3.5 Espectroscopia de fotoelétrons induzida por raios X . . . . . . . . . . 48

3.6 Difração de raios X . . . . . . . . . . . . . . . . . . . 51

4 Resultados e discussão $\quad 54$

4.1 Taxa de deposição . . . . . . . . . . . . . . . . . . . . . 54

4.2 A razão da composição química . . . . . . . . . . . . . . . . . 63

4.3 Espectros de absorção do IR dos filmes de $\mathrm{CN}_{x} \quad \ldots .$. . . . . . . . . . 65

4.3.1 Filmes depositados com o feixe de íons de nitrogênio . . . . . . . . 65

4.3.2 Filmes depositados com o feixe de íons derivado de $\mathrm{Ar}_{-} \mathrm{N}_{2} \ldots \ldots$. . 72

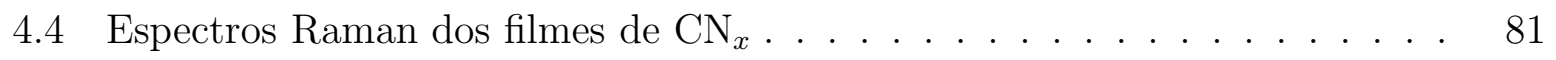

4.4.1 Filmes depositados com o feixe de íons de nitrogênio . . . . . . . . 81

4.4.2 Filmes depositados com o feixe de íons derivado de $\mathrm{Ar}_{-} \mathrm{N}_{2} \ldots \ldots$. . . 87

4.5 Difração de raios X . . . . . . . . . . . . . . . . . . . 94

4.6 Comparação com filmes de $\mathrm{CN}_{x}$ preparados com o método $\mathrm{RF}$ magnetron

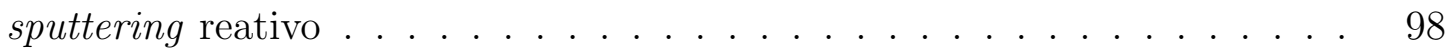


5.1 Taxa de deposição . . . . . . . . . . . . . . . . . . . . . 105

5.2 Espectroscopia do IR . . . . . . . . . . . . . . . . . 105

5.3 Espectroscopia Raman . . . . . . . . . . . . . . . . . 106

5.4 Difração de raios X . . . . . . . . . . . . . . . . . . . 107

A Razão da Taxa de Chegada, R(I/A) 114

A.1 Cálculo de fluxo de íons de nitrogênio, I . . . . . . . . . . . . . . . . . 114

A.2 Cálculo de fluxo de átomos de carbono evaporados, A . . . . . . . . . . . . 117

A.3 Cálculo de R(I/A) . . . . . . . . . . . . . . . . . . . 117

$\begin{array}{lr}\text { B Participação em congressos } & 118\end{array}$

$\begin{array}{lr}\text { C Artigos publicados } & 119\end{array}$ 


\section{Capítulo 1}

\section{Introdução}

\subsection{Considerações gerais}

O carbono (C) é, sem dúvida, o elemento químico principal da biosfera, o pilar básico da química orgânica, e portanto, a base para todos os seres vivos. Por outro lado, dependendo das condições de formação, o C pode ser encontrado na natureza em diversas formas alotrópicas, amorfo e cristalino em forma de grafite ou diamante (a estrutura material mais dura conhecida na natureza).

A partir da década de 80, os êxitos obtidos na produção de materiais amorfos de alta dureza incentivaram os estudos dos filmes de carbono amorfo $(a-\mathrm{C})$, conhecidos como os filmes de carbono diamond-like [1]. Estes filmes evidenciaram boas características para usos potenciais em aplicações ópticas, eletrônicas e tribológicas. Além de terem dureza elevada, estes materiais são quimicamente inertes e transparentes na região de infravermelho. Devido a elevada resistência química, os filmes de $a$-C são usados como recobrimento protetor para discos rígidos de computador. Contudo, certas propriedades dos filmes duros de carbono limitam sua aplicabilidade. Eles têm tensão compressiva alta 
que limita sua espessura máxima e dificulta sua adesão aos diferentes substratos [2]. Para que tenham aplicações tribológicas, é necessário, ainda, que os filmes tenham estabilidade térmica. Estes fatos têm motivado estudos sobre os filmes de carbono [3] modificados pela presença de outro átomo, o nitrogênio $(\mathrm{N})$ [4]. Os filmes com a ligação de $\mathrm{C}$ e $\mathrm{N}(\mathrm{C}-\mathrm{N})$ podem ser candidatos para ter a baixa compressibilidade [5].

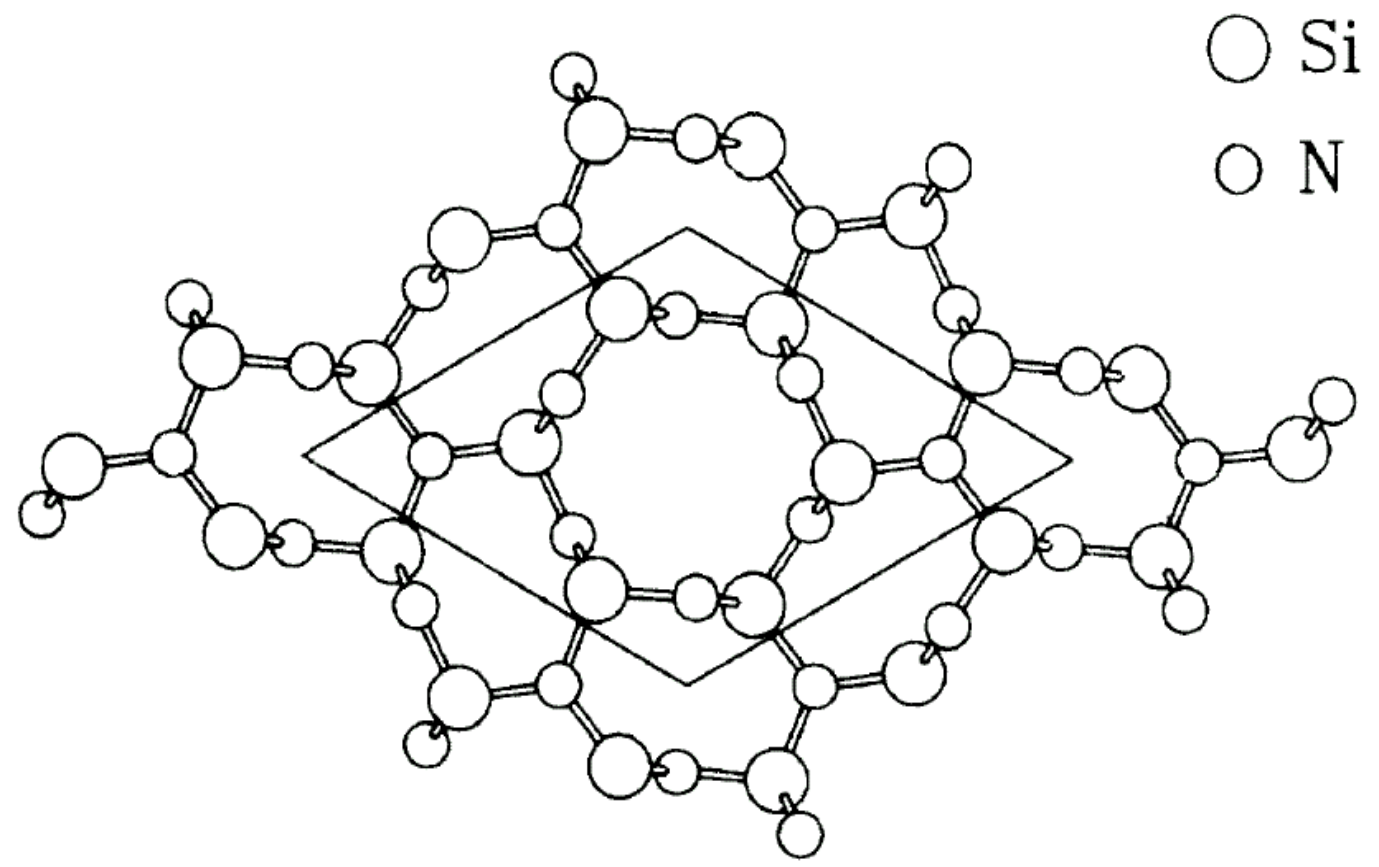

Figura 1.1: Estrutura de $\beta-S_{3} N_{4}$ no plano a-b. O eixo $c$ é normal a esta folha. O paralelogramo indica a célula unitária [5].

Em 1989 e 1990, Liu e Cohen [5, 6] apresentaram os resultados dos estudos teóricos, baseados em um formalismo de pseudo-potenciais de primeiros princípios em relação às propriedades estruturais e eletrônicas, de nitreto de silício $\left(\beta-\mathrm{Si}_{3} \mathrm{~N}_{4}\right)$ e de nitreto de carbono na forma de $\beta-\mathrm{C}_{3} \mathrm{~N}_{4}$, similar à de $\beta-\mathrm{Si}_{3} \mathrm{~N}_{4}$, mostrado na Fig. $1.1[4,5]$. O nitreto de silício apresenta duas estruturas cristalinas: $\alpha$ e $\beta$. Em todas as formas de nitreto de silício, a ordem local nos átomos de silício $(\mathrm{Si})$ tem um arranjo tetraédrico com quatro vizinhos mais próximos de $\mathrm{N}$, e cada átomo de $\mathrm{N}$ tem três vizinhos mais próximos de $\mathrm{Si}$ em uma 
geometria planar; o átomo de $\mathrm{N}$ no centro do triângulo equilátero em seus três vizinhos mais próximos de Si localizados nos vértices. A estrutura $\beta-\mathrm{C}_{3} \mathrm{~N}_{4}$ é um empilhamento da camada estrutural mostrada na Fig. 1.1, enquanto que a estrutura $\alpha-\mathrm{C}_{3} \mathrm{~N}_{4}$ pode ser descrita como empilhamento com seqüência de $\mathrm{AB} \cdots$ da câmada de $\beta-\mathrm{Si}_{3} \mathrm{~N}_{4}(\mathrm{~A})$ e da sua imagem no espelho (B) [7]. A estrutura $\beta-\mathrm{Si}_{3} \mathrm{~N}_{4}$ contém catorze átomos por célula unitária e é a mais simples das duas estruturas cristalinas, enquanto a estrutura de $\alpha-\mathrm{Si}_{3} \mathrm{~N}_{4}$ contém 28 átomos por célula unitária [5, 7]. Esses dois compostos têm o mesmo sistema cristalino hexagonal, mostrado esquematicamente na Fig. 1.1.

Liu e Cohen afirmaram que o composto $\beta-\mathrm{C}_{3} \mathrm{~N}_{4}$ possui um valor do módulo de incompressibilidade volumétrica $B$ comparável ou superior ao do diamante (435 - 444 GPa) [8, 9], cuja dureza é aproximadamente de 100 GPa [8], indicando que quanto mais baixa a ionicidade [2] e mais curto comprimento de ligação entre o C e o N [8], mais alto valor de $B$ o composto possui. Teter sugeriu teoricamente [7], baseando-se nos cálculos de primeiros princípios, alguns compostos $\mathrm{C}_{3} \mathrm{~N}_{4}$ com os parâmetros estruturais mostrados na tabela 4.1.

Tabela 1.1: Parâmetros estruturais para diferentes compostos de $C_{3} N_{4}$ e diamante.

\begin{tabular}{cccccc}
\hline \hline & $\mathrm{C}_{3} \mathrm{~N}_{4}$ grafítico & $\alpha-\mathrm{C}_{3} \mathrm{~N}_{4}$ & $\beta-\mathrm{C}_{3} \mathrm{~N}_{4}$ & $c-\mathrm{C}_{3} \mathrm{~N}_{4}$ & diamante [9] \\
\hline$a(\mathrm{~nm})$ & 0,47420 & 0,64665 & 0,64017 & 0,53973 & 0,3548 \\
$c(\mathrm{~nm})$ & 0,67205 & 0,47097 & 0,24041 & - & - \\
$B(\mathrm{GPa})$ & - & 425 & 451 & 496 & 444 \\
\hline \hline
\end{tabular}

O composto $\beta-\mathrm{C}_{3} \mathrm{~N}_{4}$ possui as seguintes propriedades: a velocidade de som foi estimada ser alta, $10^{6} \mathrm{~cm} \mathrm{~s}^{-1}$, significando que o composto apresenta uma condutividade térmica alta $[2,10]$; o band gap grande $(3,25 \mathrm{eV})[7,10]$, e o $B$ alto $(451 \mathrm{GPa})[4,7]$. 


\subsection{Hibridização do átomo de carbono}

O C é o sexto elemento da tabela periódica e é listado na parte superior da coluna

IV. Este átomo possui seis elétrons orbitando ao redor do núcleo. As órbitas representam os estados discretos de energia (estados quânticos), caracterizados pelo número quântico principal $n$. Em cada orbital $n$ podem existir diferentes sub-níveis de energia designados pelo número quântico azimutal $l$, que podem assumir valores inteiros de 0 a $n-1$, sendo normalmente representados pelas letras $s, p, d$ e $f$. A localização dos elétrons em cada um desses sub-níveis é representada através do número quântico magnético $m=l, l-1, \cdots,-l$ [11]. No caso de C atômico, o orbital 1s contem dois elétrons fortemente ligados ao núcleo, que são chamados elétrons de caroço: os outros quatro elétrons ocupam os orbitais $2 s$ e $2 p$. Como estes elétrons estão ligados mais fracamente, eles são chamados elétrons de valência. Na fase cristalina, os elétrons de valência originam os orbitais $2 s, 2 p_{x}, 2 p_{y}$, e $2 p_{z}$, importantes na formação de ligações covalentes em materiais de C. Quando os átomos de C se aproximan o suficiente a elétrons de núcleos de átomos vizinhos, os níveis de energia antes discretos são substituídos por bandas de energias.

Os orbitais, para os quatro elétrons de valência nos orbitais $2 s$ e $2 p$, podem se sobrepor realçando a energia de ligação do átomo de $\mathrm{C}$ com seus átomos vizinhos. Esta sobreposição de um orbital $2 s$ com $k$ orbitais $2 p$ é chamada hibridização $s p^{k}, k=1,2,3$ $[12]$

\subsubsection{Hibridização $s p$}

A hibridização $s p$ é formada por uma combinação linear do orbital $2 s|2 s\rangle$ e de um dos orbitais $2 p$, por exemplo, $\left|2 p_{x}\right\rangle$ : 


$$
\begin{aligned}
& \left|s p_{a}\right\rangle=C_{1}|2 s\rangle+C_{2}\left|2 p_{x}\right\rangle \\
& \left|s p_{b}\right\rangle=C_{3}|2 s\rangle+C_{4}\left|2 p_{x}\right\rangle
\end{aligned}
$$

onde $\left|s p_{a}\right\rangle$ e $\left|s p_{b}\right\rangle$ são dois orbitais hibridizados e $C_{i}$ são os coeficientes. Usando as condições de ortonormalidade, isto é, $\left\langle s p_{a} \mid s p_{b}\right\rangle=0$ e $\left\langle s p_{a} \mid s p_{a}\right\rangle=1$, obtêm-se as relações entre os coeficientes $C_{i}$ :

$$
\begin{array}{cc}
C_{1} C_{3}+C_{2} C_{4}=0, & C_{1}^{2}+C_{2}^{2}=1, \\
C_{3}^{2}+C_{4}^{2}=1, & C_{1}^{2}+C_{3}^{2}=1 .
\end{array}
$$

A última equação é dada pelo fato de que a soma dos componentes $|2 s\rangle$ no $\left|s p_{a}\right\rangle$ e $\left|s p_{b}\right\rangle$, é unidade. As soluções da equação (1.2) são $C_{1}=C_{2}=C_{3}=1 / \sqrt{2}$ e $C_{4}=-1 / \sqrt{2}$ de modo que:

$$
\begin{aligned}
& \left|s p_{a}\right\rangle=\frac{1}{\sqrt{2}}\left(|2 s\rangle+\left|2 p_{x}\right\rangle\right) \\
& \left|s p_{b}\right\rangle=\frac{1}{\sqrt{2}}\left(|2 s\rangle-\left|2 p_{x}\right\rangle\right)
\end{aligned}
$$

A Fig. 1.2 mostra uma vista esquemática dos orbitais direcionados de valência de $\left|s p_{a}\right\rangle$ (parte superior) e de $\left|s p_{b}\right\rangle$ (parte inferior).

O sombreado denota uma amplitude positiva do orbital. O orbital $|2 s\rangle+\left|2 p_{x}\right\rangle$ prolonga-se no sentido positivo do eixo $x$, enquanto que a $|2 s\rangle-\left|2 p_{x}\right\rangle$ é prolongada no sentido negativo do $x$ (Fig. 1.2). Assim quando os átomos vizinhos mais próximos estão na direção do eixo $x$, a sobreposição de $\left|s p_{a}\right\rangle$ com o orbital de átomo vizinho em $x>0$ torna-se maior comparada com o caso do orbital original $\left|2 p_{x}\right\rangle$, originando a uma energia de ligação mais alta. Se for selecionado o orbital $\left|2 p_{y}\right\rangle$ em vez de $\left|2 p_{x}\right\rangle$, o orbital apresenta uma valência direcionada na direção do eixo $y$. 


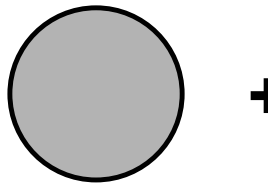

|2s>

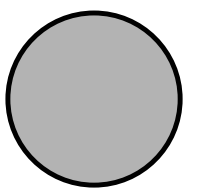

|2s >

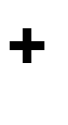

$+$
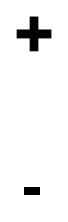

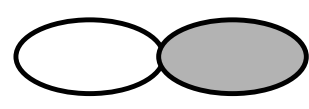

$\left|2 p_{x}\right\rangle$

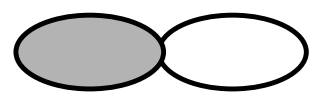

$\left|2 p_{x}\right\rangle$

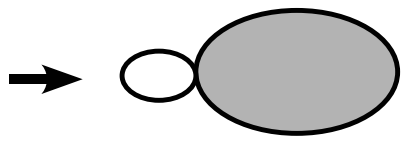

$\left|s p_{a}\right\rangle$

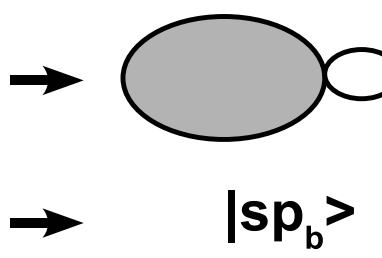

Figura 1.2: Hibridização sp.

Um material simples baseado em C mostrando a hibridização sp é o acetileno, $\mathrm{HC} \equiv \mathrm{CH}$, onde o símbolo $\equiv$ é usado para denotar uma ligação tripla entre dois átomos de $\mathrm{C}$. A molécula de acetileno $\mathrm{HC} \equiv \mathrm{CH}$ é linear com cada átomo que tem sua posição de equilíbrio ao longo de um eixo da molécula e cada átomo de $\mathrm{C}$ exibe a hibridização sp. O orbital hibridizado $\left|s p_{a}\right\rangle$ de um dos átomos de $\mathrm{C}$ em $\mathrm{HC} \equiv \mathrm{CH}$ forma uma ligação covalente com o orbital $\left|s p_{b}\right\rangle$ do outro átomo de C, chamada a ligação $\sigma$. Os orbitais $\left|2 p_{y}\right\rangle$ e $\left|2 p_{z}\right\rangle$ de cada átomo de $\mathrm{C}$ são perpendiculares à direção da ligação $\sigma$, e formam ligações relativamente fracas, ligações $\pi$, com os respectivos orbitais do outro átomo de C. Assim, uma ligação $\sigma$ e duas ligações $\pi$ produzem a ligação tripla de $\mathrm{HC} \equiv \mathrm{CH}$. 


\subsubsection{Hibridização $s p^{2}$}

Na hibridização $s p^{2}$, o orbital $2 s$ e dois orbitais $2 p$, por exemplo $2 p_{x}$ e $2 p_{y}$, são hibridizados. Um exemplo de hibridização é poliacetileno, $(\mathrm{HC}=\mathrm{CH}-)_{n}$ como é mostrado na Fig. 1.3, onde os átomos de $\mathrm{C}$ formam uma cadeia ziguezagueada com um ângulo de $120^{\circ}$. Todas as ligações $\sigma$ mostradas na figura estão em um plano $x y$. Visto que as direções das três ligações $\sigma$ do átomo de $\mathrm{C}$ central na Fig. 1.3 são $(0,-1,0),(\sqrt{3} / 2,1 / 2,0)$, e $(-\sqrt{3} / 2,1 / 2,0)$, os correspondentes orbitais hibridizados $\left|s p_{i}^{2}\right\rangle(i=a, b, c)$ são feitos dos orbitais $2 s, 2 p_{x}$, e $2 p_{y}$ como segue:

$$
\begin{gathered}
\left|s p_{a}^{2}\right\rangle=C_{1}|2 s\rangle-\sqrt{1-C_{1}^{2}}\left|2 p_{y}\right\rangle \\
\left|s p_{b}^{2}\right\rangle=C_{2}|2 s\rangle+\sqrt{1-C_{2}^{2}}\left\{\frac{\sqrt{3}}{2}\left|2 p_{x}\right\rangle+\frac{1}{2}\left|2 p_{y}\right\rangle\right\} \\
\left|s p_{c}^{2}\right\rangle=C_{3}|2 s\rangle+\sqrt{1-C_{3}^{2}}\left\{-\frac{\sqrt{3}}{2}\left|2 p_{x}\right\rangle+\frac{1}{2}\left|2 p_{y}\right\rangle\right\}
\end{gathered}
$$

Das exigências de ortonormalidade dos orbitais $\left|s p_{i}^{2}\right\rangle,|2 s\rangle$ e $\left|2 p_{x, y}\right\rangle$, obtêm-se as seguintes três equações para se determinar os coeficientes $C_{i}(i=1,2$ e 3$)$ :

$$
\begin{gathered}
C_{1}^{2}+C_{2}^{2}+C_{3}^{2}=1 \\
C_{1} C_{2}-\frac{1}{2} \sqrt{1-C_{1}^{2}} \sqrt{1-C_{2}^{2}}=0 \\
C_{1} C_{3}-\frac{1}{2} \sqrt{1-C_{1}^{2}} \sqrt{1-C_{3}^{2}}=0,
\end{gathered}
$$

As soluções da equação (1.5) são dadas por $C_{1}=C_{2}=1 / \sqrt{3}$ e $C_{3}=-1 / \sqrt{3}$. Os orbitais $s p^{2}$ assim obtidos têm uma amplitude maior nas direções aos três átomos vizinhos mais próximos, e estes três orbitais direcionados são denotados pela ligação trigonal. Há dois tipos de átomos de $\mathrm{C}$ em poliacetileno, como mostrado na Fig. 1.3, denotando diferentes direções para os átomos de hidrogênio mais próximos; os coeficientes do orbital $\left|2 p_{y}\right\rangle$ na 
equação (1.4) são positivos para os átomos de C na parte superior, e negativos para os átomos de $\mathrm{C}$ na parte inferior.

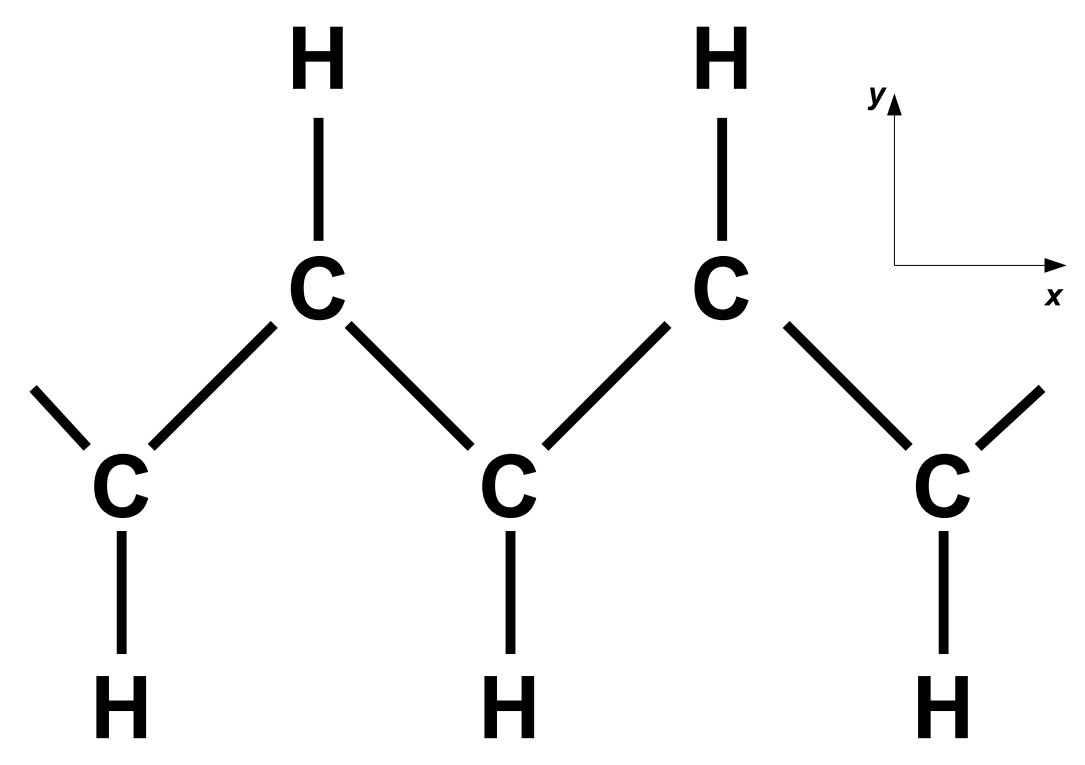

Figura 1.3: Hibridização $s p^{2}$.

\subsubsection{Hibridização $s p^{3}$}

$\mathrm{O}$ átomo de $\mathrm{C}$ no metano $\left(\mathrm{CH}_{4}\right)$ fornece um exemplo simples da hibridização $s p^{3}$ através de sua ligação tetragonal para quatro átomos vizinhos mais próximos de H. As quatro direções das ligações tetraédricas do átomo de C podem ser selecionadas como: $(1,1,1),(-1,-1,1),(-1,1,-1),(1,-1,-1)$.

A fim de formar os orbitais alongados para estas direções, o orbital $|2 s\rangle$ e os três orbitais $|2 p\rangle$ são misturados, formando uma hibridização $s p^{3}$. Usando uma maneira similar àquela utilizada na equação (1.4) para a obtenção dos orbitais $s p^{2}$, mas com os quatro coeficientes desconhecidos $C_{i}(i=1, \cdots, 4)$ e os orbitais ortonormais, obtêm-se os orbitais 
hibridizados $s p^{3}$ nestas quatro direções:

$$
\begin{aligned}
& \left|s p_{a}^{3}\right\rangle=\frac{1}{2}\left\{|2 s\rangle+\left|2 p_{x}\right\rangle+\left|2 p_{y}\right\rangle+\left|2 p_{z}\right\rangle\right\} \\
& \left|s p_{b}^{3}\right\rangle=\frac{1}{2}\left\{|2 s\rangle-\left|2 p_{x}\right\rangle-\left|2 p_{y}\right\rangle+\left|2 p_{z}\right\rangle\right\} \\
& \left|s p_{c}^{3}\right\rangle=\frac{1}{2}\left\{|2 s\rangle-\left|2 p_{x}\right\rangle+\left|2 p_{y}\right\rangle-\left|2 p_{z}\right\rangle\right\} \\
& \left|s p_{d}^{3}\right\rangle=\frac{1}{2}\left\{|2 s\rangle+\left|2 p_{x}\right\rangle-\left|2 p_{y}\right\rangle-\left|2 p_{z}\right\rangle\right\}
\end{aligned}
$$

Em geral, para a hibridização $s p^{k}, k+1$ elétrons pertencem a um átomo de $\mathrm{C}$ ocupando as ligações $\sigma$ e $4-(k+1)$ elétrons estão nas ligações $\pi$. No caso da hibridização $s p^{3}$, os quatro elétrons de valência ocupam os orbitais $2 s$ e $2 p_{i}(i=x, y, z)$. Para formar os quatro orbitais hibridizados, a excitação eletrônica na transição da configuração $(2 s)^{2}$ $(2 p)^{2}$ à $(2 s)^{1}(2 p)^{3}$ requer uma energia aproximadamente igual à diferença de energia entre os orbitais $2 s$ e $2 p(\sim 4 \mathrm{eV})$; porém, a energia de ligação para cada orbital $\sigma$ é $3-4 \mathrm{eV}$, estes fatos favorecendo energeticamente a formação da hibridização $s p^{3}$.

\subsection{Nitrogênio na matriz carbonada}

$\mathrm{O}$ átomo de $\mathrm{N}$ tem cinco elétrons de valência. Assim, o $\mathrm{N}$ ao ser introduzido na matriz carbonada pode se ligar de várias formas e as configurações de ligação de N possíveis e principais são mostradas na Fig. 1.4 [13].

Na configuração trivalente simples $N_{3}^{0}[13,14]$, onde o subscrito denota a coordenação e o sobrescrito denota a carga [14], o átomo de $\mathrm{N}$ forma três ligações $\sigma$ e os outros dois elétrons de valência ocupam o orbital $\pi$ [14], como mostra a Fig. 1.4(a). O sítio $\mathrm{N}_{3}^{0}$ é planar como em $\beta-\mathrm{C}_{3} \mathrm{~N}_{4}$ e $\mathrm{Si}_{3} \mathrm{~N}_{4}$ [14]. O átomo de $\mathrm{N}$ forma um $\mathrm{N}_{4}^{+}$, usando quatro elétrons nas quatro ligações $\sigma$ e com um elétron restante livre para dopagem, como indicado na Fig. 
1.4(b). Um outro efeito de $\mathrm{N}$ é favorecer as ligações intercamadas [15-17]; a substituição de um átomo de $\mathrm{C}\left(s p^{2}\right)$ em uma câmada grafítica por um átomo de $\mathrm{N}$ quebra a ligação $\pi$ desse átomo de $\mathrm{C}$ e o elétron que estava nessa ligação pode formar uma ligação $\sigma$ com outro átomo de C na mesma situação em uma camada adjacente [Fig. 1.4(c)].

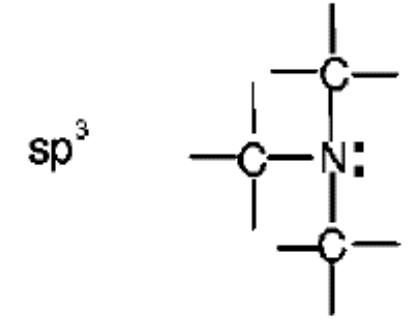

(a)

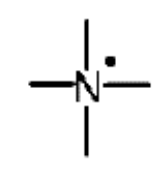

(b)

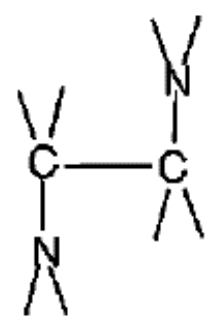

(c)

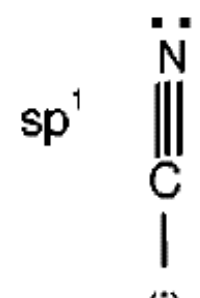

(i)

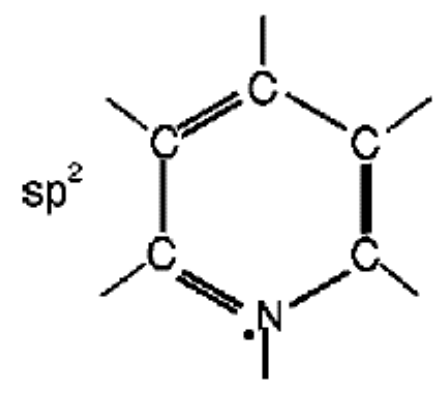

(d)

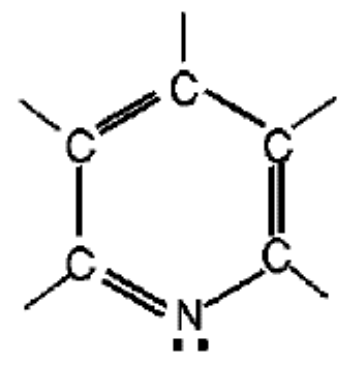

(e)

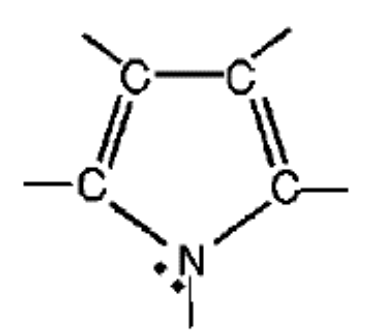

(f)

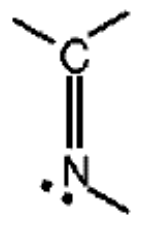

(g)

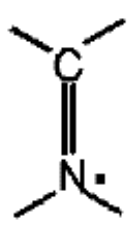

(h)

Figura 1.4: Principais configurações do $N$ dentro da matriz de carbono. As linhas representam ligações de um par de elétrons. Um ponto significa um elétron desemparelhado. Dois pontos significam um par de elétrons não ligados [13].

As configurações restantes correspondem às hibridizações $s p^{2}$ e $s p . \mathrm{O} \mathrm{N}$ pode substituir um átomo de $\mathrm{C}$ em um anel benzênico, deixando um elétron disponível para dopagem, como mostra a Fig. 1.4(d), ou formando um anel tipo piridina, indicado na Fig. 1.4(e). Por outro lado, um átomo de $\mathrm{N}$ pode formar um anel pentagonal chamado pirrol [Fig. 1.4(f)], onde o átomo de $\mathrm{N}$ utiliza seus três elétrons nas três ligações $\sigma$ e os outros dois são usados para completar o sexteto aromático [13, 14]. Os resultados teóricos e analíticos das energias de ligação [17], indicam que os anéis pentagonias em uma camada 
grafítica entortam-na, facilitando as ligações intercamadas através de átomos $\mathrm{C}\left(s p^{3}\right)$ em conseqüências do processo indicado na Fig. 1.4(c) [15-17]. Uma representação esquemática dessa estrutura é mostrada na Fig. 1.5 [16].

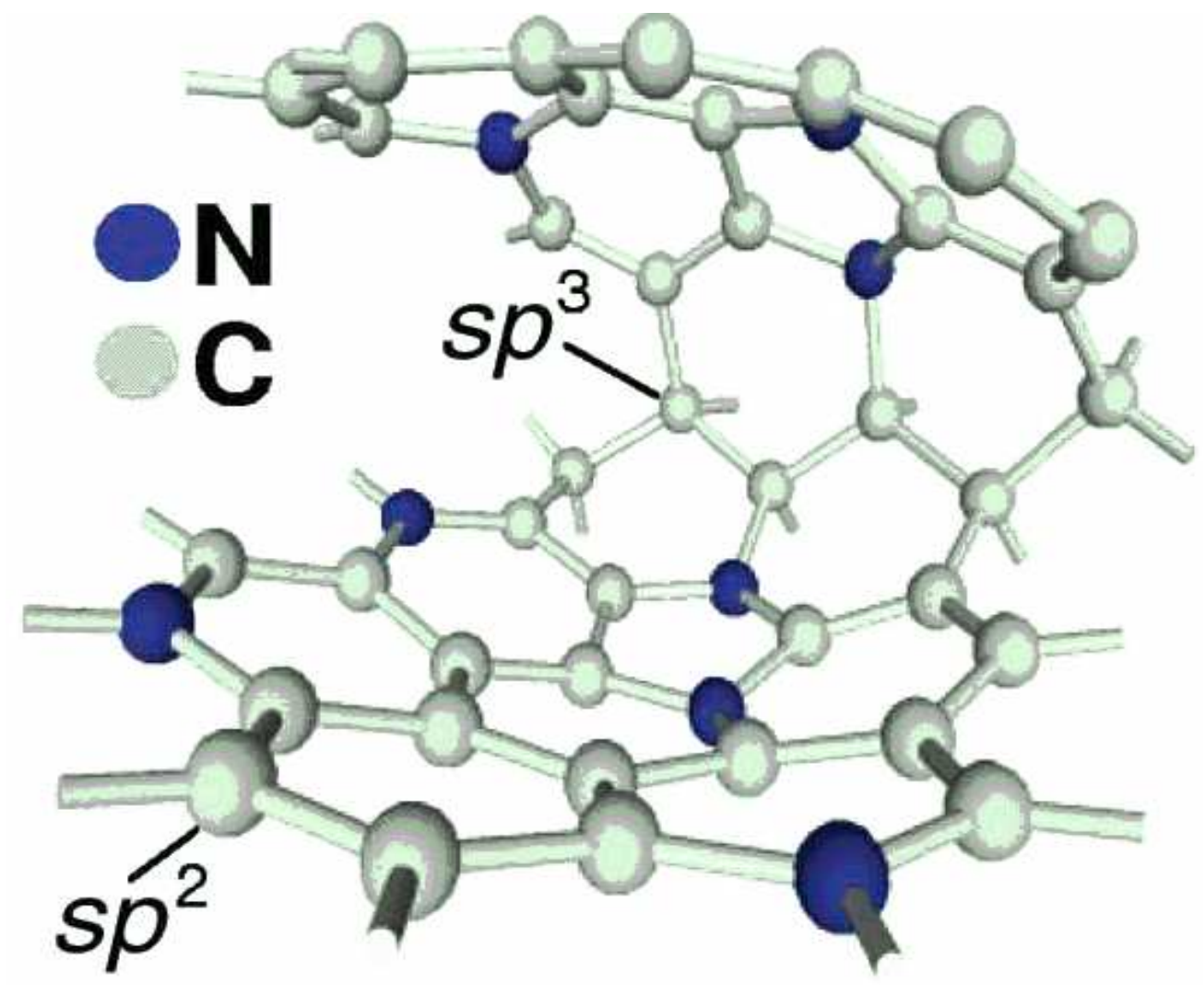

Figura 1.5: Desenho esquemático das ligações intercamadas entre duas camadas de $\mathrm{CN}_{x}$ causado pelo entortamento ao redor dos anéis pentagonais $[16,17]$.

Na Fig. 1.4(g), o N utiliza dois elétrons nas duas ligações $\sigma$ e um elétron na ligação $\pi$, deixando um par de elétrons não ligados. Na Fig. 1.4(h), o N utiliza três elétrons nas três ligações $\sigma$ e um elétron na ligação $\pi$ e o quinto elétron disponível para dopagem. Essas ligações acima mencionadas são chamadas de olefina. Finalmente, Fig. 1.4(i) no grupo nitrila, o átomo $\mathrm{N}$ forma uma ligação tripla e com um par de elétrons não ligados, terminando a cadeia de ligações. 


\subsection{Métodos de deposição}

Desde que Liu e Cohen apresentaram os resultados teóricos, mencionados na seção 1.1, do composto hipotético $\beta-\mathrm{C}_{3} \mathrm{~N}_{4}[5,6]$, consideráveis esforços experimentais estão sendo efetuados para a obtenção de filmes de nitreto de carbono $\left(\mathrm{CN}_{x}\right)$ na forma de $\beta-\mathrm{C}_{3} \mathrm{~N}_{4}$ usando vários métodos de deposição classificados em duas grandes categorias [10, 18]: (a) a deposição química de vapor (Chemical Vapor Deposition, CVD), na qual o substrato é exposto a um ou mais precursores voláteis, que reagem e/ou decompõem na superfície do substrato para a preparação de materiais sólidos, e (b) a deposição física de vapor (Physical Vapor Deposition, PVD), na qual os átomos passam para a fase gasosa por meio de mecanismo físico, que inclui evaporação ou bombardeamento por alguma forma de partículas energizadas, para a deposição de filmes finos de vários materiais sobre vários substratos. A seguir, serão apresentados alguns métodos de deposição que estão usados para a formação de filmes de $\mathrm{CN}_{x}$.

\subsubsection{CVD assistida por plasma}

Em um processo típico de CVD a energia térmica é usada para iniciar e sustentar as reações químicas. Além disso, a CVD assitida por plasma (Plasma Enhanced CVD, PECVD) utiliza o campo elétrico de radiofreqüência (RF) para: excitar os gases reagentes usados, iniciar e manter o plasma dentro de reator. Os elétrons e íons assim produzidos fornecem aos gases suas energias cinéticas suficientes para os gases transformarem-se em várias espécies ativas que podem reagir quimicamente para a formação do filme [19].

O método PECVD usa uma mistura de gás hidrocarbonado, tais como metano $\left(\mathrm{CH}_{4}\right)$, acetileno $\left(\mathrm{C}_{2} \mathrm{H}_{2}\right)$ ou etileno $\left(\mathrm{C}_{2} \mathrm{H}_{4}\right)$, com o gás de nitrogênio $\left(\mathrm{N}_{2}\right)$ ou amônia $\left(\mathrm{NH}_{3}\right)$ 
[19-22]. Os conteúdos máximos de $\mathrm{N}$ obtidos nos filmes depositados com uma mistura de $\mathrm{C}_{2} \mathrm{H}_{2} / \mathrm{N}_{2}$ e com uma de $\mathrm{CH}_{4} / \mathrm{N}_{2}$ são, respectivamente, de 53,7 [21] e 20 at.\% [22]. Foi observado, também, que a dureza dos filmes depositados com a mistura de $\mathrm{CH}_{4} / \mathrm{N}_{2}$ diminui com o aumento nas quantidades de $\mathrm{N}$ e $\mathrm{H}$ nos filmes, devido à formação dos grupos $\mathrm{NH}_{2}$ e das nitrilas $[20,22,23]$.

\subsubsection{Deposição por sputtering}

O princípio deste método é coletar, sobre um substrato, os átomos removidos da superfície de um material sólido (grafite) [24]. O material sólido é colocado no catodo conectado ao terminal negativo de uma fonte de tensão DC de alguns kV (sputtering DC) [25-27] ou a uma fonte de RF [27] de 13,56 MHz (sputtering RF), e o substrato no catodo está aterrado ou polarizado positiva ou negativamente.

Depois da evacuação de câmara, o gás de nitrogênio ou uma mistura de gases $\mathrm{N}_{2} / \mathrm{Ar}$ é introduzido a uma pressão de alguns mTorr até 100 mTorr, como um meio em que a descarga é iniciada e sustentada entre os dois eletrodos [27]. Os íons de nitrogênio ou argônio assim criados são acelerados em direção ao catodo e colidem com o material sólido, e átomos removidos do material pelos íons serão depositados sobre o substrato.

O método RF magnetron sputtering utiliza uma combinação de um campo magnético perpendicular ao campo elétrico de RF [16]. Essa combinação aprisiona os elétrons em trajetórias espirais e aumenta a probabilidade de colisão de elétrons com os gases, resultando no aumento da taxa de deposição [27].

Sjöström et al. relataram que os filmes de $\mathrm{CN}_{x}$, produzidos com o método $\mathrm{RF}$ magnetron sputtering, têm uma microestrutura do tipo fulereno em conseqüência da incorporação de N [15] (Fig. 1.5) com uma dureza de aproximadamente 60 GPa [17]. 


\subsubsection{Laser ablation}

$\mathrm{O}$ feixe de raio laser de $\mathrm{KrF}, \mathrm{CO}_{2}$ ou $\mathrm{Nd}$ :YAG tem sido usado para remoção do alvo de grafite em um ambiente de $\mathrm{N}_{2}$ ou $\mathrm{NH}_{3}$, com ou sem bombardeamento iônico do substrato $[24,28,29]$. Em um ambiente de $\mathrm{N}_{2}$, as moléculas de $\mathrm{N}_{2}$ adsorvidas na superfície da grafite são decompostas pela exposição com o feixe de raio laser e as principais espécies assim formadas são $\mathrm{C}_{x}(x=1-4)$ e $\mathrm{CN}[23,24]$. As quantidades relativas destas espécies dependem da pressão do gás de $\mathrm{N}_{2}$ no ambiente e da energia de raio laser. Em um ambiente de $\mathrm{NH}_{3}$, a formação de espécies $\mathrm{C}_{x}$ torna-se maior se comparado com a formação no ambiente de $\mathrm{N}_{2}[23,24]$. Uma característica específica desta técnica é que a energia média das partículas removidas pelo raio de laser é maior do que a energia por evaporação termal [29], favorecendo a formação de $\mathrm{C}\left(s p^{3}\right)$. Recentemente, filmes depositados com o método laser ablation mostrou, também, estruturas similares às de fulereno $[15,16,30]$. Niu et al. relataram que a razão composicional química $\mathrm{C}(\mathrm{N} / \mathrm{C})$ dos filmes irradiados simultâneamente com o feixe de íons de nitrogênio foi diretamente proporcional ao fluxo do gás de $\mathrm{N}_{2}$, sendo o valor máximo de $\mathrm{C}(\mathrm{N} / \mathrm{C}$ ) obtido igual a aproximadamente 0,7 (41 at.\% N); os filmes mostram uma dureza comparável à do diamante em conseqüência da presença de cristalitos de $\beta-\mathrm{C}_{3} \mathrm{~N}_{4}$ posicionados no interior dos filmes [31].

\subsubsection{Deposição assistida por feixe de íons}

Na década de 80, um novo método de PVD foi desenvolvido por bombardeamento de íons energéticos combinado com a deposição por evaporação, a deposição assistida por feixe de íons (Ion Beam Assisted Deposition, IBAD) [32-35].

Neste método, a deposição de carbono a vácuo sobre um substrato é combinada 
com a irradiação simultânea por íons de nitrogênio ou amônia [32, 34, 35]. Os íons, com energia de centenas de eV até dezenas de keV [32], penetram em um substrato e chocamse com átomos depositados sobre este, impelindo-os da superfície para dentro; a seguir é formada uma nova fase intermediária mista de elementos do substrato, íons incidentes e átomos. A formação dessa nova fase intermediária aumenta, conseqüentemente, a aderência do filme depositado. Com este método, a $\mathrm{C}(\mathrm{N} / \mathrm{C})$ do filme pode ser facilmente variada e controlada com os parâmetros de deposição, tais como a taxa de deposição de carbono, a energia de íons e a densidade de corrente de íons de nitrogênio [32, 35].

A maioria dos filmes de $\mathrm{CN}_{x}$ relatados é amorfa [32, 35], embora diminutos cristalitos de $\beta-C_{3} \mathrm{~N}_{4}$ tenham sido provavelmente formados [28, 34]. Estes filmes apresentaram concentrações de $\mathrm{N}$ menores que 50 at.\% [10,34, 36], substancialmente menor do que o valor estequiométrico de $\beta-\mathrm{C}_{3} \mathrm{~N}_{4}$ de 57 at.\% [24, 37]. Chubaci et al. [32] e Song et al. [34] mostraram, respectivamente, os valores máximos de dureza Knoop dos filmes de $\mathrm{CN}_{x}$ produzidos com o método IBAD iguais a 63 e $49 \mathrm{GPa}$.

Gago et al. relataram que os filmes de $\mathrm{CN}_{x}$ depositados pelo método IBAD com energias do feixe de íons de nitrogênio $<100 \mathrm{eV}$ são amorfos [23]. Recentemente, os filmes de $\mathrm{CN}_{x}$ produzidos com o método IBAD com energia do feixe de íons de nitrogênio entre 200 e $600 \mathrm{eV}$ indicam com estruturas tipo fulereno [38].

\subsection{Motivações e objetivos do trabalho}

Sabe-se bem que os filmes de $\mathrm{CN}_{x}$ com estrutura tipo fulereno possuem uma dureza alta em conseqüência da presença de ligações $s p^{2}$ e $s p^{3}$ nessa estrutura [16, 17], como foi mencioda na seção 1.4. Portanto, é interessante pesquisar o crescimento dos filmes de $\mathrm{CN}_{x}$ 
usando o método IBAD.

O presente trabalho está orientado a contribuir no entendimento do processo de formação dos filmes de $\mathrm{CN}_{x}$ e, dessa forma, auxiliar a aplicação prática dos filmes. Para isso, pretende-se alcançar os seguintes objetivos:

(i) produzir os filmes finos de $\mathrm{CN}_{x}$ com o método IBAD, variando-se os seguintes parâmetros de deposição: energia de íons, razão do fluxo de íons incidentes relativo ao fluxo de átomos de carbono transportados ao substrato, tempo de deposição monitorada pelo monitor de deposição do filme;

(ii) analisar os filmes de $\mathrm{CN}_{x}$ com as técnicas de caracterização de: perfilometria, espalhamento de partículas em recuo elástico, espectroscopia do infravermelho (IR), espectroscopia Raman, difração de raios X,

(iii) analisar os filmes de $\mathrm{CN}_{x}$ previamente depositados com o método $\mathrm{RF}$ magnetron sputtering reativo com as técnicas de caracterização de: espectroscopia Raman, espectroscopia de fotoelétrons induzida por raios X e dureza Knoop, e

(iv) correlacionar os resultados de análise dos espectros Raman para os filmes depositados com o método IBAD com os parâmetros de deposição e comparar esses resultados de análise dos filmes depositados com os dois métodos. 


\section{Capítulo 2}

\section{Sistema IBAD}

Os filmes estudados neste trabalho foram depositados pelo método IBAD. Neste capítulo, descreve-se detalhadamente este sistema e suas características.

\section{$2.1 \quad$ Sistema IBAD}

O sistema IBAD, mostrado na Fig. 2.1, consiste basicamente de: (a) uma fonte de íons tipo Kaufman (MPS-3000, Ion Tech) com diâmetro de feixe de $5 \mathrm{~cm}$ na saída, energia do feixe de íons (E) de 50 a 1200 eV e corrente de feixe máxima de $200 \mathrm{~mA}$ (densidade de corrente máxima de $10 \mathrm{~mA} / \mathrm{cm}^{2}$ na saída da fonte de íons). O gás de nitrogênio $\left(\mathrm{N}_{2}\right)$ e/ou o de argônio (Ar) foram injetados na fonte de íons (maiores detalhes na seção 2.2), e seus fluxos foram regulados pelos respectivos controladores de fluxo de massa [Mass Flow Controller (MFC) 1179A, MKS]; (b) um evaporador por feixe de elétrons (EB3, Edwards) com um porta-amostra para quatro cadinhos de $4 \mathrm{~cm}^{3}$ cada e potência de $3 \mathrm{~kW}$ ( $5 \mathrm{kV}$ e $600 \mathrm{~mA}$ ). O ângulo de incidência do fluxo de átomos evaporados ao plano de substrato é aproximadamente de $45^{\circ}$; (c) uma câmara de vácuo de aço inoxidável com diâmetro de 
$60 \mathrm{~cm}$ e altura de $70 \mathrm{~cm}$ em que estão instalados, além da fonte de íons e do evaporador por feixe de elétrons acima mencionados, dois sensores de pressão de gás (um pirani e um penning) para monitorar a pressão dentro da câmara, um suporte de substrato anexado a um aquecedor elétrico de até $550^{\circ} \mathrm{C}$ com um termopar tipo $\mathrm{K}$, sobre o qual pode ser fixado um substrato de $2,5 \times 2,5 \mathrm{~cm}^{2}$ de área máxima, um monitor de deposição por oscilador de quartzo (XTC/2, Leybold) e um copo de Faraday feito de aço inoxidável com diâmetro de 5,1 cm. O vácuo na câmara é obtido por uma bomba mecânica (taxa de bombeamento de $\left.40 \mathrm{~m}^{3} / \mathrm{h}\right)$ em pré-vácuo durante uma hora $(2,7 \mathrm{~Pa})$ e por uma criogênica $(1500 \mathrm{l} / \mathrm{s})$ durante 24 horas. Assim, a pressão de fundo da câmara de vácuo é de $\sim 7,0 \times 10^{-5} \mathrm{~Pa}$. Durante a deposição de filme a pressão de trabalho foi de $\sim 1,6 \times 10^{-2} \mathrm{~Pa}$.

Para controlar e monitorar a taxa de deposição de carbono sobre o substrato de Si, foi usado o monitor de deposição, instalado próximo ao suporte de substrato e protegido contra a exposição pelo feixe de íons. Deste modo, estimou-se o número de átomos de carbono que atingiram o substrato por unidade de área e por unidade de tempo. A corrente do feixe de íons $\left(\mathrm{I}_{T}\right)$ foi medida pelo copo de Faraday para se estimar o número de íons de nitrogênio que chegaram ao substrato. Desta forma, a razão da taxa de chegada, $\mathrm{R}(\mathrm{I} / \mathrm{A})$, é definida pelo fluxo de íons de nitrogênio em relação ao fluxo de átomos de carbono evaporados transportados ao substrato. Os cálculos da R(I/A) serão mostrados mais detalhadamente no apêndice A.

Neste método IBAD, os íons com E de 50-1200 eV penetram em um substrato e chocam-se com átomos depositados sobre este, impelindo-os da superfície para dentro. A seguir, é formada, dentro de substrato, uma nova fase intermediária mista de elementos de substrato, íons incidentes e átomos depositados. A formação dessa nova fase intermediária aumenta, conseqüentemente, a aderência de filme depositado. O método IBAD possui as 


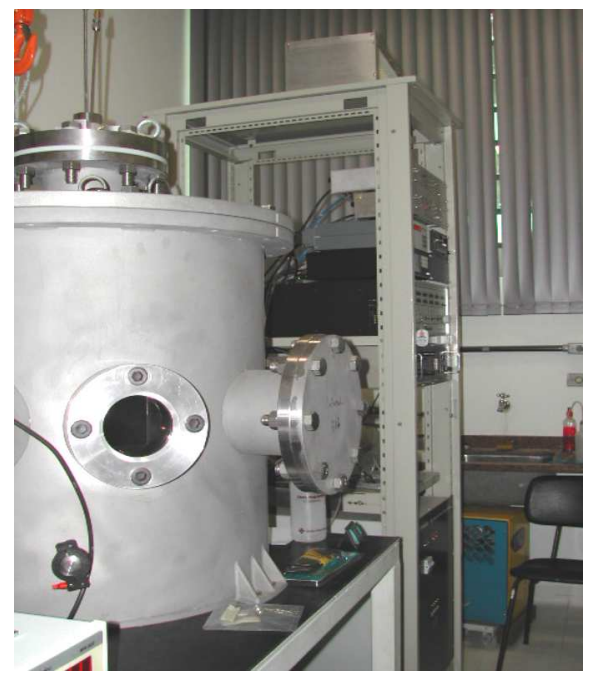

(a)

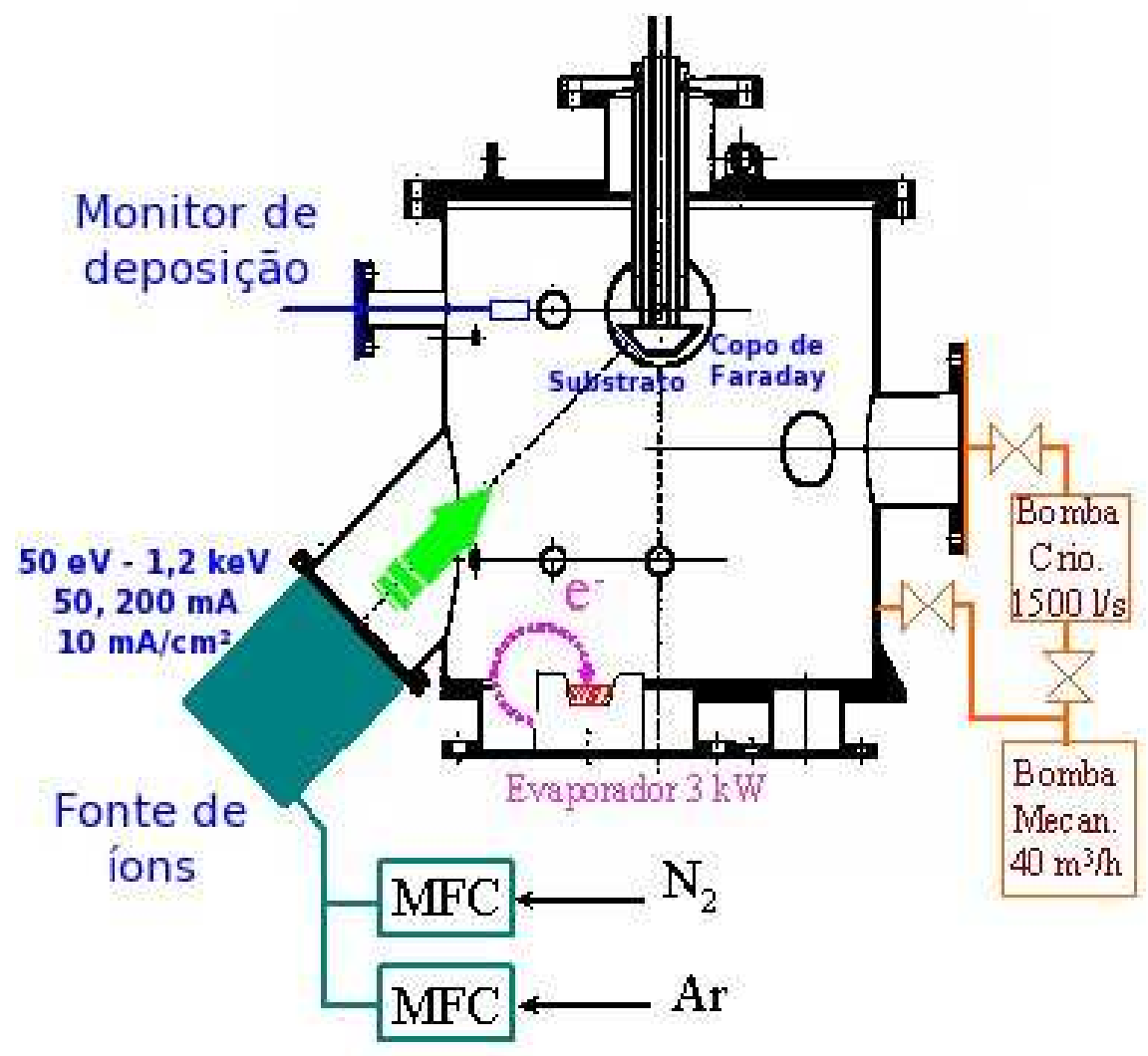

(b)

Figura 2.1: (a) Foto do sistema IBAD. (b) Diagrama esquemático do sistema IBAD. 
seguintes características: (a) boa aderência, por não existir nenhuma interface descontínua entre o substrato e o filme; (b) aplicabilidade a substratos em baixas temperaturas durante a deposição, devido ao princípio do processo de formação de filmes finos; (c) facilidade na modificação e controle das características físicas e químicas (dureza, densidade, tensão interna, morfologia, estequiometria), e de propriedades cristalográficas (nucleação, densidade de nucleação, estrutura cristalina) dos filmes produzidos.

\section{$2.2 \quad$ Fonte de íons}

A fonte de íons é um dos componentes essenciais do sistema IBAD, e consiste de um compartimento de descarga com uma entrada de gases $\left(\mathrm{N}_{2}\right.$ e/ou $\mathrm{Ar}$ ), um filamento de tungstênio (catodo, $\mathrm{V}_{c}$ ) que emite termelétrons e uma grade aceleradora [39]. Estes elétrons percorrem várias trajetórias do filamento até as paredes do compartimento de descarga que apresenta uma tensão superior (anodo, $\mathrm{V}_{d}$ ). Cada trajetória é aumentada mediante um campo magnético, induzido por um ímã, impulsionando os elétrons a percorrerem trajetórias helicoidais e atinjindo moléculas e átomos gasosos, ionizando-os e criando assim um plasma formado por espécies atômicas e moleculares, carregadas e neutras, e por elétrons. Os elétrons adicionais liberados pelo processo de colisão geram mais ionização de moléculas e átomos, resultando na manutenção do plasma no compartimento de descarga da fonte de íons. Os íons assim produzidos são atraídos pela tensão da grade aceleradora negativamente carregada $\left(-\mathrm{V}_{a}\right)$ e, em operação normal, atravessam a grade aceleradora sem qualquer colisão. Na saída da fonte de íons existe um outro filamento de tungstênio, o qual neutraliza os íons advindos da fonte de íons, uma vez que devido à repulsão coloumbiana o feixe tende a se alargar e esta divergência é minimizada pelos elétrons emitidos pelo fila- 
mento. Assim extraídos, a E é dada pela tensão do feixe $\left(\mathrm{V}_{b}\right)$ [39]. As conexões elétricas necessárias, também, estão indicadas na Fig 2.2 .

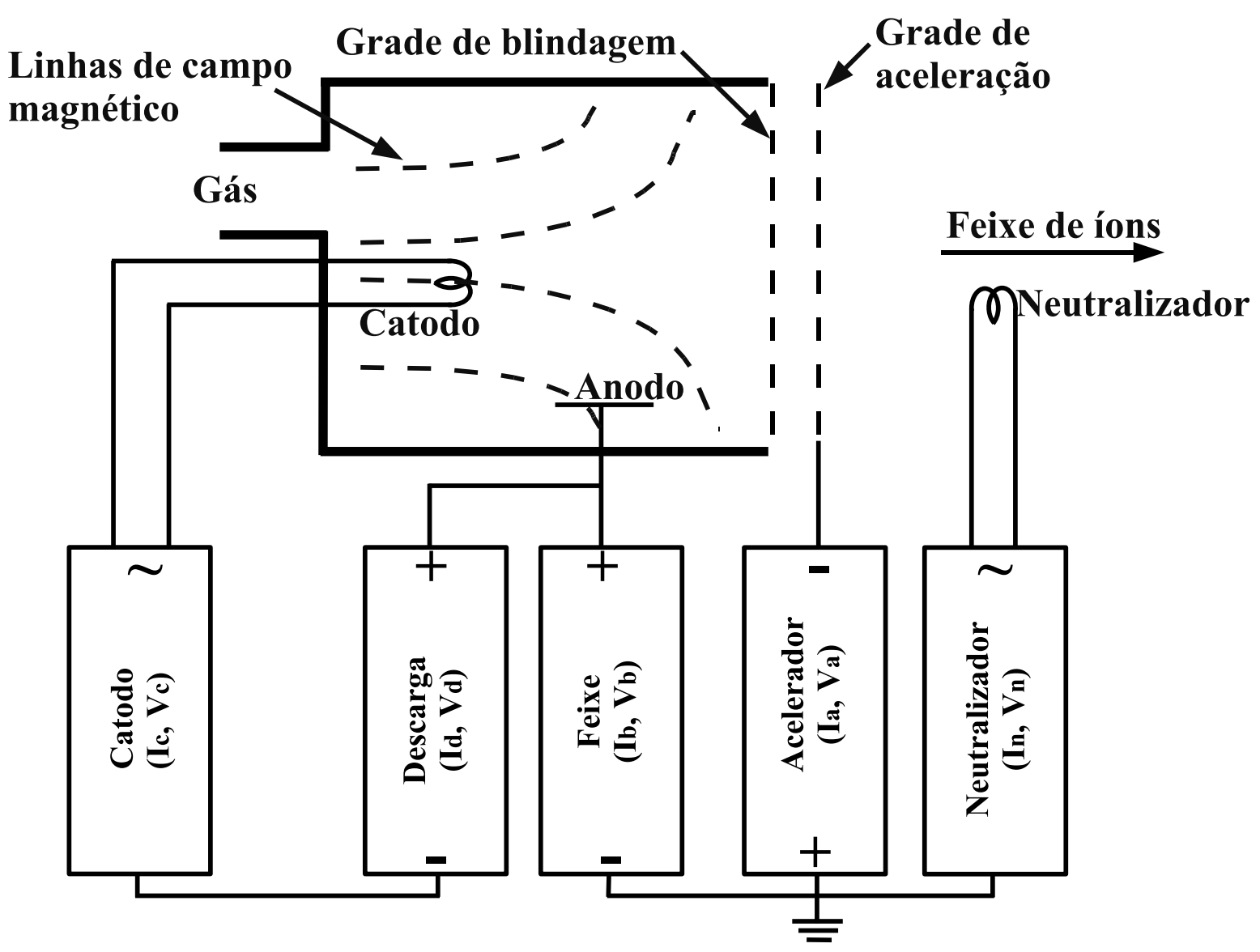

Figura 2.2: Diagrama da fonte de íons e esquema das conexões elétricas com as fontes de tensão.

\subsection{Características da fonte de íons}

A fonte de íons foi testada variando-se seus parâmetros de operação: corrente de catodo $\left(\mathrm{I}_{c}\right)$, tensão do feixe $\left(\mathrm{V}_{b}\right)$, tensão da aceleração $\left(-\mathrm{V}_{a}\right)$ e fluxo de gás. A seguir, são apresentadas algumas características da fonte de íons:

i) Fluxo de gás

A pressão de gás no interior do compartimento de descarga é um dos parâmetros fundamentais da fonte de íons. Esta pressão é controlada pelo fluxo de gás conduzido à 
fonte de íons e pela velocidade de bombeamento na câmara de vácuo. Se a pressão na câmara de descarga for reduzida, a descarga cessará. A Fig. 2.3 apresenta a variação da corrente do feixe $\left(\mathrm{I}_{b}\right)$ em função do fluxo de gás de $\mathrm{N}_{2}$ para dois valores de E. Analisando-se a figura, concluiu-se que o fluxo mínimo é de $2,3 \mathrm{sccm}$ [sccm (standar cubic centimeters per minute) significa que em um minuto um centímetro cúbico de gás estando a pressão de uma atmosfera e $293 \mathrm{~K}$ entra na câmara de vácuo] e o fluxo ótimo é considerado em torno de $2,5 \mathrm{sccm}[39]$.

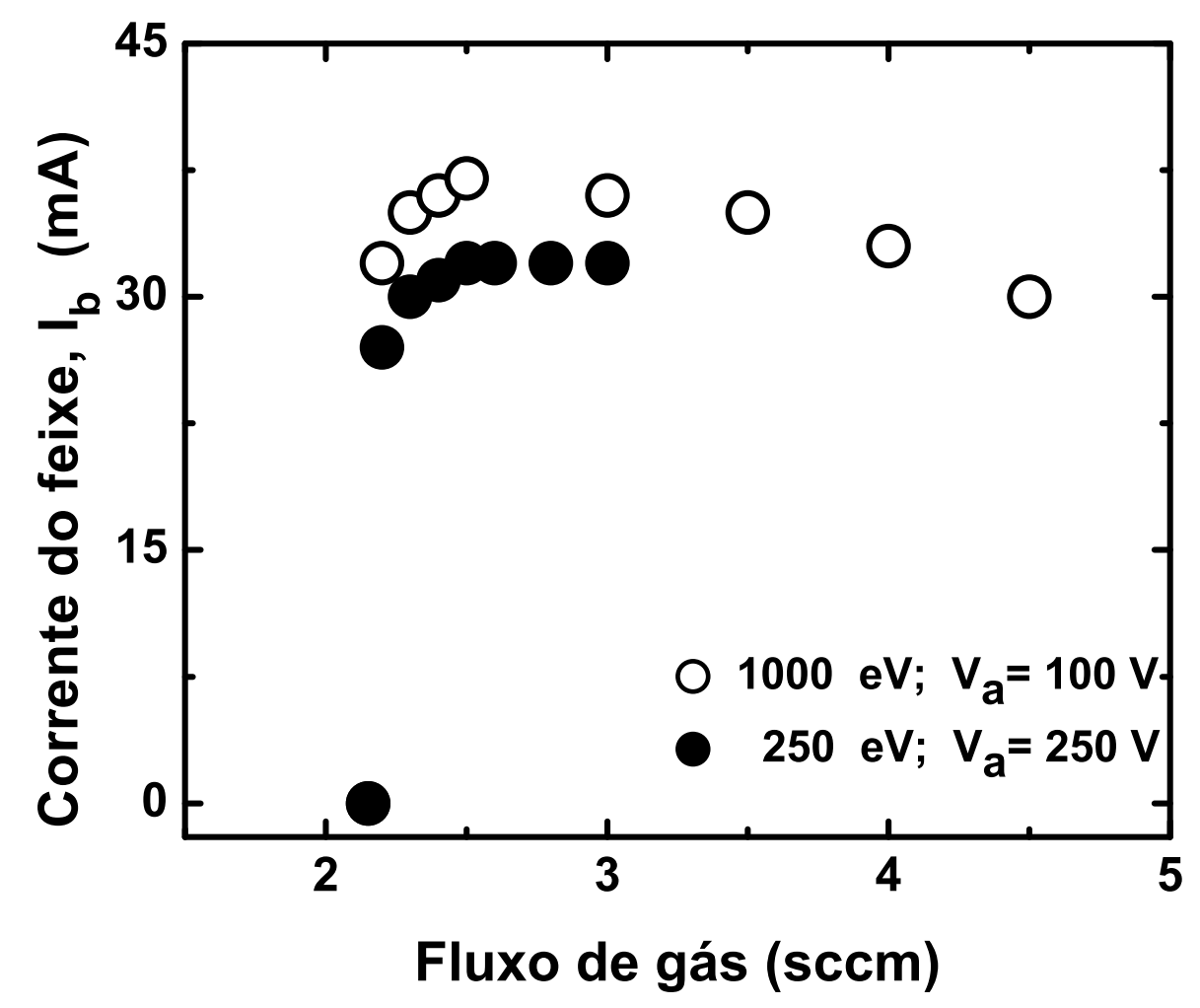

Figura 2.3: Variação da corrente do feixe $\mathrm{I}_{b}$ com o fluxo de gás de $\mathrm{N}_{2}$.

\section{ii) Limite de Carga Espacial do Catodo}

Os elétrons emitidos pelo catodo atravessam o plasma de descarga nas condições de operação normais. Porém, em condições de pressão baixa e da tensão de descarga $\left(\mathrm{V}_{d}\right)$ 
(aplicada ao anodo positivamente em relação ao catodo) baixa, a carga espacial dos elétrons próxima ao catodo tende a impedir os elétrons de migrarem do catodo para atingir o plasma de descarga [39]. Quando este fenômeno ocorre, o catodo estará operando na condição do limite de carga espacial. Na Fig. 2.4, observa-se que, para a corrente de catodo acima de 3,6 A, a fonte de íons está operando neste limite de carga espacial. Quando o limite de carga espacial é encontrado durante o funcionamento da fonte do íons, o catodo pode danificar-se durante a operação ou ter sua vida útil reduzida [39].

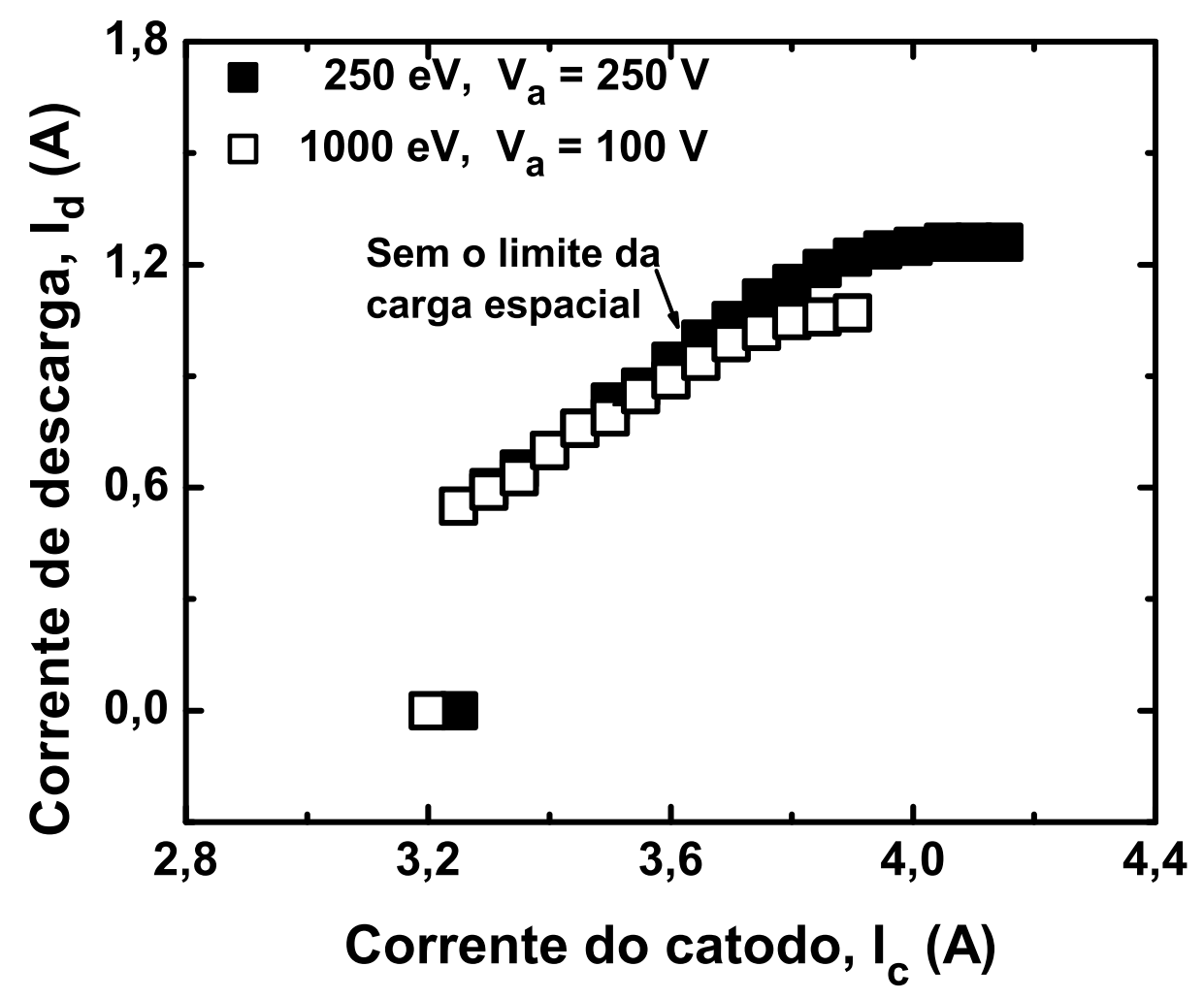

Figura 2.4: O limite de carga espacial sobre a variação da corrente de descarga $\left(I_{d}\right)$ com a corrente do catodo $\left(I_{c}\right)$.

\section{iii) Contracorrentes de Elétrons}

Se os elétrons voltam ao plasma da descarga, através das grades de blindagem e aceleradora, a unidade de potência da fonte de íons não conseguirá distinguir os íons 
acelerados no feixe de íons dessa contracorrente de elétrons [39]. A relação da $\mathrm{I}_{b}$ em função da $\mathrm{V}_{a}$, apresentada na Fig. 2.5, para três valores de $\mathrm{E}=250,500$ e $1000 \mathrm{eV}$, indica que $\mathrm{V}_{a}$ acima de $100 \mathrm{~V}$ evita a formação da contracorrente de elétrons.

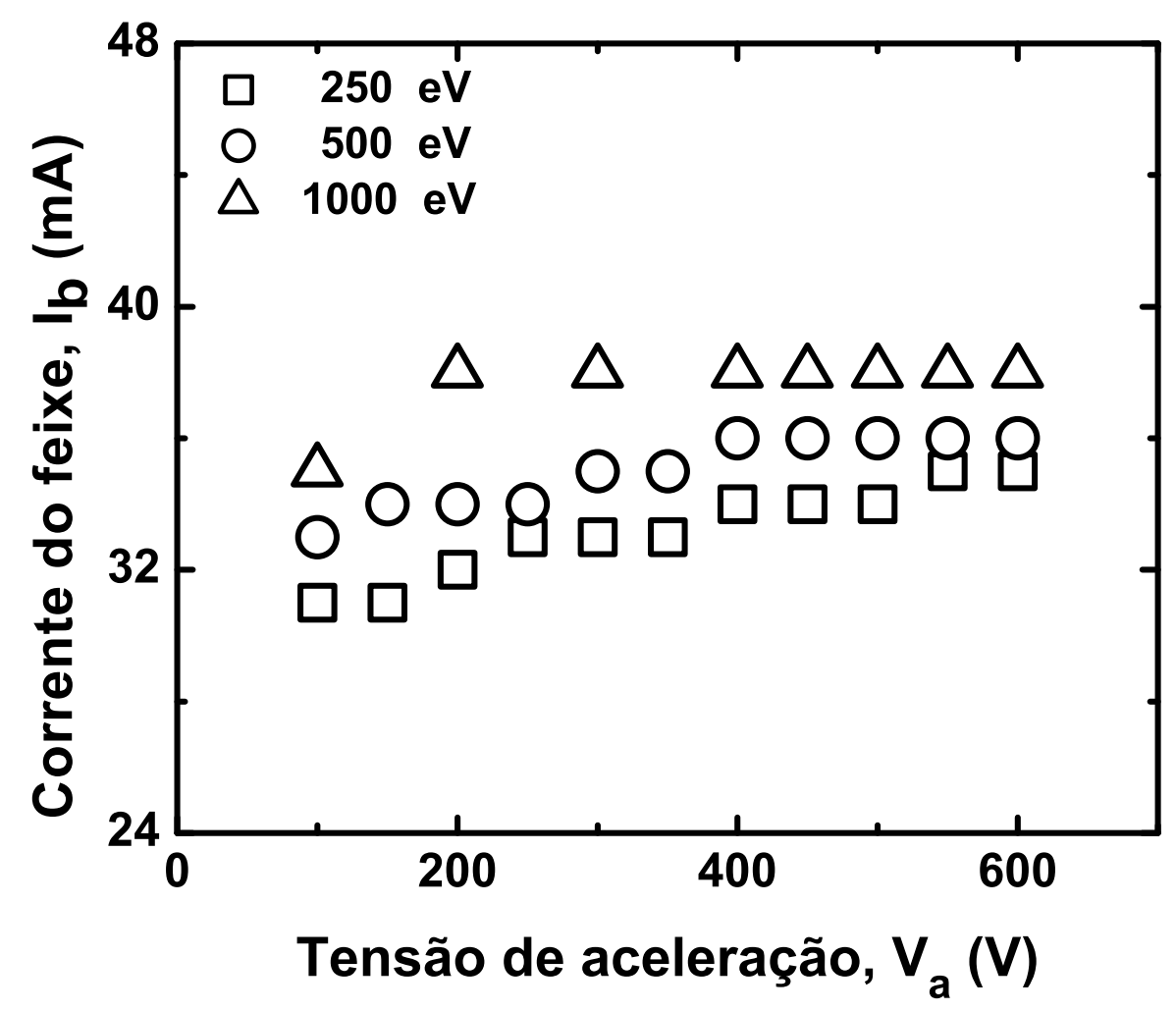

Figura 2.5: Variação da corrente do feixe $\left(\mathrm{I}_{b}\right)$ com a tensão de aceleração $\left(V_{a}\right)$.

iv) Corrente do Feixe de Íons

Os parâmetros de deposição mais importantes e fundamentais no método IBAD são a $\mathrm{E}$ relacionada à $\mathrm{V}_{b}$ e a razão da taxa de chegada, R(I/A). A Fig. 2.6 mostra a $\mathrm{I}_{T}$ medida com o copo de Faraday em função da $\mathrm{I}_{c}$ para cinco valores de $\mathrm{E}=250,400$, 600, 800 e $1000 \mathrm{eV}$. A I $\mathrm{I}_{T}$ mínima obtida nesta figura é de $0,9 \mathrm{~mA}$ para a tensão de feixe de 250 V. A $I_{T}$ está relacionada com o número de íons de nitrogênio que chegam à superfície de substrato por unidade de área e por unidade de tempo. A R(I/A) pode ser calculada a 
partir dessa corrente (ver o apêndice A).

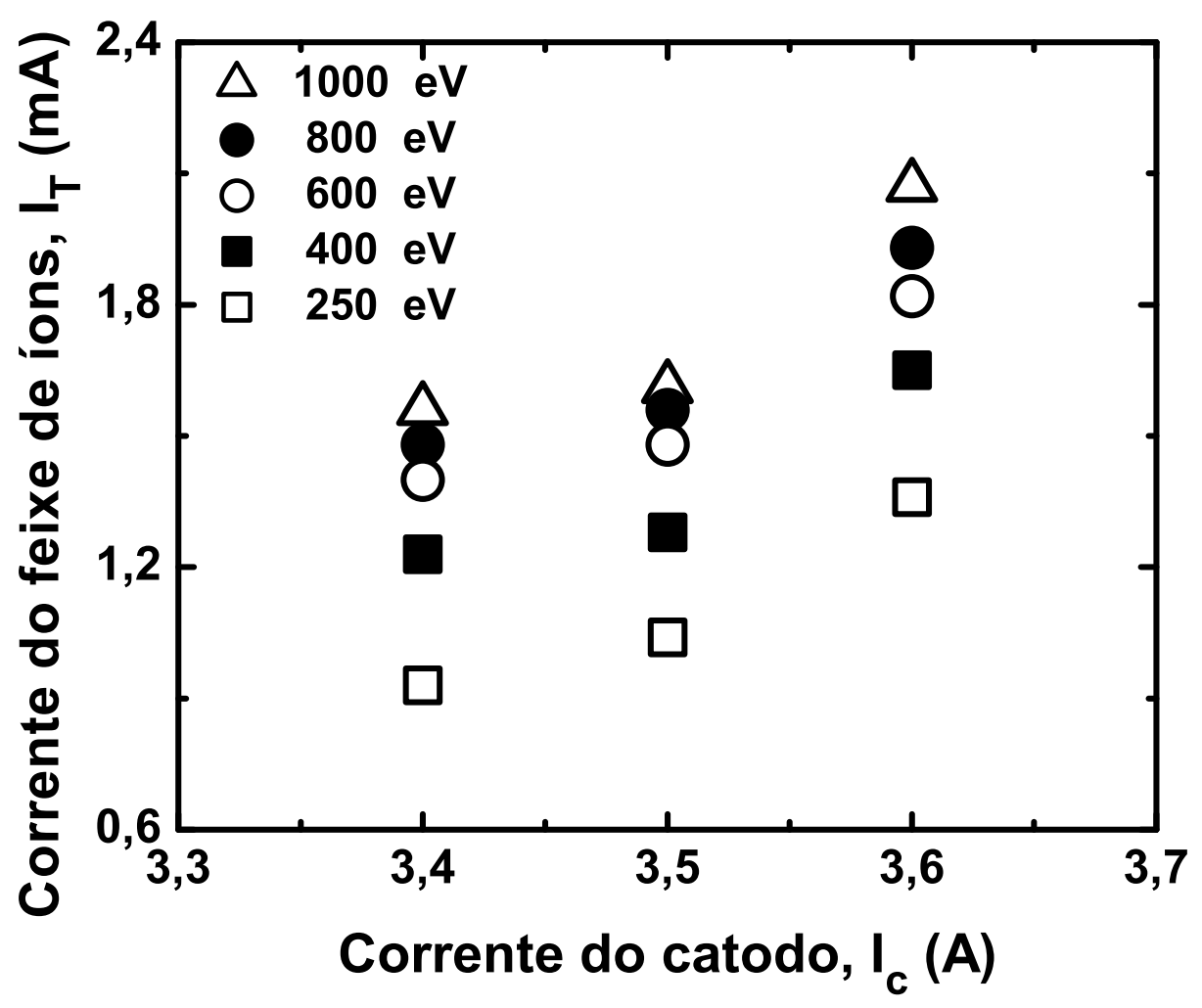

Figura 2.6: Variação da corrente de feixe de íons $\left(I_{T}\right)$ em função da corrente de catodo; fluxo de gás de $2,6 \mathrm{sccm}$ e tensão de aceleração de $600 \mathrm{~V}$.

\subsection{Evaporador}

O evaporador, mostrado na Fig. 2.7, usa um feixe de elétrons gerados de um filamento (catodo) e acelerados por uma diferença de potencial de $5 \mathrm{kV}$. Como o filamento está posicionado abaixo do cadinho, ver Fig. 2.7(a), em que é colocado um material a ser evaporado, um campo magnético gerado por magneto permanente guia o feixe de elétrons advindos do filamento até o material no cadinho numa trajetória circular.

A posição do feixe de elétrons na superfície do material pode ser ajustada para que área de aquecimento do material seja otimizada. O feixe de elétrons altamente energéticos 


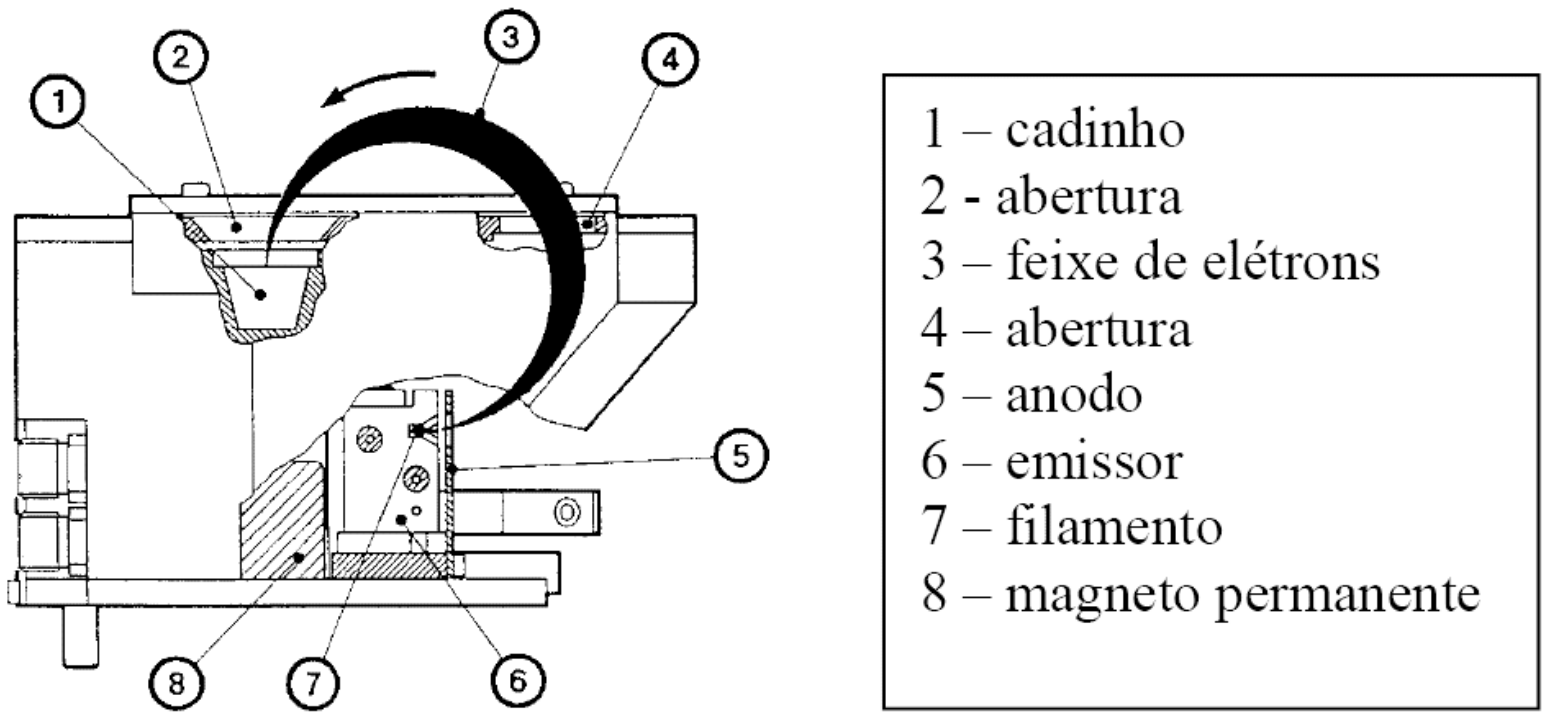

(a)

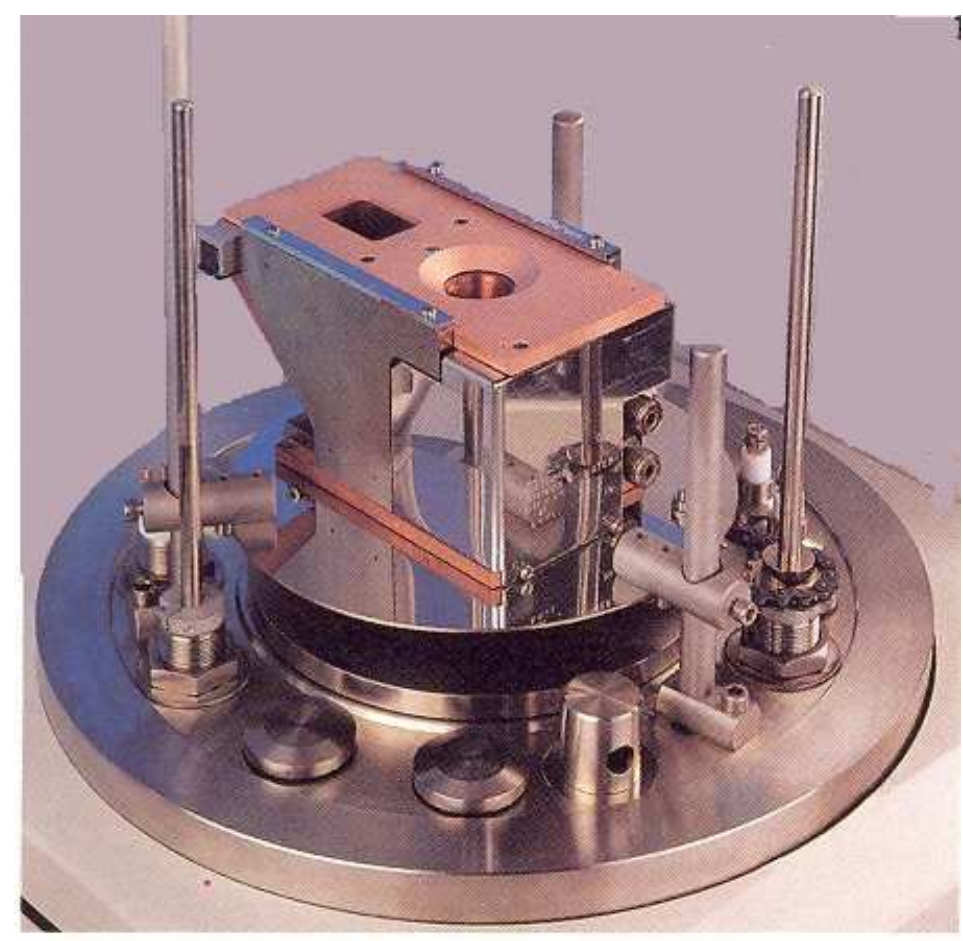

(b)

Figura 2.7: (a) Esquema do funcionamento do evaporador por feixe de elétrons; (b) evaporador instalado no sistema IBAD. 
colide o material (grafite neste trabalho) e aumenta a temperatura do material por tranferência de momento de elétrons ao material. A corrente do feixe de elétrons pode ser variada de zero até $600 \mathrm{~mA}$ para controlar a taxa de deposição do material. O portaamostra é resfriado através da circulação de água gelada.

\subsection{Preparação dos filmes de $\mathrm{CN}_{x}$}

Para a preparação dos filmes de $\mathrm{CN}_{x}$ foram utilizados os substratos de Si de 2,5 $\times 2,5 \mathrm{~cm}^{2}$ orientados no plano (100) ou no (111) com um lado polido, a fim de estudar o efeito da orientação cristalina do substrato na deposição do filme. Para a limpeza química de cada substrato foi submerso em uma solução de HF de 5\% (v/v) (significa que o volume do soluto é $5 \%$ do volume total da solução ou mistura) durante alguns segundos e depois na água purificada. Assim que esses substratos são colocados no suporte de substrato, o vácuo na câmara é obtido inicialmente pela bomba mecânica por uma hora até atingir uma pressão de 2,7 Pa. Em seguida, a câmara é evacuada pela bomba criogênica até a pressão de fundo de $\sim 7 \times 10^{-5} \mathrm{~Pa}$, assim garantindo a limpeza no processo de preparação dos filmes. Grafite de alta pureza de 99,999\% é evaporado pelo aquecimento e o vapor de carbono é depositado no substrato mantido à temperatura ambiente (RT), 350, 400 ou $500^{\circ} \mathrm{C}$. A taxa de deposição de carbono, medida pelo monitor de deposição, foi mantida a aproximadamente $0,05 \mathrm{~nm} / \mathrm{s}$. Durante a deposição do filme, a superfície do substrato foi exposta perpendicularmente ao feixe de íons de nitrogênio e/ou argônio. A E foi selecionada para 150, 200, 400, 600 ou $1000 \mathrm{eV}$, e a variação da $\mathrm{R}(\mathrm{I} / \mathrm{A})$ executou-se variando a $\mathrm{I}_{T}$. Nas tabelas 2.1 e 2.2 são apresentadas as condições de deposição dos filmes com o feixe de íons de nitrogênio e o feixe de íons derivado da mistura de $A r-\mathrm{N}_{2}$, respectivamente, e as espessuras dos filmes depositados que foram medidas com o perfilômetro. Durante a 
preparação dos filmes, a pressão de trabalho na câmara de vácuo foi mantida em cerca de $1,6 \times 10^{-2} \mathrm{~Pa}$.

Tabela 2.1: Parâmetros de deposição dos filmes de $C N_{x}$ com o feixe de íons de nitrogênio.

\begin{tabular}{cccccccc}
\hline \hline Amostra & $\begin{array}{c}\text { Temperatura } \\
\left({ }^{\circ} \mathrm{C}\right)\end{array}$ & $\begin{array}{c}\mathrm{N}_{2} \\
(\%)\end{array}$ & $\begin{array}{c}\mathrm{Ar} \\
(\%)\end{array}$ & $\mathrm{R}(\mathrm{I} / \mathrm{A})$ & $\begin{array}{c}\mathrm{E} \\
(\mathrm{eV})\end{array}$ & Substrato & $\begin{array}{c}\text { Espessura } \\
( \pm 6 \mathrm{~nm})\end{array}$ \\
\hline $\mathrm{CN}-01$ & 350 & 100 & 0 & 0,9 & 200 & $\mathrm{Si}(100)$ & 71 \\
$\mathrm{CN}-02$ & 350 & 100 & 0 & 1,5 & 200 & $\mathrm{Si}(100)$ & 45 \\
$\mathrm{CN}-03$ & 350 & 100 & 0 & 2,0 & 200 & $\mathrm{Si}(100)$ & 21 \\
\hline $\mathrm{CN}-04$ & 350 & 100 & 0 & 1,1 & 400 & $\mathrm{Si}(100)$ & 47 \\
$\mathrm{CN}-05$ & 350 & 100 & 0 & 1,4 & 400 & $\mathrm{Si}(100)$ & 41 \\
$\mathrm{CN}-06$ & 350 & 100 & 0 & 2,5 & 400 & $\mathrm{Si}(100)$ & - \\
\hline $\mathrm{CN}-07$ & 350 & 100 & 0 & 1,1 & 600 & $\mathrm{Si}(100)$ & 42 \\
$\mathrm{CN}-08$ & 350 & 100 & 0 & 1,3 & 600 & $\mathrm{Si}(100)$ & 41 \\
$\mathrm{CN}-09$ & 350 & 100 & 0 & 2,2 & 600 & $\mathrm{Si}(100)$ & 26 \\
\hline \hline
\end{tabular}

Tabela 2.2: Parâmetros de deposição dos filmes de $\mathrm{CN}_{x}$ com o feixe de íons derivado de $\operatorname{Ar}-\mathrm{N}_{2}$.

\begin{tabular}{cccccccc}
\hline \hline Amostra & $\begin{array}{c}\text { Temperatura } \\
\left({ }^{\circ} \mathrm{C}\right)\end{array}$ & $\begin{array}{c}\mathrm{N}_{2} \\
(\%)\end{array}$ & $\begin{array}{c}\mathrm{Ar} \\
(\%)\end{array}$ & $\mathrm{R}(\mathrm{I} / \mathrm{A})$ & $\begin{array}{c}\mathrm{E} \\
(\mathrm{eV})\end{array}$ & $\mathrm{Substrato}$ & $\begin{array}{c}\text { Espessura } \\
( \pm 6 \mathrm{~nm})\end{array}$ \\
\hline $\mathrm{C}-01$ & 400 & 0 & 0 & 0 & 0 & $\mathrm{Si}(100)$ & 86 \\
$\mathrm{C}-02$ & $\mathrm{RT}$ & 0 & 100 & 0 & 200 & $\mathrm{Si}(100)$ & 82 \\
$\mathrm{C}-03$ & $\mathrm{RT}$ & 0 & 100 & 0 & 1000 & $\mathrm{Si}(100)$ & 28 \\
\hline $\mathrm{CN}-10$ & $\mathrm{RT}$ & 90 & 10 & 1,2 & 200 & $\mathrm{Si}(100)$ & 37 \\
$\mathrm{CN}-11$ & $\mathrm{RT}$ & 90 & 10 & 1,2 & 200 & $\mathrm{Si}(111)$ & 45 \\
\hline $\mathrm{CN}-12$ & 400 & 90 & 10 & 1,0 & 150 & $\mathrm{Si}(100)$ & 65 \\
$\mathrm{CN}-13$ & 400 & 90 & 10 & 1,0 & 200 & $\mathrm{Si}(100)$ & 55 \\
$\mathrm{CN}-14$ & 400 & 90 & 10 & 1,9 & 200 & $\mathrm{Si}(100)$ & 19 \\
$\mathrm{CN}-15$ & 400 & 90 & 10 & 1,0 & 400 & $\mathrm{Si}(100)$ & 19 \\
$\mathrm{CN}-16$ & 400 & 90 & 10 & 1,1 & 600 & $\mathrm{Si}(100)$ & - \\
\hline $\mathrm{CN}-17$ & 500 & 90 & 10 & 1,1 & 200 & $\mathrm{Si}(100)$ & 39 \\
$\mathrm{CN}-18$ & 500 & 90 & 10 & 2,0 & 200 & $\mathrm{Si}(100)$ & 23 \\
$\mathrm{CN}-19$ & 500 & 90 & 10 & 1,1 & 400 & $\mathrm{Si}(100)$ & 46 \\
$\mathrm{CN}-20$ & 500 & 90 & 10 & 1,9 & 400 & $\mathrm{Si}(100)$ & 22 \\
$\mathrm{CN}-21$ & 500 & 90 & 10 & 1,2 & 600 & $\mathrm{Si}(100)$ & - \\
$\mathrm{CN}-22$ & 500 & 90 & 10 & 2,1 & 600 & $\mathrm{Si}(100)$ & - \\
\hline $\mathrm{CN}-23$ & 500 & 90 & 10 & 1,1 & 200 & $\mathrm{Si}(111)$ & 26 \\
$\mathrm{CN}-24$ & 500 & 90 & 10 & 2,0 & 200 & $\mathrm{Si}(111)$ & 14 \\
$\mathrm{CN}-25$ & 500 & 90 & 10 & 1,1 & 400 & $\mathrm{Si}(111)$ & 45 \\
$\mathrm{CN}-26$ & 500 & 90 & 10 & 1,9 & 400 & $\mathrm{Si}(111)$ & 18 \\
$\mathrm{CN}-27$ & 500 & 90 & 10 & 1,2 & 600 & $\mathrm{Si}(111)$ & 24 \\
$\mathrm{CN}-28$ & 500 & 90 & 10 & 2,1 & 600 & $\mathrm{Si}(111)$ & - \\
\hline \hline
\end{tabular}

O símbolo (-) significa que a espessura do filme depositado não foi detectada com o perfilômetro, mas o filme apresentou o espectro Raman. 


\section{Capítulo 3}

\section{Técnicas de caracterização}

Foram usadas, neste trabalho para avaliar os filmes de $\mathrm{CN}_{x}$ obtidos, as seguintes cinco técnicas de caracterização: perfilometria, deteção de espalhamento de partículas em recuo elástico, espectroscopia Raman, espectroscopia de infravermelho e espectroscopia de fotoelétrons induzida por raios-X. Uma breve descrição de cada técnica com o fundamento teórico, útil para interpretação dos resultados de caracterização dos filmes, será apresentada nas seções seguintes.

\subsection{Perfilometria}

O perfilômetro é um instrumento eletromecânico que basicamente mede a variação de planicidade dos filmes; o sensor usado no aparelho consiste de uma fina agulha de diamante que pode realizar movimentos horizontais sobre a superfície do filme, e as translações verticais que sofre a agulha durante o percurso são detectadas como as mudanças elétricas de um transformador diferencial variável linear (Linear Variable Differential Transformer: LVDT), cujo núcleo magnético está acoplado mecanicamente ao eixo da agulha. A mudança 
do fluxo magnético no interior da bobina do LVDT produz um sinal elétrico proporcional ao deslocamento vertical da agulha na saída do LVDT; esse sinal é amplificado, digitali-

zado, através de um conversor $\mathrm{A} / \mathrm{D}$, processado, visualizado em um monitor de vídeo e armazenado na memória de computador em forma de dados para posterior manipulação.

Foi utilizado um perfilômetro (3030, Dektak), com uma agulha de diamante de 12,5 $\mu \mathrm{m}$ de diâmetro, pertencente ao Laboratório de Sistemas Integrais (LSI) da Escola Politécnica da USP (EPUSP), para medidas de espessura dos filmes depositados neste trabalho. A precisão da medida foi de $\pm 60 \AA$ A. Esse equipamento foi montado sobre uma mesa de isolamento vibracional numa área livre de vibrações, evitando fontes de ruídos externas que afetem o processo de medida.

Como cada substrato foi montado e fixo no suporte de substrato com uma ou duas chapas metálicas finas de aço inoxidável antes da deposição, a espessura do filme pode ser determinada medindo-se a altura do degrau formado pelo filme depositado sobre o substrato e pela parte da superfície do substrato coberta pela chapa metálica. A espessura de cada filme foi medida em três posições diferentes do filme, para se determinar a variação na espessura da não uniformidade de deposição. A não uniformidade da deposição é representada pelo desvio padrão da média, indicado como uma barra de erro nos gráficos apresentados no capítulo 4 .

\subsection{Espalhamento de partículas em recuo elástico}

A análise de deteção de espalhamento de partículas em recuo elástico (Elastic Recoil Detection Analysis, ERDA) é uma técnica analítica de alta eficiência para a identificação e quantificação de substâncias implantadas ou depositadas sobre a superfície de um 
material. A técnica consiste na produção das partículas em recuo a partir das substâncias pelo bombardeamento por elementos pesados e na deteção dessas partículas em recuo usando a câmara de ionização. Esta técnica se torna muito útil quando as substâncias a serem identificadas são compostas por elementos leves, tais como $\mathrm{C}$ e $\mathrm{N}$, região dessas massas na qual outras técnicas de análise por feixes iônicos como retroespalhamento Rutherford (Rutherford Backscattering: RBS) têm baixa eficiência [40].

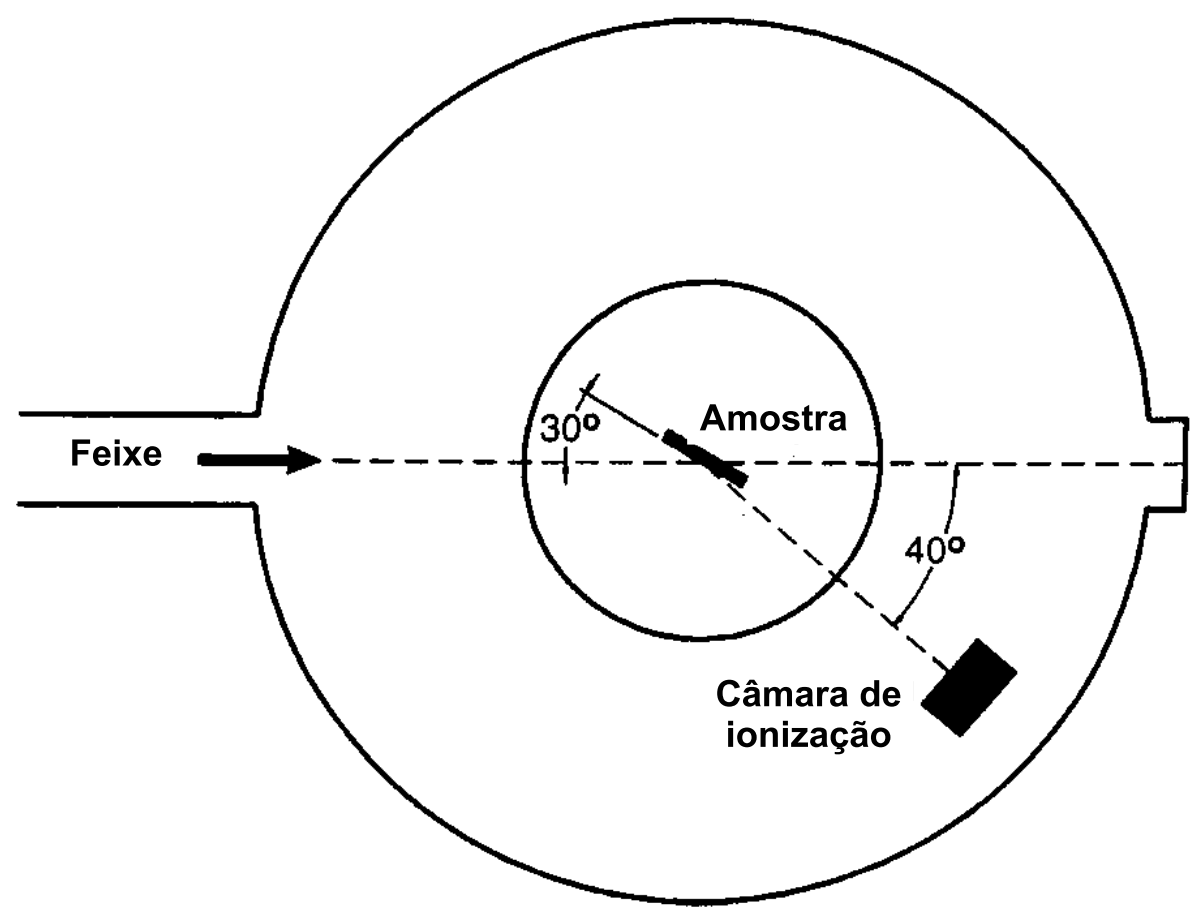

Figura 3.1: Esquema do arranjo experimental da câmara de espalhamento.

As medidas de ERDA foram realizadas usando-se um feixe pulsado de ${ }^{35} \mathrm{Cl}$ em $58 \mathrm{MeV}$ ativado pelo Acelerador Pelletron 8UD tipo tandem instalado no Instituto de Física da USP. Para a viabilizar essas medidas, montou-se uma câmara de espalhamento 15B de $1 \mathrm{~m}$ de diâmetro na linha do feixe do aceleredor, apresentada na Fig. 3.1. A câmara de ionização, instalada dentro da câmara de espalhamento, foi posicionada a $40^{\circ}$ 
em relação à direção do feixe incidente e preenchida com uma mistura de gases de $90 \%$ de Ar e $10 \%$ de $\mathrm{CH}_{4}$ a pressão de trabalho de aproximadamente $15 \mathrm{mPa}$. O suporte de alvos foi posicionado de maneira que o ângulo de incidência do feixe incidente na superfície de amostra previamente clivada no formato $10 \times 10 \mathrm{~mm}^{2}$ fosse de $60^{\circ}$ [40].

Todos os sinais obtidos na câmara de ionização foram processados através do sistema CAMAC (Computer Automated Measurement and Control), que se trata de uma norma para interface de instrumentos de medição e controle.

\subsection{Espectroscopia Raman}

A espectroscopia Raman, uma técnica não destrutiva, baseia-se no espalhamento inelástico de uma radiação monocromática devido a mudança da polarizabilidade pelas vibrações na rede dos materiais [41]. Esta técnica é muito utilizada para algumas estruturas cristalinas de carbono: amorfos, nanoestruturados e carbonos tipo diamond-like, fulerenos, nanotubos, grafite, diamante, polímeros e $\mathrm{CN}_{x}[13,16,20,25,42-47]$.

O princípio do experimento é ilustrado na Fig. 3.2. Um feixe da luz monocromática de freqüência $\omega_{l}$ colide com a amostra e o espectro da luz espalhada é examinado. O espalhamento elástico da luz (espalhamento Rayleigh) governa o espectro com um pico intenso na energia dos fótons incidentes, pois o processo de espalhamento elástico ocorre com alta probabilidade se comparada com o de espalhamento inelástico. Os picos adicionais são observados em $h\left(\omega_{l} \pm \omega_{k}\right)$ por um processo inelástico [41, 48], onde $\omega_{k}$ é a freqüência de vibração da molécula na amostra e/ou da rede cristalina da amostra. Assim, no processo de espalhamento inelástico, os fótons espalhados terão energia maior e energia menor do que os incidentes [41, 48]. Estes picos são conhecidos como picos Raman originando-se do 
nome do físico indiano C.V. Raman que observou estes efeitos em 1928.

Um tratamento teórico de espalhamento Raman é essencial para a compreensão, interpretação e apreciação dos espectros Raman obtidos experimentalmente para as amostras de $\mathrm{CN}_{x}$. A seguir será apresentada uma descripção clássica simples do efeito Raman que fornece uma compreensão qualitativa do fenômeno.

\section{Luz incidente}

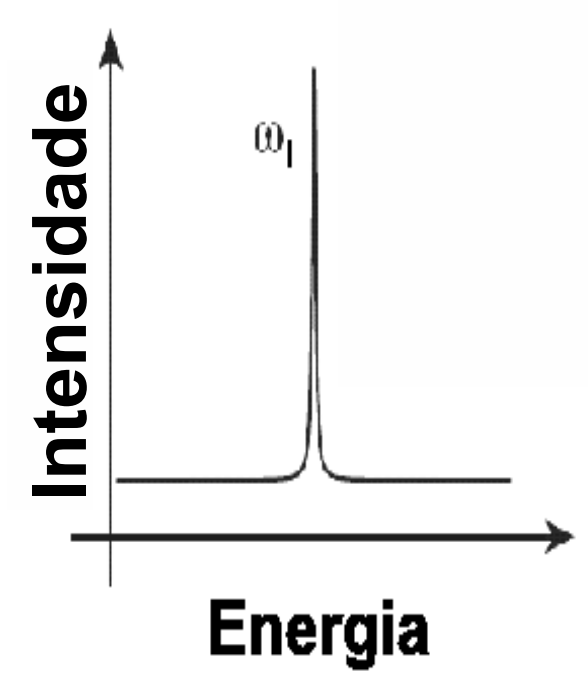

\section{Luz espalhada}

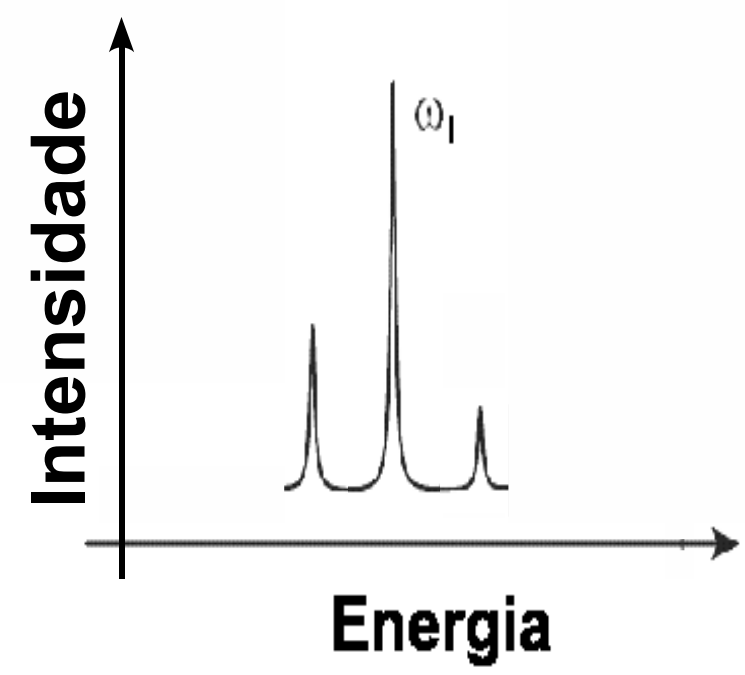

Figura 3.2: Espectros da luz incidente e da luz espalhada.

A atividade está ligada ao momento de dipolo $\mathbf{P}$ induzido, em uma molécula, pelo campo elétrico da luz incidente monocromática de freqüência $\omega_{l}, \mathbf{E}=\mathbf{E}_{0} \cos \left(\omega_{l} t\right)$ e o momento de dipolo pode ser escrito por [48]

$$
\mathbf{P}=\alpha \mathbf{E}=\alpha \mathbf{E}_{0} \cos \left(\omega_{l} t\right),
$$

onde $\alpha$ é a polarizabilidade da molécula e dada por um tensor. A polarizabilidade em geral será uma função das distâncias interatômicas e, conseqüentemente, alterada se a molécula 
estiver vibrando. Sabe-se, dos mecanismos clássicos, que as vibrações de um sistema de N átomos podem ser decompostas em modos normais das freqüências $\omega_{k}(k=1,2, \cdots, 3 N)$ com as correspondentes coordenadas normais $Q_{k}$.

Matematicamente, as coordenadas normais são definidas tal que a energia cinética $T$ e a energia potencial $U$ da molécula podem ser expressas, respectivamente, por:

$$
T=\frac{1}{2} \sum_{k}\left(\frac{d Q_{k}}{d t}\right)^{2} \quad \text { e } \quad U=\frac{1}{2} \sum_{k} \omega_{k} Q_{k}^{2}
$$

onde as constantes $\omega_{k}$ são as freqüências vibracionais; estas equações obedecem à seguinte equação de movimento referente à oscilação harmônica simples:

$$
\frac{d^{2} Q_{k}}{d t^{2}}+\omega_{k}^{2} Q_{k}=0
$$

Portanto, as coordenadas normais podem ser escritas por [48, 49]:

$$
Q_{k}=Q_{0 k} \cos \left(\omega_{k} t+\phi_{k}\right)
$$

Como as Q's são quantidades pequenas, a $\alpha$ pode ser expandida em uma série de Taylor das coordenadas normais como [48, 49]:

$$
\alpha=\alpha_{0}+\sum_{k}\left(\frac{\partial \alpha}{\partial Q_{k}}\right)_{0} Q_{k}+\frac{1}{2} \sum_{k, k^{\prime}}\left(\frac{\partial^{2} \alpha}{\partial Q_{k} \partial Q_{k^{\prime}}}\right)_{0} Q_{k} Q_{k^{\prime}}+\cdots
$$

As somatórias estão sobre todas as coordenadas normais e zero se refere à posição de equilíbrio. Considera-se até a primeira ordem na expansão desprezando-se os termos de ordem mais alta. Usando esta aproximação, as equações (3.1) e (3.4), e fórmulas trigonométricas para o produto de cossenos, o momento do dipolo induzido torna-se [48]:

$$
\mathbf{P}=\alpha_{0} \mathbf{E}_{0} \cos \left(\omega_{l} t\right)+\frac{1}{2} \sum_{k}\left(\frac{\partial \alpha}{\partial Q_{k}}\right)_{0} \mathbf{E}_{0} Q_{0 k}\left[\cos \left\{\left(\omega_{l}+\omega_{k}\right) t+\phi_{k}\right\}+\cos \left\{\left(\omega_{l}-\omega_{k}\right) t-\phi_{k}\right\}\right]
$$


Para o segundo termo ter contribuição, é necessário que $\left(\frac{\partial \alpha}{\partial Q_{k}}\right)_{0} \neq 0$, ou seja, que haja variação da polarizabilidade com um mínimo deslocamento da coordenada $Q_{k}$ em torno da posição de equilíbrio.

O primeiro termo na equação 3.6 possui somente a freqüência da radiação incidente e corresponde ao espalhamento Rayleigh. No segundo termo, aparecem radiações espalhadas com freqüência $\omega_{l}+\omega_{k}$ (espalhamento Raman anti-Stokes) e $\omega_{l}-\omega_{k}$ (espalhamento Raman Stokes), como mostra a Fig. $3.3[41,48]$.

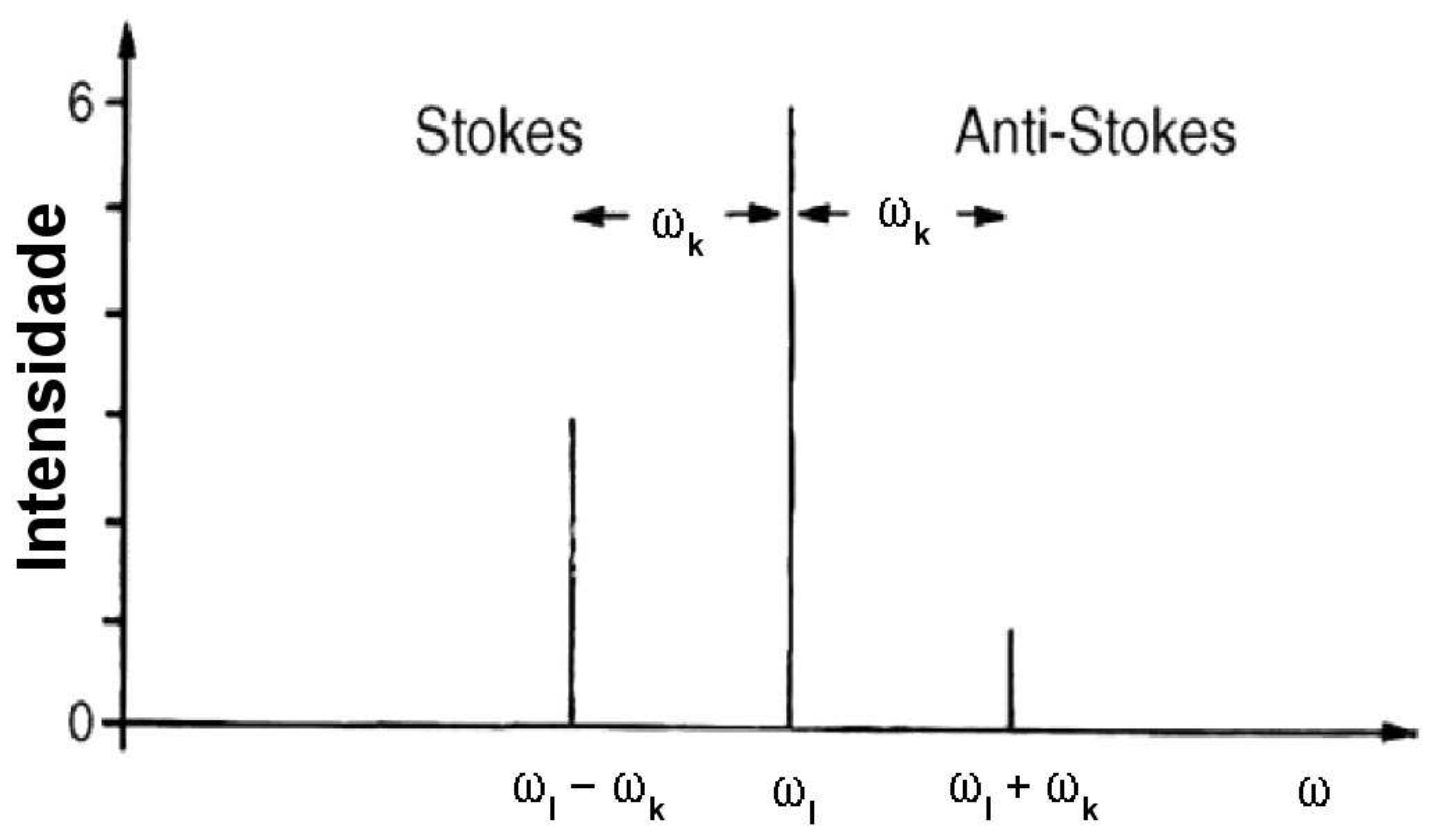

Figura 3.3: A linha anti-Stokes e a linha Stokes [41].

Os mecanismos de espalhamento podem ser visualizados pelos esquemas da Fig. 3.4. No espalhamento Raman Stokes, a molécula, no estado fundamental, sofre colisão com o fóton de energia $h \omega_{l}$, passa a um estado intermediário (ou virtual), que não precisa ser um estado estacionário da molécula e, decai em seguida, para um estado vibracionalmente excitado de enegia $h \omega_{k}$; o fóton espalhado, $h\left(\omega_{l}-\omega_{k}\right)$, terá energia menor do que o incidente. No espalhamento Rayleigh, após a interação do fóton com a molécula, esta volta 
ao mesmo nível de energia inicial e o fóton é espalhado sem modificação de freqüência. No espalhamento Raman anti-Stokes o fóton encontra a molécula já num estado excitado e, após a interação com a molécula, decai para o estado fundamental. Esta diferença é cedida ao fóton, que é espalhado com energia $h\left(\omega_{l}+\omega_{k}\right)[48]$.
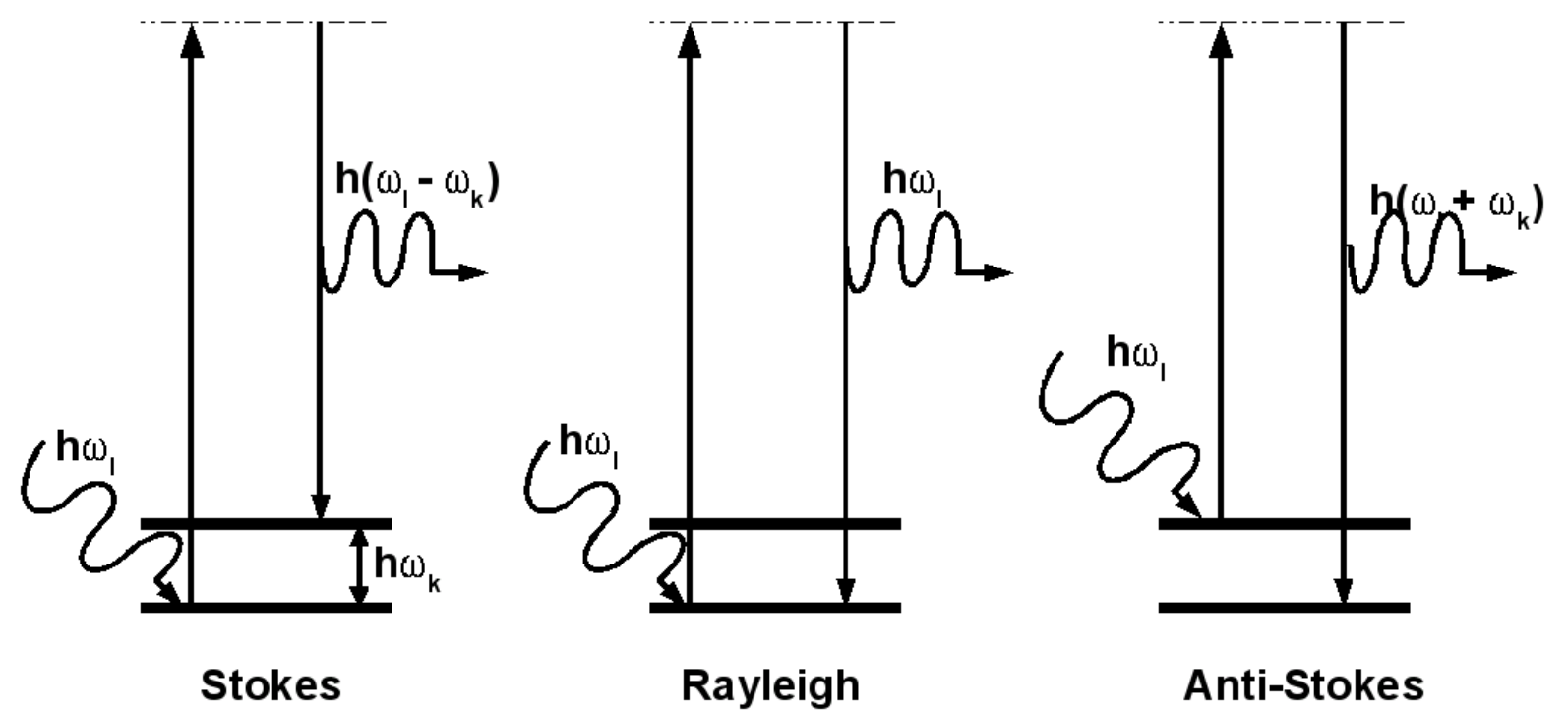

Anti-Stokes

Figura 3.4: Esquemas dos mecanismos de espalhamento [48].

A técnica de espectroscopia Raman é amplamente usada para caracterizar a qualidade estrutural do diamante, grafite, carbono diamond-like e nanotubos de carbono [50]. Os espectros Raman do diamante, da grafite e de filmes de carbono desordenado $[13,50]$ são mostrados na Fig. 3.5 para a comparação. Nota-se que o diamante apresenta um único pico no espectro Raman em $1332 \mathrm{~cm}^{-1}$, devido ao modo da simetria $\mathrm{T}_{2 g}[13,50]$. A grafite monocristalina também apresenta um único pico simétrico em $1580 \mathrm{~cm}^{-1}$ associado ao modo da simetria $\mathrm{E}_{2 g}$ stretching de qualquer par dos sítios $s p^{2}$ em anéis aromáticos ou em cadeias de olefina, este pico é chamado do pico G, referente à grafite [44, 50-52].

A grafite desordenada apresenta um segundo pico ao redor de $1350 \mathrm{~cm}^{-1}$ devido ao modo da simetria $\mathrm{A}_{1 g}$ breathing dos sítios $s p^{2}$ nas aglomerações de anéis aromáticos, 
sendo chamado do pico D, referente à desordem [14, 44, 51, 52], enquanto que esse modo $\mathrm{A}_{1 g}$ é Raman inativo para a grafite monocristalina [51].

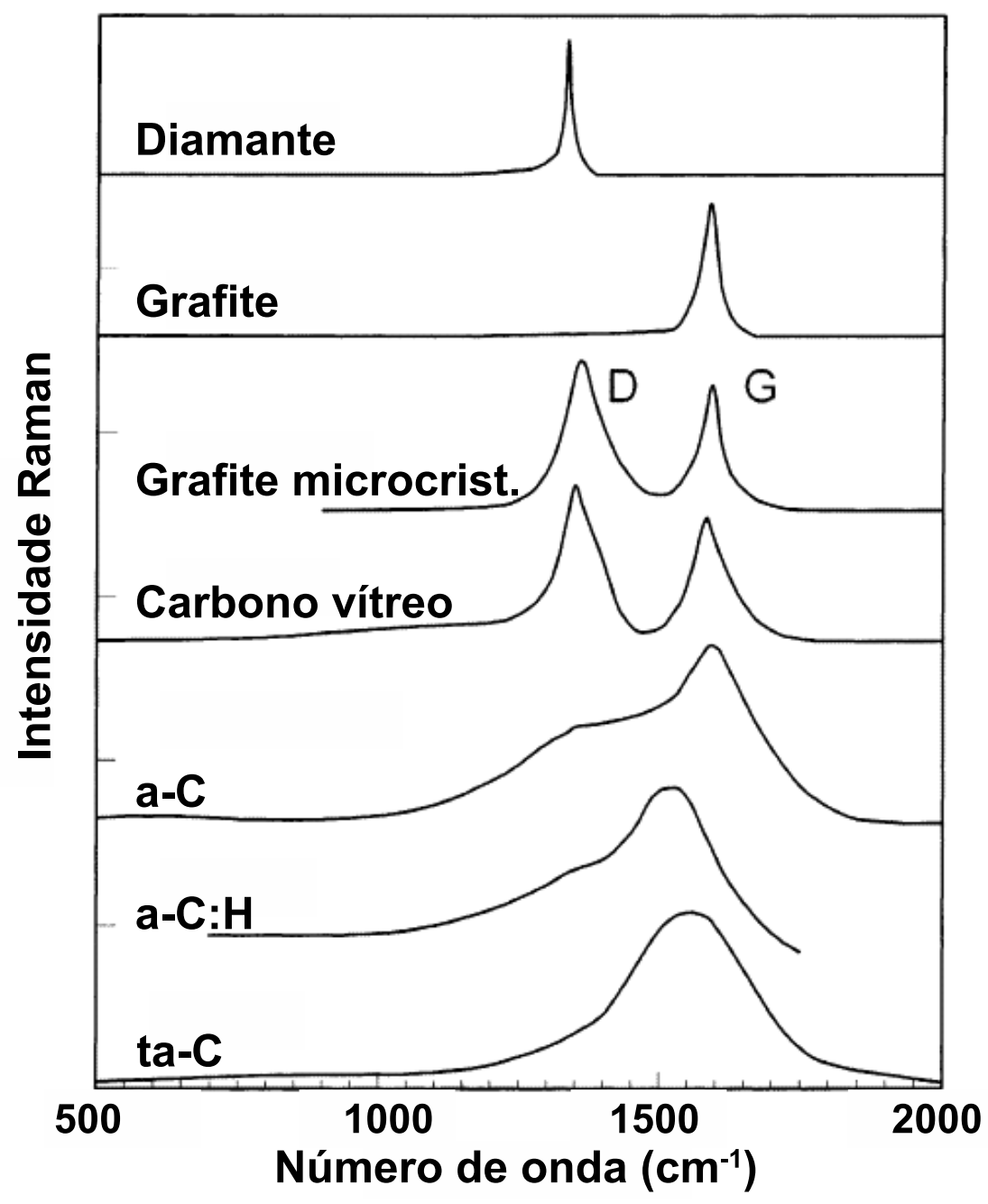

Figura 3.5: Comparação dos espectros Raman típicos do carbono [13, 14].

Um fato significante é que os espectros Raman da maioria dos carbonos desordenados sempre ficam dominados pelos picos $\mathrm{G}$ e $\mathrm{D}$, mesmo quando os carbonos não têm ordem grafítica particular [14]. Uma razão para esse fato é que os espectros Raman de carbonos desordenados são dominados pelo espalhamento nos sítios $s p^{2}$ [44, 50]; a energia das ligações $\pi$ é menor do que a das ligações $\sigma$ e portanto as ligações $\pi$ são muito mais polarizáveis, dando aos sítios $s p^{2}$ uma seção de choque Raman 50-230 vezes maior que os sítios $s p^{3}$ [50]. Assim os dois picos dominam até os espectros Raman dos filmes de carbono 
amorfo tetrahédrico ( $t a-\mathrm{C})$, que tem um conteúdo residual de 10-15\% de $s p^{2}$. O espectro Raman torna-se controlado pela ordem dos sítios $s p^{2}$, e não pela fração deles [50].

Como foi dito anteriormente, os espectros Raman dos filmes de carbono desordenado mostram os dois picos G e D. Um simples ajuste para estes picos consiste de duas gaussianas ou duas lorentzianas $[2,20,25]$. Neste trabalho serão usadas a função BreitWigner-Fano (BWF) para o pico G e uma lorenziana para o pico D [13, 15, 16, 42, 43, 45]. Esta maneira de ajuste está sendo usada não só para filmes de $\mathrm{CN}_{x}$ mas também para nanotubos de carbono. A função BWF tem uma forma assimétrica e é dado por [44, 50]:

$$
I(k)=\frac{I_{0}\left[1+2\left(k-k_{0}\right) / q \Gamma\right]^{2}}{1+\left[2\left(k-k_{0}\right) / \Gamma\right]^{2}}
$$

com a posição máxima em

$$
k_{\max }=k_{0}+\frac{\Gamma}{2 q}
$$

onde $I(k)$ é a intensidade em função do número de onda $k, I_{0}$ é a intensidade do pico, $k_{0}$, $k_{\max }$ e $\Gamma$ são a posição do pico média, a posição do pico, e a largura à meia altura (Full Width at Half-Maximum, FWHM), respectivamente, e $q$ é o coeficiente de acoplamento de BWF. A posição do pico G é definida por $k_{\max }$ e, no limite $q^{-1} \rightarrow 0$, a função BWF tornase a lorentziana. Estes parâmetros fornecem informações importantes sobre as estruturas dos filmes de carbono desordenado.

O espectro Raman é considerado dependente de [44]:

(i) aglomeração da fase $s p^{2}$;

(ii) desordem da ligação;

(iii) presença dos anéis $s p^{2}$ ou das cadeias $s p^{2}$, e

(iv) a razão $s p^{2} / s p^{3}$. 
Como mostrados esquematicamente na Fig. 3.6, esses fatores acima citados atuam como forças competitivas na aparência dos espectros Raman [44], deslocando os picos G e D e alterando suas intensidades relativas.

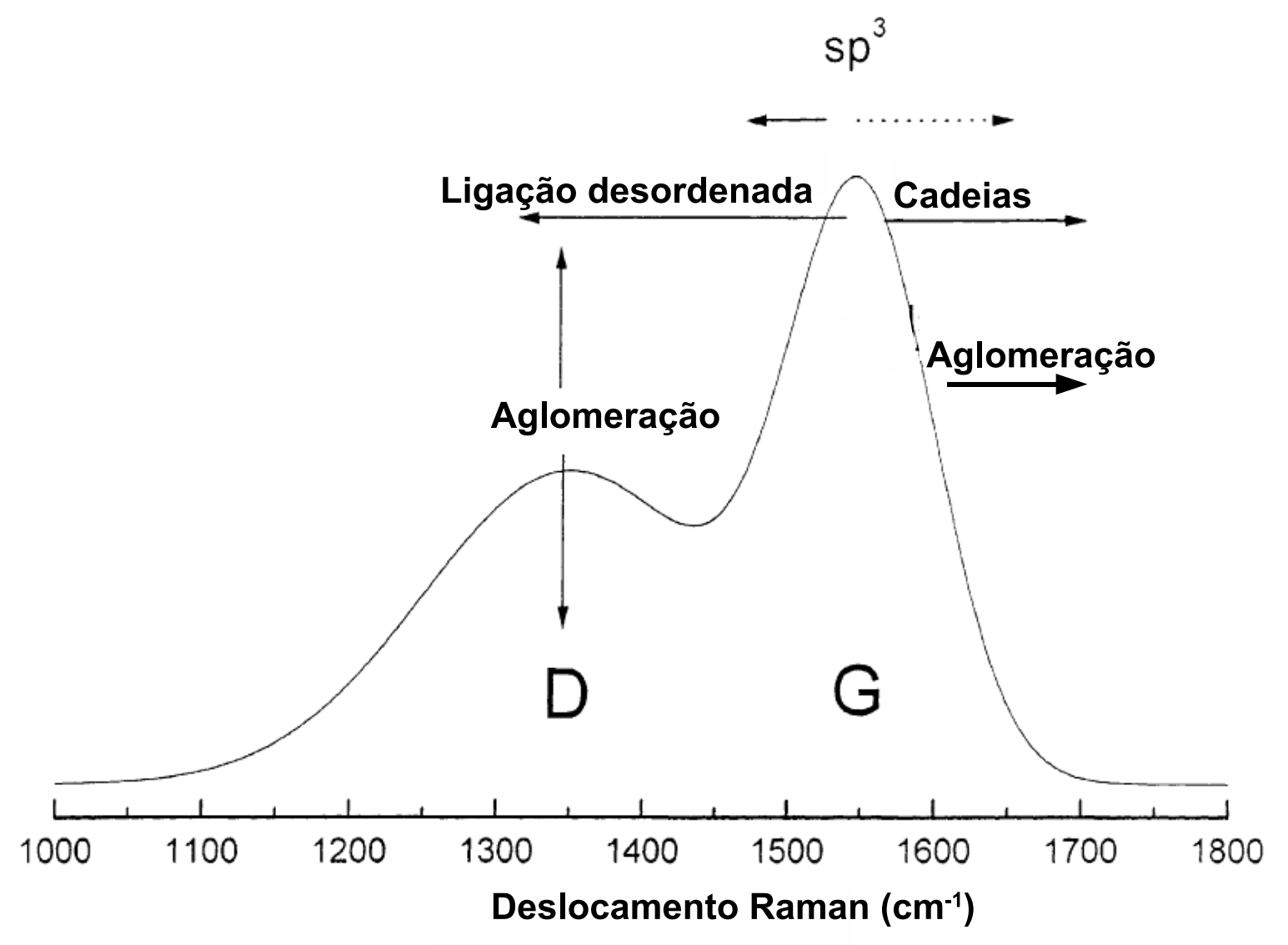

Figura 3.6: Diagrama esquemático das influências nos espectros Raman. A seta pontilhada sinaliza a influência indireta do conteúdo de $s p^{3}$ no incremento da posição do pico G [44].

Ferrari et al. sugeriram que é possível classificar os espectros Raman para carbonos desordenados usando um modelo de três estágios [13] que está mostrado na Fig. 3.7:

(a) Estágio 1, da grafite perfeita à grafite nanocristalina;

(b) Estágio 2, da grafite nanocristalina ao carbono amorfo $s p^{2}, a-\mathrm{C}\left(s p^{2}\right)$, e

(c) Estágio 3, de $a-\mathrm{C}\left(s p^{2}\right)$ ao $t a-\mathrm{C}$ ou diamante. 

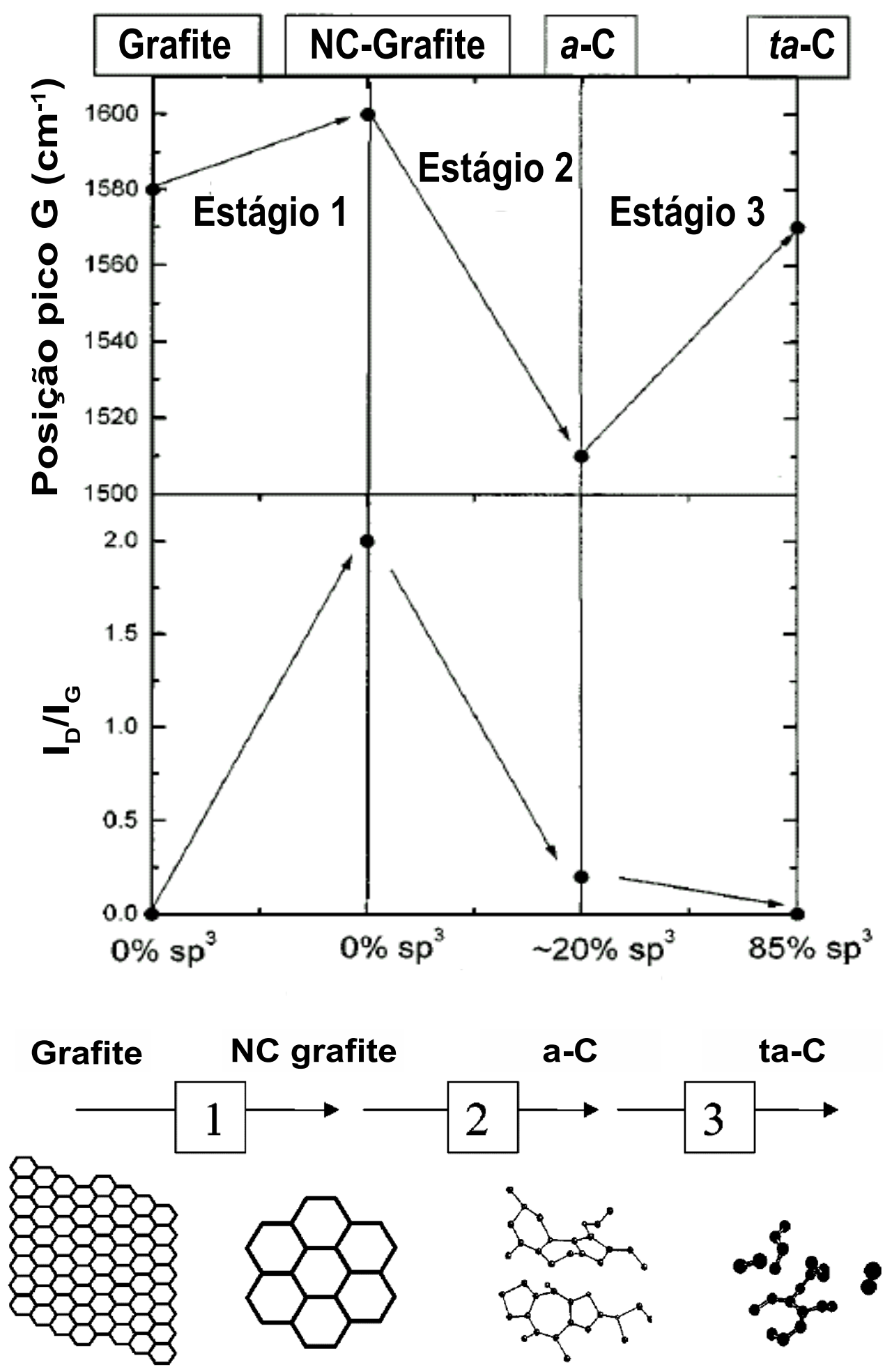

Figura 3.7: Modelo de três estágios, mostrando uma variação esquemática da posição do pico $G$ e a razão $I_{D} / I_{G}$. A parte inferior mostra o processo de amorfia a partir dos aneis aromáticos às cadeias curtas $[13,44,50]$. 
O Estágio 1 corresponde à redução progressiva no tamanho de grãos de camadas grafíticas ordenadas, enquanto mantendo os anéis aromáticos. Com a diminuição do tamanho de grãos, o confinamento de fónons nos grãos causa um deslocamento de pico G para altas energias $[44,50]$. Como o pico D está ausente na grafite perfeita, a desordem na grafite é responsável pelo aparecimento deste pico. Portanto a intensidade do pico D aumenta com a diminuição do tamanho de grãos $L_{a}$ de acordo com a relação Tuinstra-Koening $[44,45,51]:$

$$
\frac{I_{D}}{I_{G}}=\frac{C(\lambda)}{L_{a}}
$$

onde $\mathrm{I}_{D} / \mathrm{I}_{G}$ é a razão da intensidade do pico $\mathrm{D}$ em relação à do pico $\mathrm{G}$ e $C(\lambda)$ é aproximadamente de 4,4 nm para o comprimento de onda da luz incidente $\lambda=514,8 \mathrm{~nm}[44,45]$. Esta expressão é válida para tamanhos de grãos maiores que $2 \mathrm{~nm}$ [44].

O Estágio 2 corresponde à disordem topológica de camadas grafíticas e à perda de ligações aromáticas, mas permanece com uma rede puramente $s p^{2}$. A desordem e a perda da aromaticidade enfraquecem as ligações e baixam a densidade de estados vibracionais de comparação com aquela para a grafite perfeita, causando deslocamento do pico G para baixas energias [50].

Como o tamanho de grãos reduz-se abaixo de $2 \mathrm{~nm}$, o número de anéis aromáticos diminui e a $\mathrm{I}_{D}$ começa a decrescer. Como o pico $\mathrm{G}$ está associado ao modo stretching de pares de $s p^{2}$, a $\mathrm{I}_{G}$ mantém sua intensidade e a razão $\mathrm{I}_{D} / \mathrm{I}_{G}$ diminui com o processo de amorfização. Neste caso dimensões de grãos $(<2 \mathrm{~nm})$, a relação Tuinstra-Koening não se aplica e Ferrari e Robertson propuseram a seguinte relação [44, 50]: 


$$
\frac{I_{D}}{I_{G}}=C(\lambda) L_{a}^{2}
$$

com $\mathrm{C}(\lambda)$ de aproximadamente $0,55 \mathrm{~nm}^{-2}$ para $\lambda=514,8 \mathrm{~nm}[44,45]$.

No Estágio 3, ocorre a variação da configuração $s p^{2}$ de anéis em cadeias curtas (olefinas). O comprimento de ligações de cadeias é mais curto do que o dos anéis e a freqüência vibracional é mais alta [44]. Neste estágio, a intensidade do pico G cresce, enquanto que o pico D permanece em intensidade nula, resultando na tendência da $\mathrm{I}_{D} / \mathrm{I}_{G}$ a zero.

Nos filmes de $\mathrm{CN}_{x}$, as freqüências vibracionais de ligações $\mathrm{C}=\mathrm{N}$ em forma de cadeia ou em anel são similares às de ligações de $\mathrm{C}=\mathrm{C}$ [43]. Então, é esperado que haja pouca diferença entre os espectros Raman para os filmes de $a$-C e os filmes de $\mathrm{CN}_{x}$. Porém, como mencionado no capítulo 1, o $\mathrm{N}$ tem papel importante na formação de ligações, devido à capacidade de o $\mathrm{N}$ acomodar diferentes arranjos atômicos [13], substituindo o $\mathrm{C}$ em anéis aromáticos e terminando em configuração de piridina, pirrol ou de nitrilas. Portanto, espera-se que os filmes de $\mathrm{CN}_{x}$ possam exibir diferentes proporções das estruturas de cadeia e de anel aromático, diferentes graus de comprimento de ligação, distorção no ângulo de ligação e da desordem nas camadas grafíticas [43]. Serão analisados, no capítulo 4, os espectros Raman para os filmes de $\mathrm{CN}_{x}$ depositados no presente trabalho usando o modelo de três estágios acima apresentado para os filmes de $a$-C.

As medidas dos espectros Raman dos filmes de $\mathrm{CN}_{x}$ foram realizadas utilizandose um aparelho Micro-Raman Renishaw 2000, operando com uma linha de excitação do raio laser de $\mathrm{Ar}^{+}$em 514,8 nm, encontrado no Laboratório Associado de Sensores (LAS), do Centro de Tecnologia Especiais (CTE) do Instituto Nacional de Pesquisas Espaciais (INPE). Os espectros foram registrados na região de $600-3000 \mathrm{~cm}^{-1}$. Foram realizadas 
três leituras acumuladas para cada espectro obtido.

\subsection{Espectroscopia do infravermelho}

A radiação infravermelha (IR) foi descoberta por Herschel em 1800 e, por volta de 1900, Coblentz obteve espectros de absorção de compostos orgânicos na região de IR [48]. Desde então, a espectroscopia de IR se tornou uma técnica analítica muito importante e poderosa para o esclarecimento das ligações químicas e da estrutura molecular dos compostos [41].

Para se comprender melhor o mecanismo da absorção da radiação IR por moléculas, se deve estudar, segundo as idéias clássicas, o caso mais simples da vibração de uma molécula diatômica heteronuclear. Para pequenas vibrações, essa molécula pode considerarse, com uma boa aproximação, como um sistema mecânico formado por duas massas pontuais $m_{1}$ e $m_{2}$ unidas através de uma mola perfeitamente elástica de massa desprezível, representando a ligação química entre ambos os átomos [53]. Na posição de equilíbrio, representada esquematicamente na Fig. 3.8(a), $r_{0}$ é a distância internuclear ou a distância da ligação. Devido à diferença da eletronegatividade entre os átomos da molécula, os seus elétrons não estão distribuídos simetricamente respeito ao centro da ligação, mas, estão deslocados para o átomo mais eletronegativo; este fato origina um momento de dipolo elétrico representado por $u_{0}=e^{*} r_{0}$, onde $e^{*}$ é a carga efetiva [Fig. 3.8(a)] [53].

Para um deslocamento pequeno da distância internuclear $r$ em relação à $r_{0}$ haverá uma força de restauração que obedece à lei de Hooke, isto é:

$$
F=-k\left(r-r_{0}\right)
$$

onde $k$ é a constante da força de ligação e o sinal negativo indica que o sentido da força é 
oposto ao do deslocamento $\left(r-r_{0}\right)$.

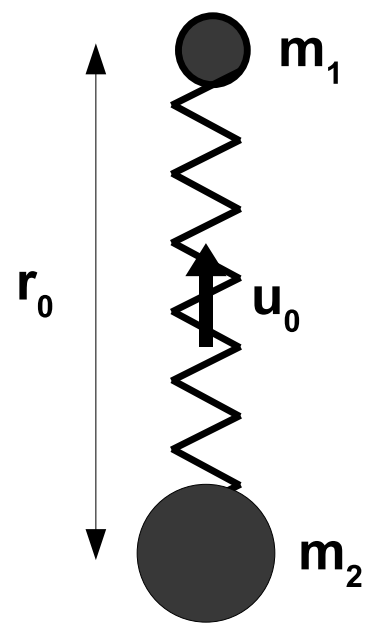

(a)

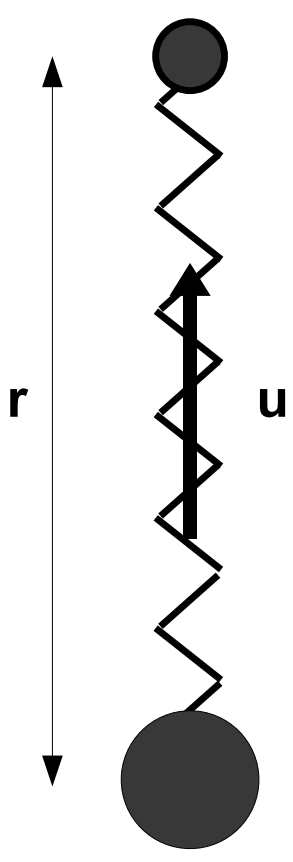

(b)

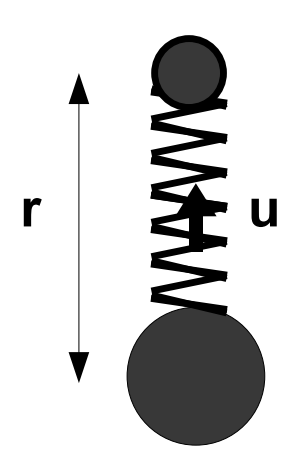

(c)

Figura 3.8: Esquema da vibração de uma molécula diatômica heteronuclear: (a) em posição de equilíbrio; (b) e (c) em posições de elongação máxima e mínima, respectivamente [53].

Tendo-se em conta que, nas vibrações moleculares, o centro de gravedade da molécula permanece fixo [53] e, aplicando-se a primeira lei de Newton, pode deduzir-se a seguinte equação do movimento da vibração $[48,53]$ :

$$
-k\left(r-r_{0}\right)=\mu \frac{d^{2}\left(r-r_{0}\right)}{d t^{2}}
$$

onde $\mu=\frac{m_{1} m_{2}}{m_{1}+m_{2}}$ é a massa reduzida da molécula. Esta equação diferencial é bem conhecida e uma solução dela (não a única) é dada pela forma de oscilador harmônico linear:

$$
r-r_{0}=a \operatorname{sen}\left(\sqrt{\frac{k}{\mu}} t+\delta\right)
$$

onde a constante $a$ representa a amplitude de vibração. A equação (3.13) pode ser escrita na seguinte forma:

$$
r-r_{0}=a \operatorname{sen}\left(2 \pi \nu_{s} t+\delta\right)
$$


onde $\nu_{s}$ é a freqüência de vibração e dada por:

$$
\nu_{s}=\frac{1}{2 \pi} \sqrt{\frac{k}{\mu}}
$$

Multiplicando a equação (3.14) por $e^{*}$, obtem-se:

$$
u=u_{0}+b \operatorname{sen}\left(2 \pi \nu_{s} t+\delta\right)
$$

onde $u=e^{*} r$ e $b=e^{*} a$. A Fig. 3.9 mostra $\left(r-r_{0}\right)$ e $u$ em função do tempo.

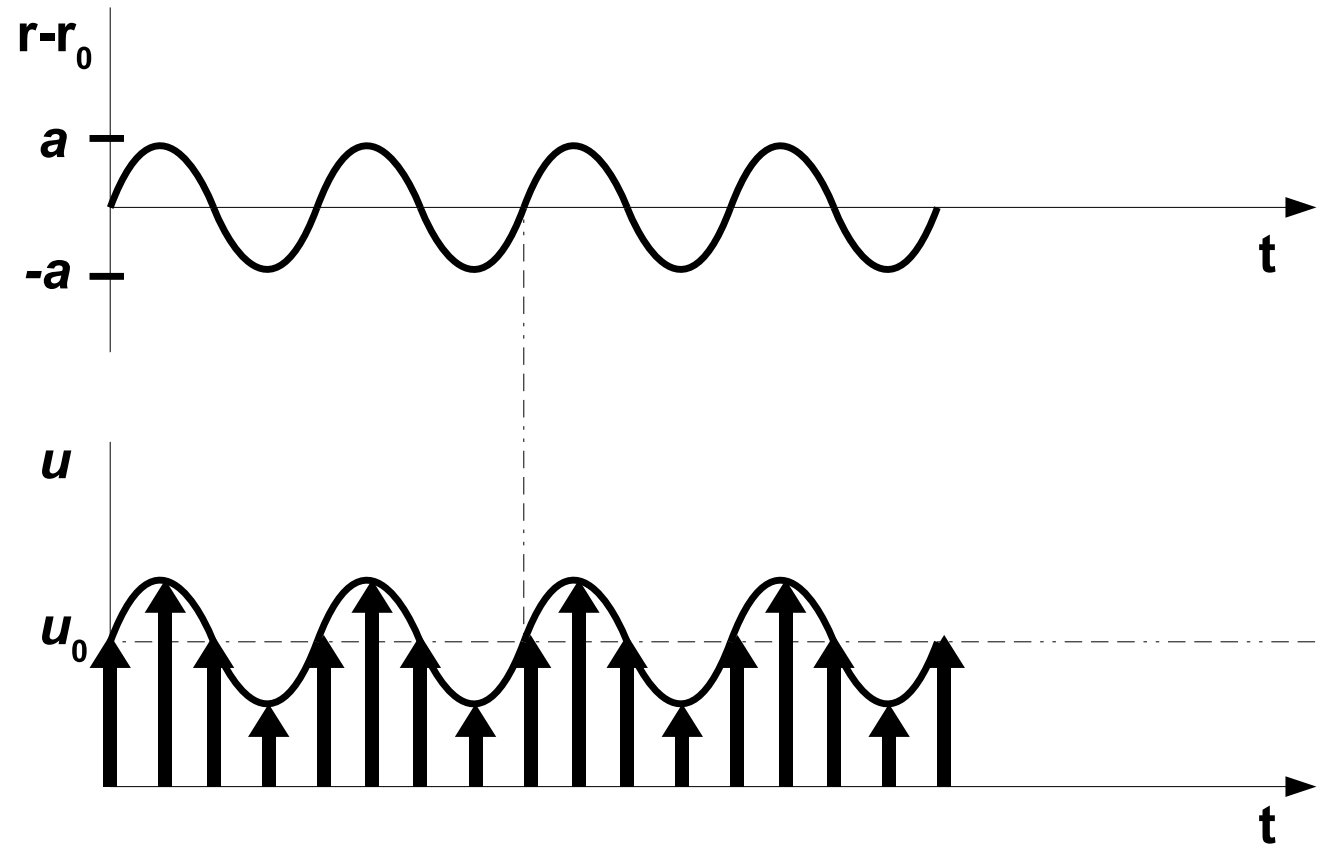

Figura 3.9: Variações periódicas de $\left(r-r_{0}\right)$ (parte superior) e do momento dipolar (parte inferior) de uma molécula diatômica heteronuclear [53].

Classicamente, a absorção de radiação eletromagnética por uma molécula é devida à variação periódica de seu momento de dipolo elétrico permanente, sendo a freqüência absorvida idêntica à da vibração do dipolo elétrico. Assim, desde que esse momento possa oscilar com a mesma freqüência de uma radiação incidente, a molécula absorverá esta radiação $[41,48,53]$. 
O momento de dipolo elétrico de uma molécula poliatômica pode ser expandido em série de Taylor das coordenadas normais Q's, quando o deslocamento de cada átomo em relação à sua posição de equilíbrio é pequeno:

$$
u=u_{0}+\sum_{k}^{3 N-6}\left(\frac{\partial u}{\partial Q_{k}}\right)_{0} Q_{k}+\frac{1}{2} \sum_{k}^{3 N-6} \sum_{j}^{3 N-6}\left(\frac{\partial^{2} u}{\partial Q_{k} \partial Q_{j}}\right)_{0} Q_{k} Q_{j}+\cdots
$$

onde a derivada é considerada na posição de equilíbrio, e $Q_{k}, Q_{j} \cdots$ são as coordenadas normais [49]. Desprezam-se aqui os termos de ordem mais altos. A condição de a variação do momento de dipolo devida à vibração da molécula induzir absorção no infravermelho implica que $\left(\frac{\partial u}{\partial Q_{k}}\right)_{0} \neq 0$.

Como a energia cinética e a energia potencial são dadas em termos das coordenadas normais [equação (3.2)], a equação de onda vibracional normal é separada em $(3 N-6)$ equações, uma para cada coordenada normal. Portanto a função de onda vibracional $\Psi_{V}$ é dada por $[48,49]$ :

$$
\Psi_{V}=\prod_{k=1}^{3 N-6} \psi_{v_{k}}\left(Q_{k}\right)
$$

onde $\psi_{v_{k}}\left(Q_{k}\right)$ é a função de oscilador harmônico para a coordenada normal $Q_{k}$ com o número de quântico vibracional $v_{k}$.

Pela mecânica quântica, a transição de um estado $\Psi_{V^{\prime}}$ a $\Psi_{V^{\prime \prime}}$ é descrita pelo momento de transição do dipolo. A integral para o momento de dipolo $u$ é dada por:

$$
\int \Psi_{V^{\prime \prime}}^{*} u \Psi_{V^{\prime}} d \tau_{V}=u_{0} \int \Psi_{V^{\prime \prime}}^{*} \Psi_{V^{\prime}} d \tau_{V}+\sum_{k=1}^{3 N-6}\left(\frac{\partial u}{\partial Q_{k}}\right)_{0} \int \Psi_{V^{\prime \prime}}^{*} Q_{k} \Psi_{V^{\prime}} d \tau_{V}
$$

onde $d \tau_{V}$ é o elemento de volume do espaço de coordenação e igual a $d Q_{1} d Q_{2} \cdots d Q_{3 N-6}$. O primeiro termo do segundo membro da equação acima é igual a zero, em consequiência de $V^{\prime} \neq V^{\prime \prime}$ e a ortogonalidade da função $\Psi_{V}$. E a integral do segundo termo pode ser separada em [49]:

$$
\int \Psi_{V^{\prime \prime}}^{*} Q_{k} \Psi_{V^{\prime}} d \tau_{V}=
$$




$$
\int \psi_{v_{1}^{\prime \prime}}^{* \prime}\left(Q_{1}\right) \psi_{v_{1}^{\prime}}\left(Q_{1}\right) d Q_{1} \int \psi_{v_{2}^{\prime \prime}}^{*}\left(Q_{2}\right) \psi_{v_{2}^{\prime}}\left(Q_{2}\right) d Q_{2} \cdots \int \psi_{v_{k}^{\prime \prime}}^{*}\left(Q_{k}\right) Q_{k} \psi_{v_{k}^{\prime}}\left(Q_{k}\right) d Q_{k} \cdots
$$

Se $v_{1}^{\prime}=v_{1}^{\prime \prime}, v_{2}^{\prime}=v_{2}^{\prime \prime}, \cdots, v_{1}^{\prime}=v_{k}^{\prime \prime} \pm 1, \cdots ;$ isto é, somente um número quântico $v_{k}^{\prime \prime}$

muda por unidade, a transição vibracional pode ocorrer com a absorção da radiação, em outra palavra, a vibração associada à coordenada normal $Q_{k}$ é ativa no infravermelho.

As bandas de absorção observadas em um espectro de IR podem ser relacionadas com os modos normais de vibração, alguns dos quais são mostrados na Fig. 3.10. Vibrações conhecidas como stretching, mostradas na Fig. 3.10, são de estiramento e relaxação de dois átomos externos nas direções paralelas às das respectivas ligações ao átomo central; stretching simétrico e stretching assimétrico referem-se aos movimentos dos dois átomos para dentro e para fora, respectivamente, em fase e alternadamente, como mostra a figura. As vibrações bending significam os movimentos dos dois átomos nas direções perpendiculares às direções das respectivas ligações ao átomo central.

A técnica da espectroscopia de IR tem sido usada extensivamente para os estudos dos filmes de $a$-C e $\mathrm{CN}_{x}$ [24]. Os espectros de IR dos filmes de $\mathrm{CN}_{x}$ relatados na literatura compreendem em quatro regiões espectrais: (a) 3200-3600 $\mathrm{cm}^{-1}$, na qual encontram-se picos devidos às vibrações stretching de $\mathrm{NH}$ ou $\mathrm{OH}[24,43]$; (b) 2700-3000 $\mathrm{cm}^{-1}$, onde picos das vibrações vibrações stretching de $\mathrm{CH}_{x}$ podem ser observados $[24,41,43,54]$; (c) $2000-2500 \mathrm{~cm}^{-1}$, na qual aparecem picos dos grupos $-\mathrm{C} \equiv \mathrm{N},-\mathrm{N} \equiv \mathrm{C},-\mathrm{N}=\mathrm{C}=\mathrm{N}-\mathrm{e} \mathrm{CO}_{2}$ [24, 43, 55]; e (d) 1100-1700 $\mathrm{cm}^{-1}$, onde observam-se picos das vibrações stretching de $\mathrm{C}-\mathrm{C}, \mathrm{C}-\mathrm{N}, \mathrm{C}=\mathrm{C}$ e $\mathrm{C}=\mathrm{N}$, e pico da vibração bending de $\mathrm{C}-\mathrm{H}[13,24,41,43,46,47]$.

Foi utilizado neste trabalho um equipamento Digilab FTS-40 FTIR (BIO-RAD), que se encontra no Laboratório da Microeletrônica (LME) da EPUSP. Esse equipamento tem resolução máxima de $4 \mathrm{~cm}^{-1}$ e uma região espectral entre 400 e $4000 \mathrm{~cm}^{-1}$ no modo 
de absorbância. Foram acumuladas 32 leituras para cada espectro. O equipamento opera em temperatura ambiente e em atmosfera de $\mathrm{N}_{2}$. Os resultados obtidos para os filmes de $\mathrm{CN}_{x}$ são aprasentados no capítulo 4.

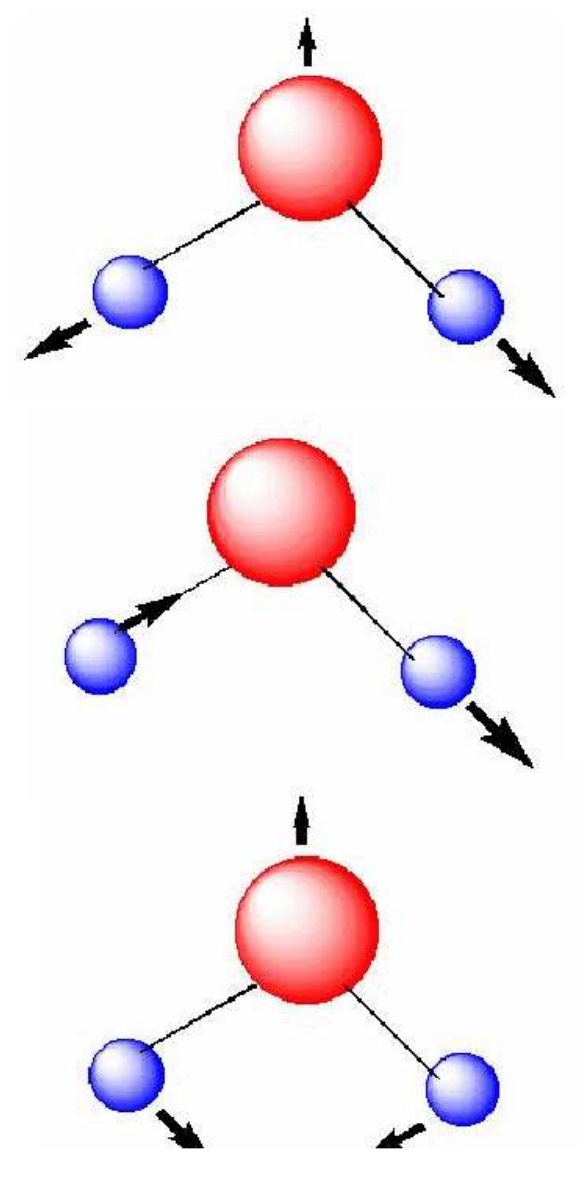

\section{Stretching simétrico}

\section{Stretching assimétrico}

\section{Bending}

Figura 3.10: Representação dos modos normais de vibração.

\subsection{Espectroscopia de fotoelétrons induzida por raios $\mathrm{X}$}

A espectroscopia de fotoelétrons induzida por raios $\mathrm{X}$ (X-ray photoelectron spec-

troscopy, XPS) [41] foi desenvolvida pelo grupo do Prof. Kai Siegbahn, em Uppsala, Suécia, nas décadas de 40 e 50, tendo sido denominada ESCA (Electron Spectroscopy for Chemical 
Analysis) [56]. Na espectroscopia de fotoelétrons uma fonte de radiação eletromagnética é usada para ejetar elétrons de átomos constituintes da amostra. São usados dois tipos de fontes de fótons convencionais: lâmpadas de descarga de hélio, que emite radiação ultravioleta ( $\mathrm{h} \nu=21,2 \mathrm{e} 40,8 \mathrm{eV}$ para He I e He II, respectivamente), dando origem à espectroscopia de fotoelétrons excitados por ultravioleta (Ultraviolet Photoelectron Spectroscopy, UPS), e raios X moles ( $\mathrm{h} \nu=1486,6 \mathrm{e} 1253,6 \mathrm{eV}$ para a linha $\mathrm{K} \alpha$ de $\mathrm{Al}$ e a K $\alpha$ de Mg, respectivamente), usados na XPS. Para análise de superfícies, a XPS é muito mais importante que a UPS, pois a primeira é mais específica aos elétrons de valência. O rápido desenvolvimento na instrumentação, a interpretação dos resultados e a gama de aplicações fez com que XPS tornasse uma técnica espectroscópica de superfícies da mais poderosas, sendo hoje empregada na análise de vários tipos de amostras (metais, polímeros, cerâmicas, compósitos, semicondutores e amostras biológicas, em forma de lâminas, fibras, pós, partículas ou filmes).

Considere a configuração eletrônica de um átomo não excitado, descrito de forma esquemática na Fig. 3.11(a). As notações $\mathrm{K}, \mathrm{L}_{1}, \mathrm{~L}_{2,3}$, etc., e os correspondentes estados eletrônicos 1s, 2s, 2p, etc. são indicados na mesma figura [57]. A Fig. 3.11(b) mostra um processo de fotoemissão no diagrama dos níveis de energia.

Como os níveis de energia são quantizados, os fotoelétrons possuem uma distribuição de energia cinética, que consiste de picos discretos associados aos níveis de energia de onde elétrons foram induzidos. O termo referente à função trabalho, $\phi$, podem ser compensados eletronicamente, assim a energia cinética do fotoelétron é representada por:

$$
E_{K}=h \nu-E_{B}
$$

onde $E_{B}$ é a energia de ligação deste elétron em relação ao nível de vácuo e $h \nu$ é a energia 
do fóton incidente.
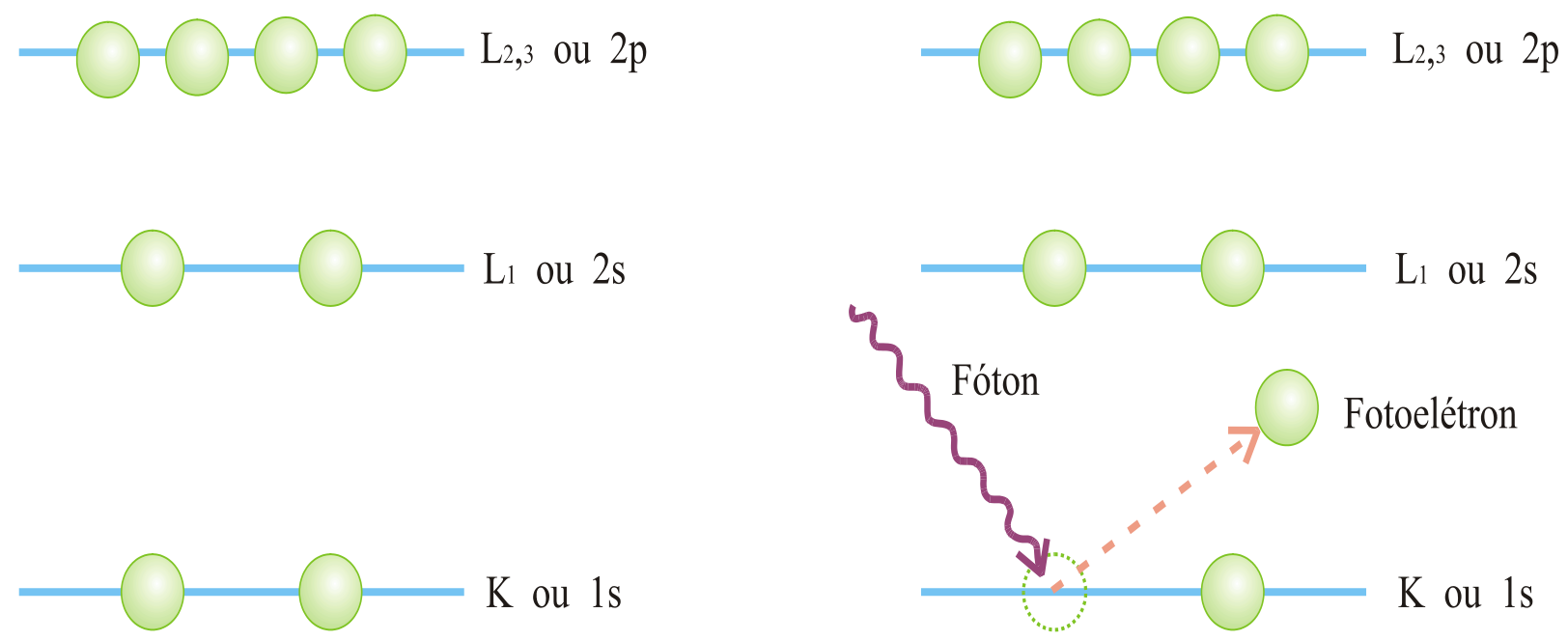

a)

b)

Figura 3.11: Diagrama dos níveis de energia envolvidos em XPS.

A identificação dos elementos presentes na superfície é feita diretamente através da determinação das energias de ligação referentes aos picos fotoelétricos que aparecem no espectro de XPS [57]. A intensidade (área integrada do pico fotoelétrico) é proporcional ao número de átomos no volume detectado, permitindo, portanto, obter-se informações sobre a composição química da superfície.

A posição exata de um pico fotoelétrico indica o estado químico do átomo emissor. As energias de ligação dos níveis de caroço dos átomos são suficientemente afetadas pelo seu ambiente químico (ou seja, estado de oxidação, sítios da rede, estrutura molecular, etc.) que provoca um deslocamento de $0,1 \mathrm{a} 10 \mathrm{eV}$ nas energias dos fotoelétrons [57]. Estes deslocamentos químicos devem-se às variações na blindagem eletrostática sofridas pelos elétrons de caroço, quando os elétrons de valência do átomo de interesse são atraídos ou repelidos. Considerando-se um mesmo elemento em dois estados químicos, a diferença entre 
as energias de ligação (referentes ao nível de vácuo) é dada pela diferença entre as energias cinéticas dos fotoelétrons. Entretanto, vários efeitos influenciam o deslocamento das energias dos fotoelétrons medidos, como o carregamento nas superfícies isolantes e as variações na função trabalho, e ainda não há teoria que explique completamente os deslocamentos químicos. A interpretação destes deslocamentos é geralmente feita comparando as energias de ligação observadas, no material analisado, com as dos padrões correspondentes.

\subsection{Difração de raios $\mathrm{X}$}

O fenômeno da difração ocorre quando qualquer tipo de onda interage com um conjunto de objetos espalhadores regularmente espaçados e quando o comprimento de onda é da ordem de grandeza das distâncias entre os objetos espalhadores. Hoje em dia, os raios $\mathrm{X}$ produzidos por um tubo de raios X e selecionados por uma rede de difração são usados em análises estruturais de qualquer composto cristalino. Pois, os raios X têm comprimentos de onda bem definidos de ordem de grandeza de angstrom e podem ser difratados por sólido cristalinos com as distâncias interatômicas da mesma ordem de grandeza. A difração de raios X (X-Ray Diffraction, XRD) desempenha um papel importante na determinação das propriedades estruturais em materiais orgânicos e inorgânicos, permitindo a identificação do composto cristalino, bem como a determinação dos parâmetros da rede cristalina, tamanho de grãos, orientação preferencial e grau de cristalinidade do material. As primeiras considerações sobre o fenômeno de difração de raios X em cristais foram feitas em 1912 pelo físico alemão Max von Laue.

Num cristal, os objetos espalhadores são formados por átomos contidos nos planos virtuais (Fig. 3.12), os quais são denominados planos cristalográficos e indexados 


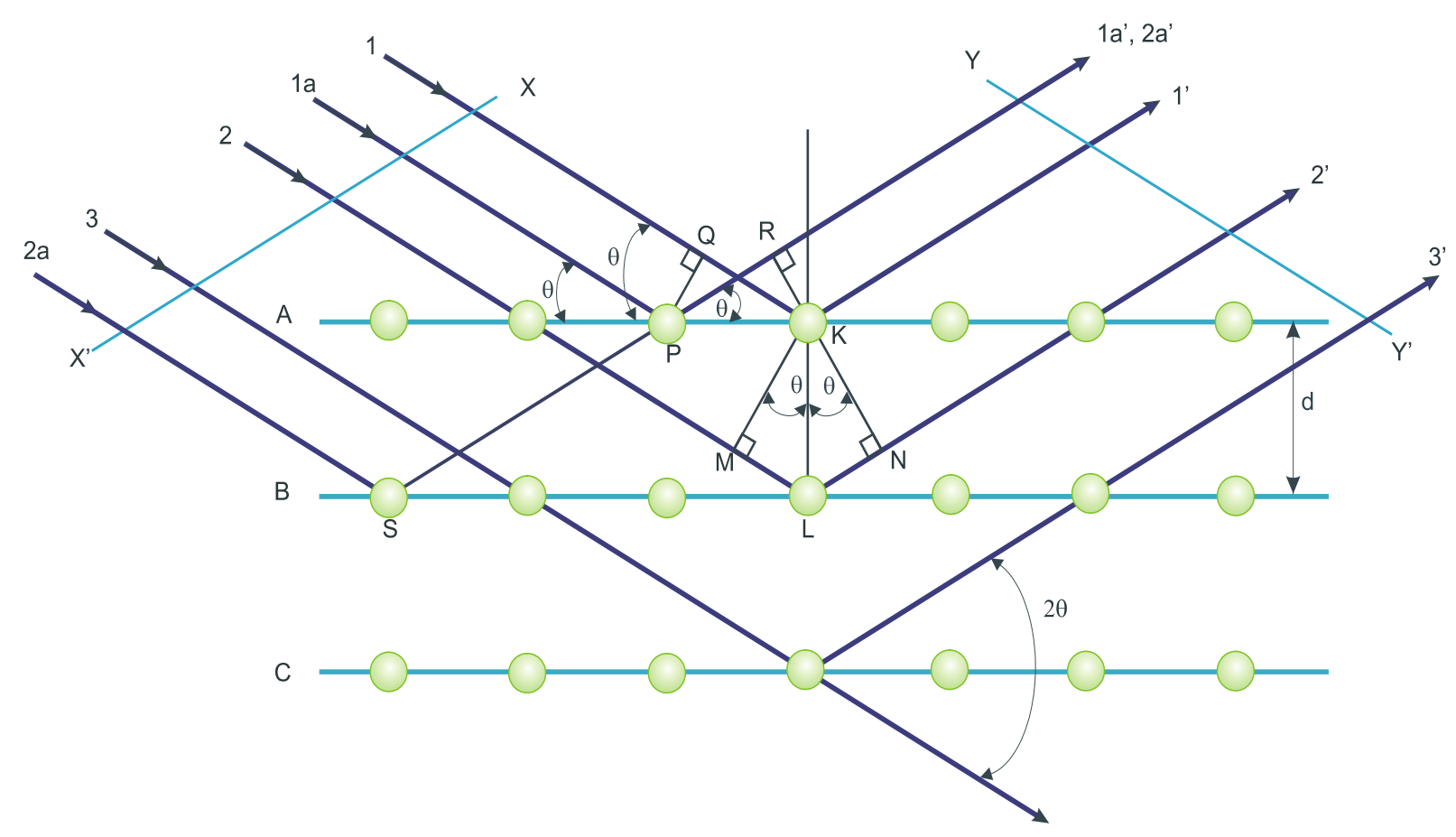

Figura 3.12: Difração de raios $X$ por um cristal.

através dos índices de Miller, $h k l$, separados por uma distância $d_{h k l}$. Por meio de relações geométricas entre o feixe incidente e o feixe difratado pelos planos, W.L. Bragg formulou uma equação através da qual é possível obter o espaçamento entre os planos, sabendo-se o ângulo de incidência e o comprimento de onda do feixe incidente. A lei de Bragg, como é conhecida esta equação, é dada por:

$$
n \lambda=2 d_{h k l} \operatorname{sen} \theta
$$

onde $n$ é a ordem da difração (normalmente considerada $n=1$ ); $\lambda$ é o comprimento de onda do feixe incidente; $d_{h k l}$ é a distância interplanar e $\theta$ é o semi-ângulo de difração medido em relação aos raios $\mathrm{X}$ incidentes.

A Fig. 3.12 ilustra a interação dos raios que incidem nos planos cristalográficos e que são difratados. Uma distinção que deve ser feita com relação à óptica geral é que o ângulo entre o feixe incidente e o difratado é sempre $2 \theta$. A partir da análise do feixe 
difratado, é possível obter informação sobre o arranjo atômico do cristal, ou seja, a simetria e distâncias interatômicas que determinam a chamada célula unitária.

Para estudar a cristalinidade dos filmes, usou-se o difratômetro de raios X, fabricado pela RIGAKU, instalado no Laboratório de Cristalografia do Instituto de Física da USP com o método de $\theta-2 \theta$. Os difratogramas foram obtidos em função do ângulo $2 \theta$ variando de $15^{\circ}$ a $60^{\circ}$ e a variação do ângulo foi de $0,05^{\circ}$ em cada $10 \mathrm{~s}$. 


\section{Capítulo 4}

\section{Resultados e discussão}

Neste capítulo serão apresentados e discutidos os resultados experimentais referentes às características físicas dos filmes de $\mathrm{CN}_{x}$ depositados neste estudo e os filmes de $\mathrm{CN}_{x}$ formados anteriormente com o método RF magnetron sputtering reativo. As técnicas de caracterização mencionadas no capítulo 3 foram usadas para determinar a taxa de deposição, a composição química e a ligação atômica dos filmes.

\subsection{Taxa de deposição}

A taxa de deposição foi definida pela divisão da espessura do filme, determinada usando o perfilômetro, pelo tempo de deposição utilizado. Na Fig. 4.1 observa-se a taxa de deposição em função de R(I/A) para os filmes produzidos sobre os substratos de $\operatorname{Si}(100)$ em $350^{\circ} \mathrm{C}$ com o feixe de íons de nitrogênio de 200, 400 e $600 \mathrm{eV}$. Note-se nessa figura que: (i) os pontos experimentais correspondentes a $\mathrm{R}(\mathrm{I} / \mathrm{A})=0$ são para os filmes de a-C depositados sobre os substratos de $\operatorname{Si}(100)$ com as seguintes condições de deposição: temperatura de substrato de $400^{\circ} \mathrm{C}$ sem irradiação por feixe de íons (círculo cheio); RT 
com irradiação por feixe de íons de 200 (triângulo cheio) e 1000 eV (quadrado cheio); (ii) a espessura do filme depositado com $\mathrm{E}=400 \mathrm{eV}$ e $\mathrm{R}(\mathrm{I} / \mathrm{A})=2,5$ não foi detectada pelo perfilômetro; seu espectro Raman foi observado e o sinal de ERDA, também, foi detectado (porém, foi pequeno de mais para analisá-lo).

A taxa de deposição dos filmes de $a$-C diminui com o aumento de energia de íons de Ar. Para os filmes de $\mathrm{CN}_{x}$, a taxa de deposição diminui linearmente com o aumento de R(I/A) e é difícil observar sua dependência da energia de íons na figura. Estes fatos serão analisados mais adiante.

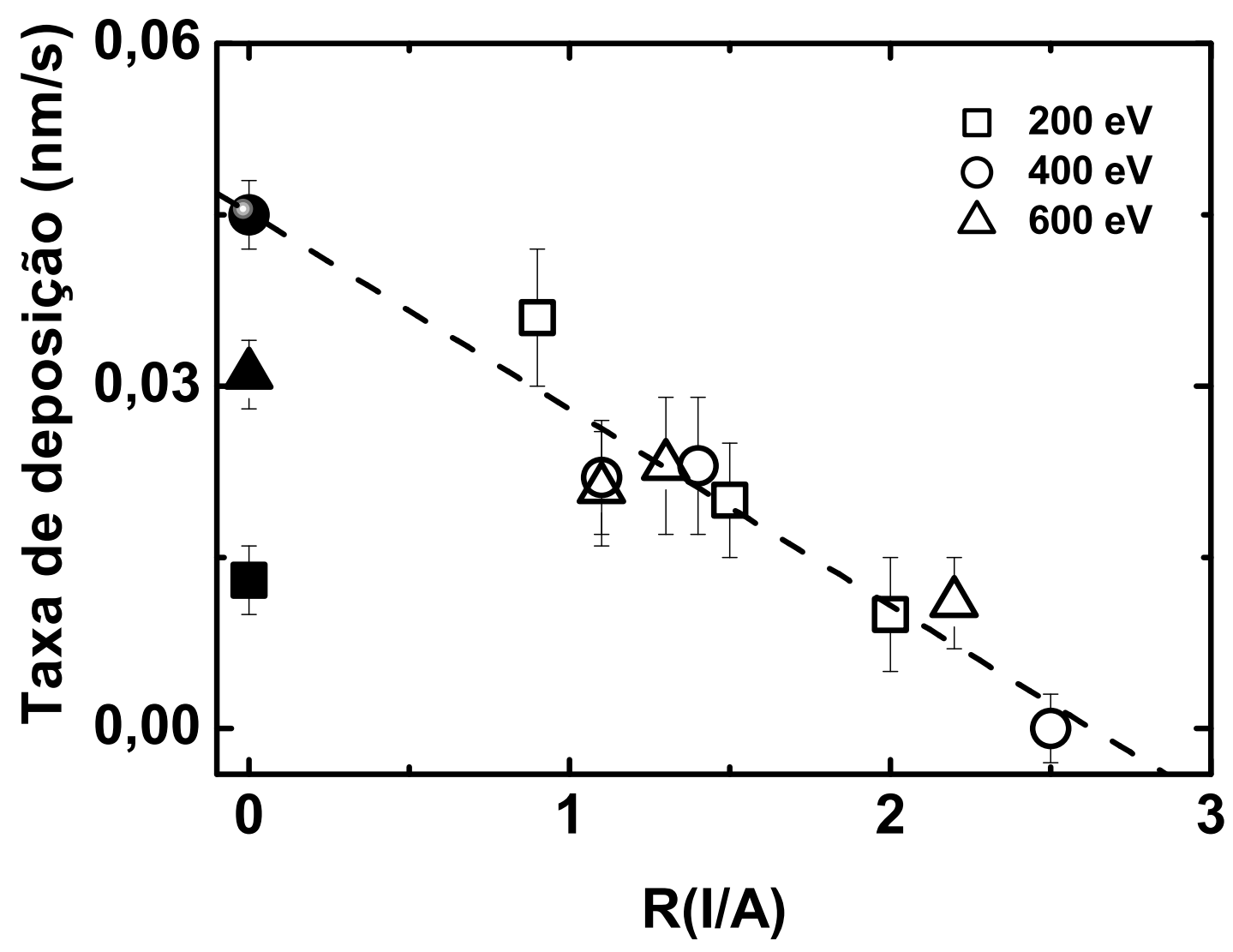

Figura 4.1: Taxa de deposição em função de $R(I / A)$ para os filmes de $C N_{x}$ depositados sobre os substratos de $\mathrm{Si}(100) \mathrm{em} 350^{\circ} \mathrm{C}$ com o feixe de íons de nitrogênio.

As Figs. 4.2(a) e 4.2(b) mostram as taxas de deposição em função de R(I/A) para 

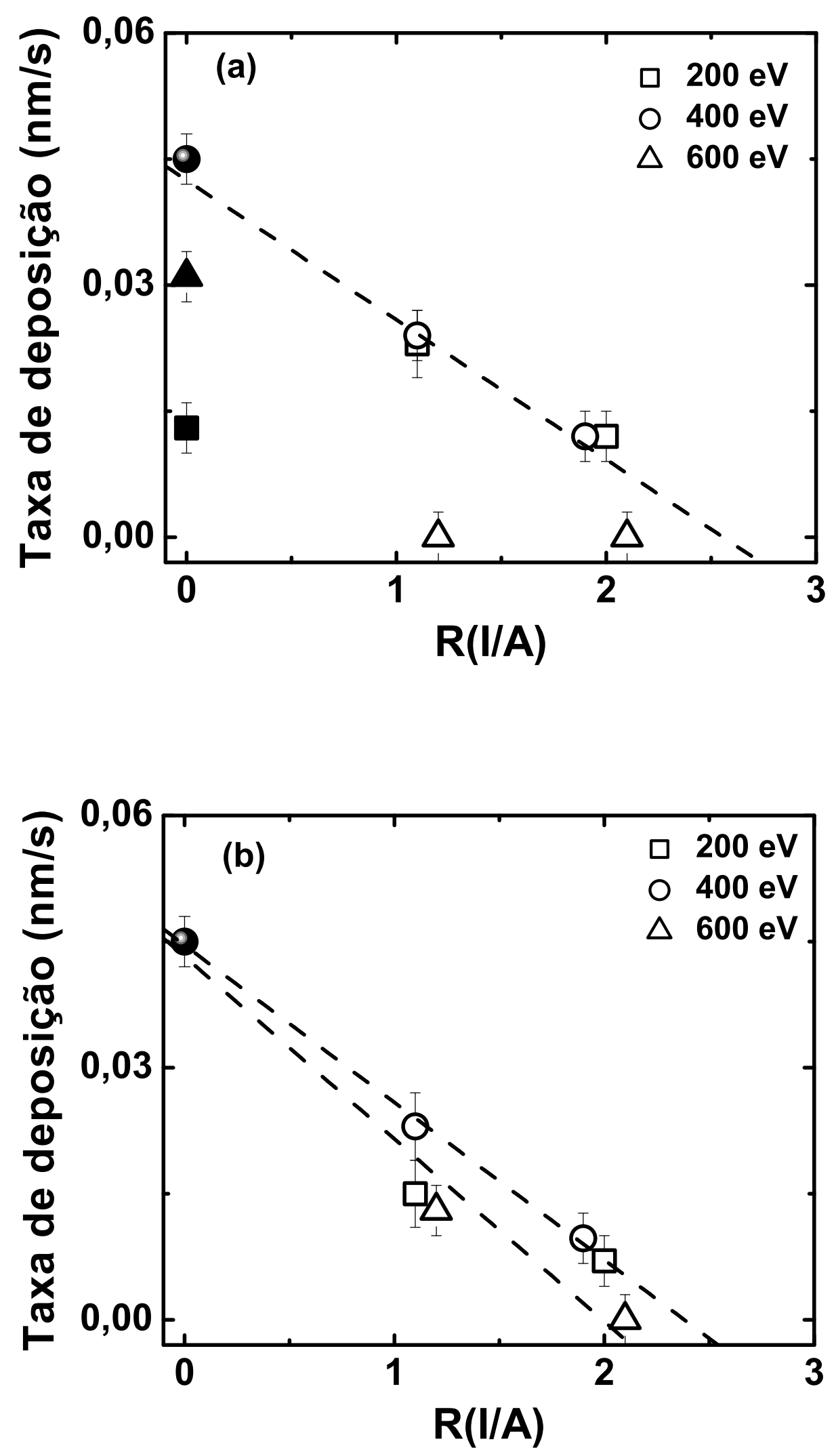

Figura 4.2: Taxa de deposição em função de $R(I / A)$ para os filmes de $C N_{x}$ depositados sobre os substratos de $\operatorname{Si}(100)$ (a) e Si(111) (b) em $500^{\circ} \mathrm{C}$ com o feixe de íons derivado de Ar- $N_{2}$. 
os filmes depositados sobre os respectivos substratos de $\mathrm{Si}(100)$ e de $\operatorname{Si}(111)$ em $500^{\circ} \mathrm{C}$ com o feixe de íons derivado de Ar- $\mathrm{N}_{2}$. Para dois filmes depositados sobre os substratos de $\operatorname{Si}(100)$ com $\mathrm{E}=600 \mathrm{eV}$ e $\mathrm{R}(\mathrm{I} / \mathrm{A})=1,2$ e 2,1, e um sobre o substrato de $\mathrm{Si}(111)$ com $\mathrm{E}=600 \mathrm{eV}$ e $\mathrm{R}(\mathrm{I} / \mathrm{A})=2,1$, não foram detectadas as espessuras dos filmes nas medidas com o perfilômetro, apesar de que seus espectros Raman foram observados. Nas figuras observa-se que a taxa de deposição para os filmes depositados com $\mathrm{E}=600 \mathrm{eV}$ decai mais rapidamente com o aumento de $\mathrm{R}(\mathrm{I} / \mathrm{A})$.

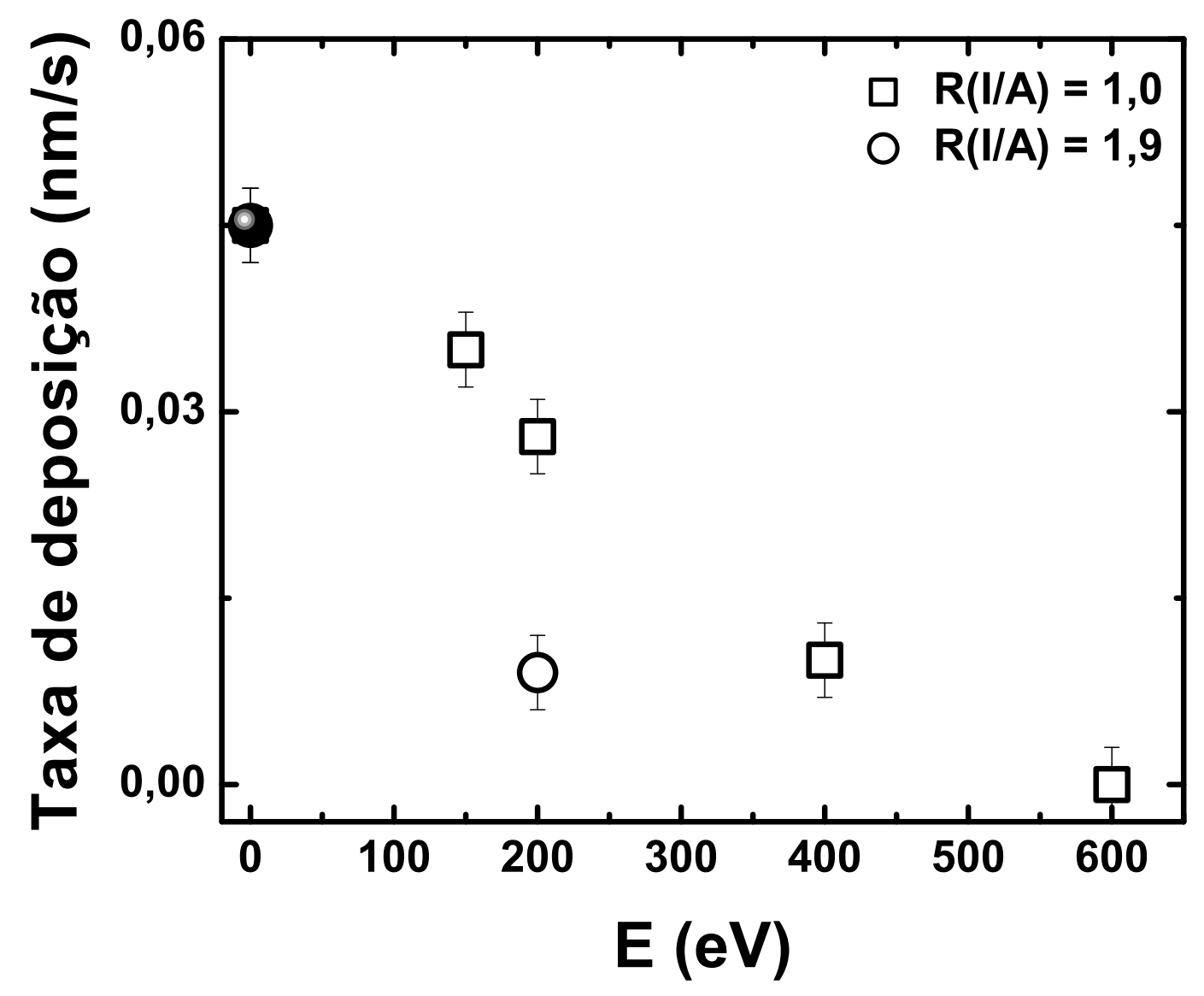

Figura 4.3: Taxa de deposição em função de $E$ para os filmes de $C N_{x}$ depositados sobre os substratos de $\mathrm{Si}(100) \mathrm{em} 400^{\circ} \mathrm{C}$ com o feixe de íons derivado de $\operatorname{Ar}-N_{2}$.

A Fig. 4.3 indica a taxa de deposição em função de $\mathrm{E}$ para os filmes de $\mathrm{CN}_{x}$ 
depositados sobre os substratos de $\operatorname{Si}(100)$ em $400^{\circ} \mathrm{C}$ com o feixe de íons derivado de Ar$\mathrm{N}_{2}$ e $\mathrm{R}(\mathrm{I} / \mathrm{A})=1,0$ e 1,9. Não foi possível detectar a espessura do filme depositado com $\mathrm{E}=600 \mathrm{eV}$ na medida com o perfilômetro, mas foi observado seu espectro Raman. É interessante que em $\mathrm{E}=200 \mathrm{eV}$, a taxa de deposição do filme depositado com R(I/A) $=1,9$ é menor do que o filme depositado com $\mathrm{R}(\mathrm{I} / \mathrm{A})=1,0$. Gago et al. relataram um comportamento similar ao presente resultado para os filmes de $\mathrm{CN}_{x}$ depositados por eles com o método IBAD na região de 0-500 eV, relacionando a diminuição da taxa de deposição à formação de compostos voláties induzidos pela corrente de íons de nitrogênio [58]. Este fato será discutido mais adiante.

O impacto de um íon energético com um sólido produz diversos efeitos e pode modificar as propriedades do sólido. Íons incidentes penetram no sólido e causam a cascata de colisões, desalojando átomos ligados no sólido. Quando o projétil ou o átomo de recuo transfere a energia suficiente para um átomo de superfície ou um grupo desses átomos superar a energia de ligação de superfície, ocorre o sputtering físico. Este processo, induzido por íons, pode ser quantitativamente entendido através de cálculos feitos com o programa computacional de Monte Carlo, chamado SRIM (The Stopping and Range of Ions in Matter) [59]. O SRIM está baseado na aproximação de colisões binárias, e é usado com êxito em cálculos de: em rendimento de sputtering físico, perfil de profundidade de implantação de íons e rendimento de desalojamento de átomos.

Quando, no processo de sputtering, é envolvida uma reação química, ativada por íons, entre o íon e o sólido e/ou entre as espécies adsorvidas no sólido e o sólido, a reação pode render produtos voláteis cujas energias de ligação de superfície são reduzidas, resultando na remoção desses produtos (sputtering químico) da superfície do sólido. Portanto, o rendimento de sputtering químico geralmente é bem maior do que o de sputtering físico. 
Infelizmente, o sputtering químico não está incluso no programa SRIM.

O rendimento de sputtering, $\mathrm{Y}(\mathrm{C} / \mathrm{N})$, é definido pelo número de átomos de carbono removidos por nitrogênio atômico incidente no feixe de íons [60, 61]. Apesar de o número de pontos experimentais nas Figs. 4.1 e 4.2 ser insuficiente para se investigar a dependência energética de $\mathrm{Y}(\mathrm{C} / \mathrm{N})$, foram determinados os valores de $\mathrm{R}(\mathrm{I} / \mathrm{A})$ quando a formação do filme começa cessar, $\mathrm{R}_{c}(\mathrm{I} / \mathrm{A})$, a fim de estimar os valores de $\mathrm{Y}(\mathrm{C} / \mathrm{N})$. Na Fig. 4.1 é difícil observar a dependência energética da taxa de deposição; mas, nas Figs. 4.2(a) e 4.2(b) são observadas ao menos duas dependências energéticas diferentes para os filmes depositados com $\mathrm{E}=200$ e $400 \mathrm{eV}$, e os filmes com E = $600 \mathrm{eV}$. Levando em conta estas dependências, a Tabela 4.1 indica os valores obtidos de $R_{c}(\mathrm{I} / \mathrm{A})$ e $\mathrm{Y}(\mathrm{C} / \mathrm{N})$. Ao estimar cada valor de $\mathrm{Y}(\mathrm{C} / \mathrm{N})$ a partir do valor $\mathrm{R}_{c}(\mathrm{I} / \mathrm{A})$ foi considerada a composição de íons de nitrogênio de $89 \%$ de $\mathrm{N}_{2}^{+}$e $11 \%$ de $\mathrm{N}^{+}[58,62,63]$

Tabela 4.1: Valores obtidos de $R_{c}(I / A)$ e $Y(C / N)$.

\begin{tabular}{lcc}
\hline \hline $\begin{array}{l}\text { Filmes de } \mathrm{CN}_{x} \text { depositados em } \\
\text { substratos/temperatura/íons/energia }\end{array}$ & $\mathrm{R}_{c}(\mathrm{I} / \mathrm{A})$ & $\mathrm{Y}(\mathrm{C} / \mathrm{N})$ \\
\hline $\mathrm{Si}(100) / 350^{\circ} \mathrm{C} /$ nitrogênio/200, 400, $600 \mathrm{eV}$ & 2,63 & 0,20 \\
$\mathrm{Si}(100) / 500^{\circ} \mathrm{C} / \mathrm{Ar}-\mathrm{N}_{2} / 200,400 \mathrm{eV}$ & 2,62 & 0,20 \\
$\mathrm{Si}(100) / 500^{\circ} \mathrm{C} / \mathrm{Ar}-\mathrm{N}_{2} / 600 \mathrm{eV}$ & $<1,20$ & $>0,44$ \\
$\mathrm{Si}(111) / 500^{\circ} \mathrm{C} / \mathrm{Ar}-\mathrm{N}_{2} / 200,400 \mathrm{eV}$ & 2,38 & 0,22 \\
$\mathrm{Si}(111) / 500^{\circ} \mathrm{C} / \mathrm{Ar}-\mathrm{N}_{2} / 600 \mathrm{eV}$ & 1,99 & 0,27 \\
\hline \hline
\end{tabular}

Hammer et al. produziram filmes de $\mathrm{CN}_{x}$ em $100-400^{\circ} \mathrm{C}$ usando o método de deposição de duplo feixe de íons na faixa de energia de 100-800 eV e observaram com um analisador quadrupolo de gases a produção de alguns compostos voláteis, tais como cianogênio $\left(\mathrm{C}_{2} \mathrm{~N}_{2}\right)$, e radicais $\mathrm{CN}^{+}, \mathrm{HCN}^{+}[61]$. E eles estimaram o rendimento de sputtering 
$\mathrm{Y}(\mathrm{C} / \mathrm{N})$ igual a $0,25 \pm 0,05$, assumindo que o sputtering físico nessa faixa de energia é desprezível em relação ao sputtering químico. Os valores de $\mathrm{Y}(\mathrm{C} / \mathrm{N})$ obtidos e mostrados na Tabela 4.1 estão de acordo com esse valor, exceto para o filme depositado com o feixe de íons derivado de $\mathrm{Ar}-\mathrm{N}_{2}$ de $\mathrm{E}=600 \mathrm{eV}$ sobre o substrato de $\mathrm{Si}(100)$.

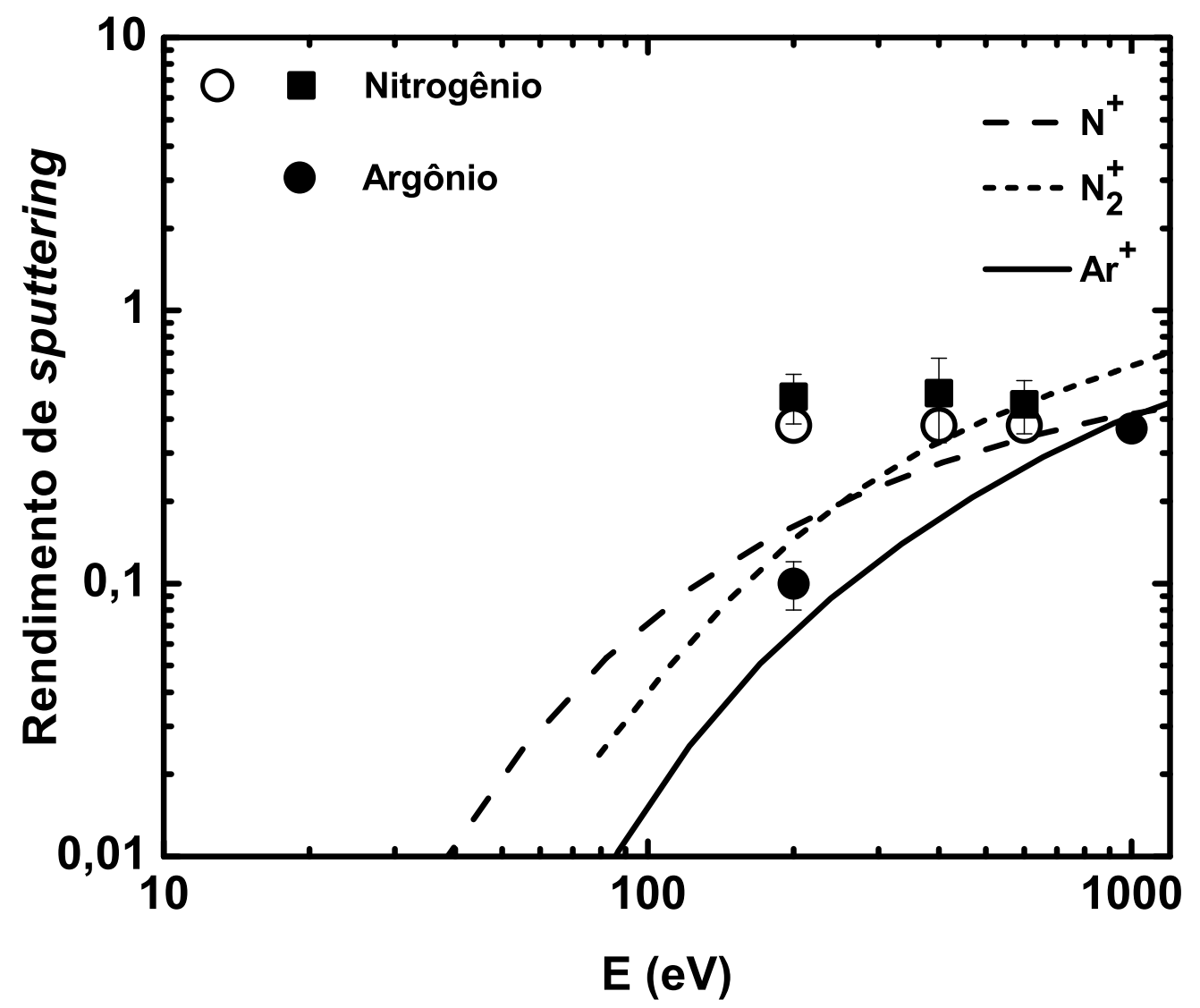

Figura 4.4: $O$ rendimento de sputtering de átomos de $C$ por íon em função de $E$.

A Fig. 4.4 mostra o rendimento de sputtering, definido como o número de átomos de $\mathrm{C}$ removidos por cada íon incidente, em função da energia de íons. Os rendimentos de sputtering físico da grafite por íons de $\mathrm{N}^{+}, \mathrm{N}_{2}^{+}$e $\mathrm{Ar}^{+}$, simulados neste trabalho usando o programa SRIM, são dependentes da energia de íons e estão mostrados na figura com as linhas traçada, pontilhada e cheia, respectivamente. Como o SRIM não trata de íons 
moleculares, um íon de $\mathrm{N}_{2}^{+}$foi considerado como dois íons de $\mathrm{N}^{+}$com a metade da energia, e o valor da energia de ligação de superfície foi usado de 2,8 eV para a grafite [64].

Calculou-se tentativamente o valor do rendimento de sputtering, usando a diferença entre a espessura de um filme indicada, após da deposição, pelo monitor de deposição (corresponde à espessura do filme sem irradiação por feixe de íons) e a espessura do mesmo filme medida pelo perfilômetro, e a fluência de íons durante a deposição do filme. Na Fig. 4.4 os círculos cheios e quadrados cheios representam o rendimento de sputtering assim calculado para os filmes de $a$-C depositados com o feixe de íons de $\mathrm{Ar}$ e os filmes de $\mathrm{CN}_{x}$ formados com o feixe de íons de nitrogênio; os círculos vazios representam o rendimento de sputtering estimado pelo inverso do valor de $\mathrm{R}_{c}(\mathrm{I} / \mathrm{A})=2,63$, indicado na tabela 4.1, para os filmes de $\mathrm{CN}_{x}$ preparados com o feixe de íons de nitrogênio.

Na Fig. 4.4 observa-se uma coincidência razoalvel entre o rendimento de sputtering simulado com o SRIM (linha cheia) e o acima calculado (círculos cheios) [65]. Essa figura mostra que: o rendimento de sputtering calculado para os filmes de $\mathrm{CN}_{x}$ (quadrados cheios e círculos vazios) é praticamente independente da energia de íons, e maior do que o rendimento de sputtering físico simulado com o SRIM (linha traçada ou linha pontilhada). Esta independência energética concorda com o resultado experimental obtido por Jacob et al. [64] de que o rendimento de sputtering químico de carbono por íons de $\mathrm{N}_{2}^{+}$é praticamente constante e igual a um na região de 50-900 eV.

Por outro lado, para os filmes depositados com o feixe de íons derivado de $\mathrm{Ar}-\mathrm{N}_{2}$, a Fig. 4.3 indica que, quanto maior R(I/A) ou maior a energia de íons, menor é a taxa de deposição, isto é, maior é o rendimento de sputtering. O sputtering por íons de Ar é drasticamente aumentado se estiver presente um fluxo de íons de nitrogênio reativo e o rendimento de sputtering neste caso é muito mais alto do que a soma dos rendimentos 
de sputtering pelos feixes de íons individuais (ver a Fig. 4.3). Hopf et al. observaram esse aumento no rendimento de sputtering para filmes de $a$-C:H sob a presença de dois fluxos de átomos de $\mathrm{H}$ e de íons de Ar [65]; o rendimento de sputtering varia de 0,6 a 3,4 quando a energia de íons de Ar muda de 20 a 800 eV. Eles atribuíram esse aumento ao sputtering químico ao fato de que íons de Ar incidentes rompem ligações do filme nas cascatas de colisões e as rupturas de ligações resultantes são instantaneamente passivadas por átomos de H (nitrogênio, neste trabalho) conduzindo a produção de compostos voláteis que difundem à superfície do filme e dessorvem. 


\subsection{A razão da composição química}

A razão da composição química $\mathrm{C}(\mathrm{N} / \mathrm{C})$ em cada filme depositado sobre o substrato de $\operatorname{Si}(100)$ em $350^{\circ} \mathrm{C}$ com o feixe de íons de nitrogênio é mostrada na Fig. 4.5 em função de $\mathrm{R}(\mathrm{I} / \mathrm{A})$. Da figura, a $\mathrm{C}(\mathrm{N} / \mathrm{C})$ aumenta com o aumento de $\mathrm{R}(\mathrm{I} / \mathrm{A})$ para os três valores de energia, exeto dois filmes formados com $\mathrm{E}=200 \mathrm{eV}$ e $\mathrm{R}(\mathrm{I} / \mathrm{A})=0,9$ e 1,5 . O valor mais alto da $\mathrm{C}(\mathrm{N} / \mathrm{C})$ igual a 0,9 (47\% atômica de $\mathrm{N})$ foi observado para o filme depositado com $\mathrm{R}(\mathrm{I} / \mathrm{A})=1,4$ e $\mathrm{E}=400 \mathrm{eV}$. Observe na figura que o filme depositado a um determinado valor de $\mathrm{R}(\mathrm{I} / \mathrm{A})$ com $\mathrm{E}=400 \mathrm{eV}$ sempre mostra o valor maior de $\mathrm{C}(\mathrm{N} / \mathrm{C})$ de todos os filmes.

Hammer et al. mostraram, sem nenhum comentário, um gráfico de que a concentração de $\mathrm{N}$ no filme depositado em $100^{\circ} \mathrm{C} \operatorname{com} \mathrm{E}=300 \mathrm{eV}$ foi duas vezes maior que aquela no filme depositado na mesma temperatura com $\mathrm{E}=800 \mathrm{eV}$ para um mesmo valor de $\mathrm{R}(\mathrm{I} / \mathrm{A})$ [60]. Gago et al., também, observaram um aumento linear de $\mathrm{C}(\mathrm{N} / \mathrm{C})$ com o aumento de E na região de $0-450 \mathrm{eV}[58]$.

Suspeita-se que as reações químicas entre as espécies adsorvidas na superfície do filme que podem conduzir à formação de compostos voláties devem ser dependente de $\mathrm{E}$ $[38,58]$. Note-se na Fig. 4.5 que os filmes depositados com $\mathrm{E}=200,400$ e 600 eV mostraram as faixas de concentração de $\mathrm{N}$ de $28-40,37-47$, e 17-37\% atômica [38], respectivamente, significando que todos os filmes são deficientes de $\mathrm{N}$ em comparação à estequiometria de $\beta-\mathrm{C}_{3} \mathrm{~N}_{4}(57 \%$ atômica de $\mathrm{N})$. É conhecido que a concentração de $\mathrm{N}$ nos filmes de $\mathrm{CN}_{x}$ produzidos até hoje não excede um valor de $45 \%$ atômica de $\mathrm{N}$ [24, 38]. A limitação do conteúdo de $\mathrm{N}$ é freqüentemente atribuída à dessorção química das espécies voláties de $\mathrm{C}_{2} \mathrm{~N}_{2}, \mathrm{CN}^{+}$e $\mathrm{HCN}^{+}$da superfície do filme [23]. Gago et al. relacionaram essa limitação na 
$\mathrm{C}(\mathrm{N} / \mathrm{C})$ em torno de 0,3 (23\% atômica de $\mathrm{N}$ ) à produção de compostos voláties induzidos com o aumento da corrente de íons de nitrogênio [58].

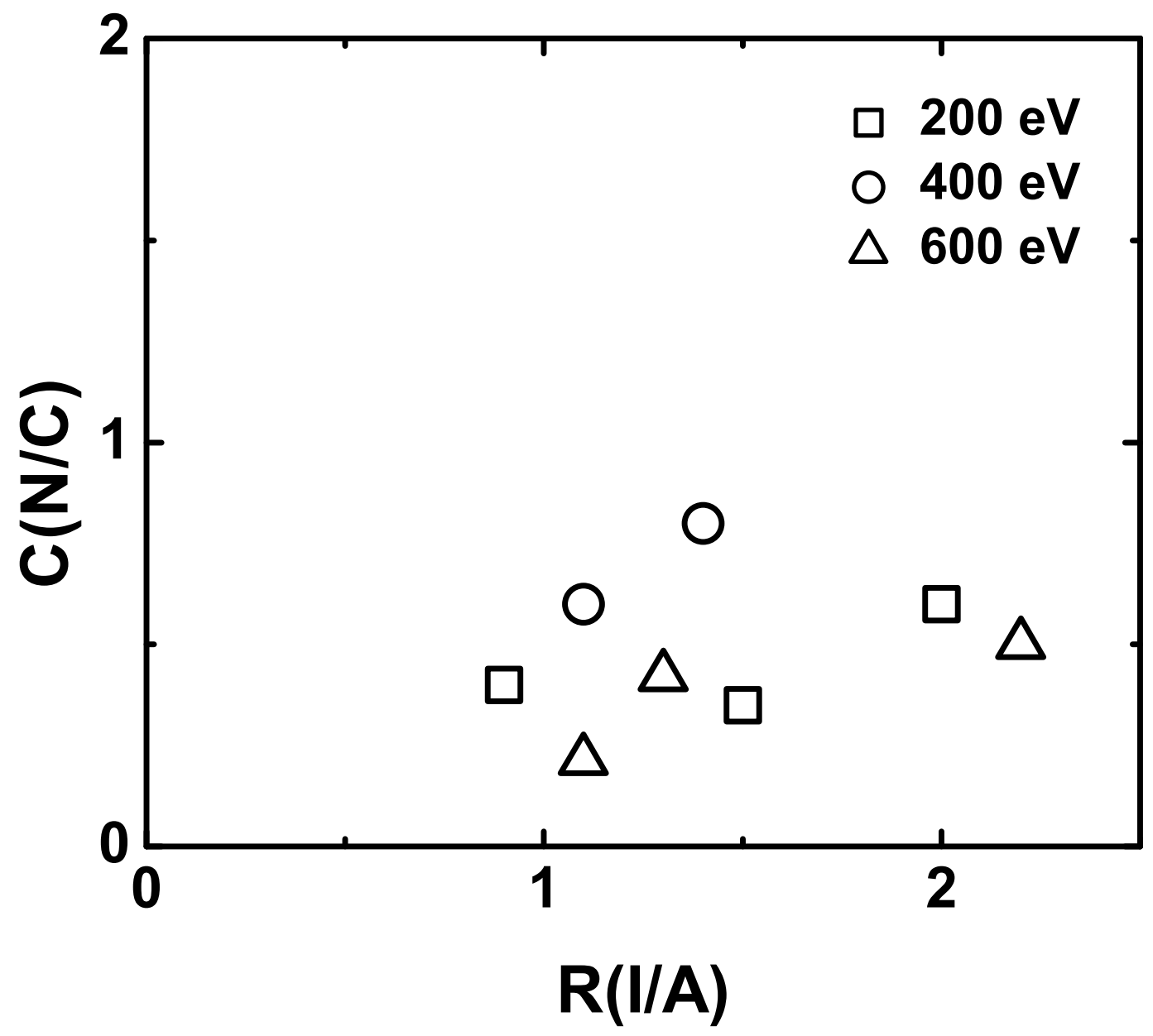

Figura 4.5: A razão da composição química $C(N / C)$ em função de $R(I / A)$ para os filmes de $C N_{x}$ depositados sobre os substratos de $\mathrm{Si}(100) \mathrm{em} 350^{\circ} \mathrm{C}$ com o feixe de íons de nitrogênio. 


\subsection{Espectros de absorção do IR dos filmes de $\mathrm{CN}_{x}$}

\subsubsection{Filmes depositados com o feixe de íons de nitrogênio}

A Fig. 4.6 mostra os espectros do IR para os filmes de $a$-C depositados sobre os substratos de $\operatorname{Si}(100)$ com as seguintes condições de deposição: temperatura de substrato de $400^{\circ} \mathrm{C}$ sem irradiação por feixe de íons (a); RT com irradiação por feixe de íons de Ar de 200 (c) e $1000 \mathrm{eV}$ (c). Neles observam-se uma banda larga em 900-1700 $\mathrm{cm}^{-1}$ com um pico em $1590 \mathrm{~cm}^{-1}$, cujas origens ainda não são conhecidas; uma banda em $2800-3000 \mathrm{~cm}^{-1}$, devida aos modos vibracionais stretching de $\mathrm{CH}_{n}[43,54,66]$; uma banda em 3200-3500 $\mathrm{cm}^{-1}$, associada aos modos stretching de $\mathrm{OH}[13,66,67]$; dois picos em 660 e $1100 \mathrm{~cm}^{-1}$ do substrato de $\mathrm{Si}$, relacionados, respectivamente, com $\mathrm{Si}-\mathrm{Si}$ e $\mathrm{SiO}_{2}$ na superfície do substrato [43]; um pico duplo em aproximadamente $2360 \mathrm{~cm}^{-1}$, atribuído ao gás $\mathrm{CO}_{2}$ do ambiente no compartimento de amostra do espectrômetro [55]. A presença da banda de $\mathrm{CH}_{n}$ e da banda de $\mathrm{OH}$ indica a contaminação do filme por $\mathrm{H}$ e $\mathrm{O}$; a origem dos contaminadores deve ser de gases residuais na câmara de vácuo durante a deposição e/ou da umidade atmosférica adquirida após a deposição.

Com respeito ao sinal na região de $900-1700 \mathrm{~cm}^{-1}$ nos espectros do IR, é conhecido que os materiais carbonados amorfos não apresentam nenhuma sinal [32, 60]. No entanto, Ferrari et al. observaram os espectros do IR para três filmes de $a$-C com diferentes concentrações dos sítios de $s p^{2}$ de 20,50 e $80 \%$, e descobriram que somente o filme com $20 \%$ dos sítios de $s p^{2}$ não apresenta sinal na região de $600-1800 \mathrm{~cm}^{-1}$ [13]. E concluíram que o surgimento do sinal em questão para os filmes de $a$-C está associado com deslocamento de elétrons nas ligações $\pi$ conjugadas $(\cdots \mathrm{C}=\mathrm{C}-\mathrm{C}=\mathrm{C}-\mathrm{C} \cdots)$ em anéis aromáticos e cadeias [68] que induz a atividade do IR. Portanto, os filmes de $a$-C obtidos no presente trabalho devem 


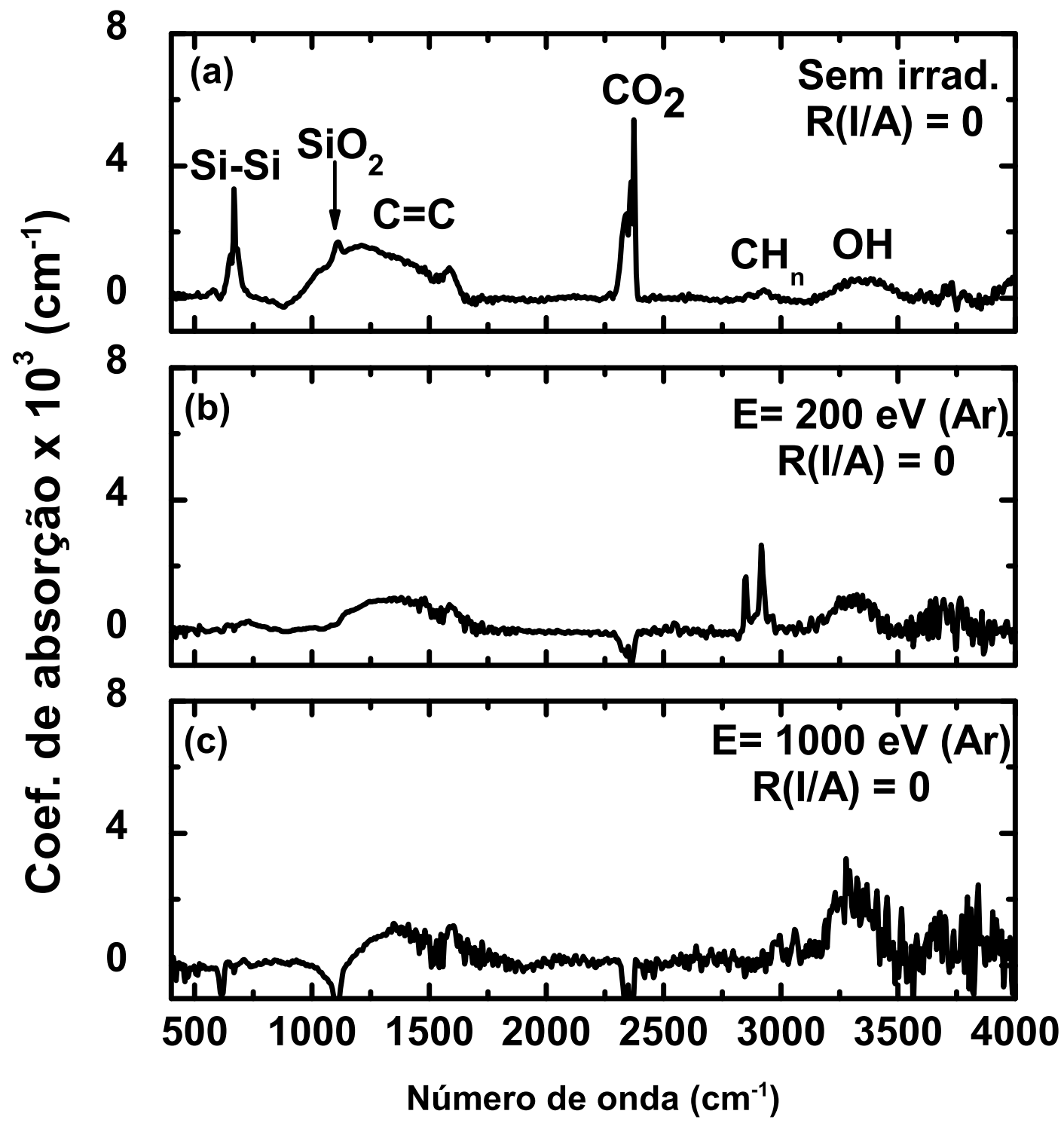

Figura 4.6: Espectros do IR dos filmes de a-C depositados sobre os substratos de Si(100): (a) em $400^{\circ} \mathrm{C}$ sem nenhuma irradiação; (b) e (c), RT com irradiação por feixe de íons de Ar de 200 e 1000 eV, respectivamente. 
ter a concentração dos sítios de $s p^{2}$ acima de $20 \%$. Este ponto será mais aprofundado na seção 4.4.1.

Por outro lado, Kaufman et al. [47] e Nakayama et al. [69] afirmaram que os modos vibracionais normalmente inativos no filme $a-\mathrm{C}$ tornam-se ativos, quando átomos de N são adicionados nesse filme, destorcendo a simetria molecular dos anéis aromáticos. As Figs. 4.7-4.9 mostram os espectros do IR para os filmes de $\mathrm{CN}_{x}$ depositados sobre os substratos de $\mathrm{Si}(100)$ em $350^{\circ} \mathrm{C}$ com o feixe de íons de nitrogênio e os respectivos valores de $\mathrm{E}$ de 200, 400 e 600 eV. Os valores de R(I/A) utilizados são indicados nas figuras. Os espectros são parecidos com aquele para o filme de $a-\mathrm{C}$ (Fig. 4.6), pois, as freqüências vibracionais de $\mathrm{C}=\mathrm{N}$ são bastante próximas às freqüências dos modos vibracionais de $\mathrm{C}=\mathrm{C}$ (1500-1600 $\mathrm{cm}^{-1}$ para cadeias, e $1300-1600 \mathrm{~cm}^{-1}$ para os anéis aromáticos) [13, 43]. Nas figuras são observados: a banda larga em 900-1700 $\mathrm{cm}^{-1}$ com um pico agudo e isolado em $1590 \mathrm{~cm}^{-1}$; uma banda em $2180 \mathrm{~cm}^{-1}$; um conjunto de picos de $\mathrm{CH}_{n}$ em $2800-3000 \mathrm{~cm}^{-1}$ $[43,54,66]$; e a banda de $\mathrm{OH}$ e de $\mathrm{N}-\mathrm{H}$ em $3400 \mathrm{~cm}^{-1}[13,66,67]$.

A banda em $2180 \mathrm{~cm}^{-1}$ refere-se aos modos vibracionais de $\mathrm{C} \equiv \mathrm{N}$. Os dois picos principais em 2850 e $2920 \mathrm{~cm}^{-1}$ no conjunto de picos são atribuídos, respectivamente, às vibrações de $\mathrm{C}\left(s p^{3}\right)-\mathrm{H}_{2}$ (assimétricas), e às vibrações de $\mathrm{C}\left(s p^{3}\right)-\mathrm{H}$ e de $\mathrm{C}\left(s p^{3}\right)-\mathrm{H}_{2}$ (simétricas). Um pico pequeno em $2950 \mathrm{~cm}^{-1}$, sobreposto ao pico em $2920 \mathrm{~cm}^{-1}$, é atribuído às vibrações de olefina $\mathrm{C}\left(s p^{2}\right)-\mathrm{H}_{2}$ [54]. A presença da banda de $\mathrm{CH}_{n}$ e da banda de $\mathrm{OH}$ e de NH nos espectros confirma a contaminação por $\mathrm{H}$ e $\mathrm{O}$ nos filmes produzidos. Estes elementos não foram detectados através das medidas de ERDA.

A identificão da banda larga e a do pico agudo em $1590 \mathrm{~cm}^{-1}$ são ainda muito controversos. Cuomo et al. propuseram que os filmes de $\mathrm{CN}_{x}$ produzido por eles com o método de sputtering reativo fossem do tipo paracianogênio (composto de ligações triplas 
e duplas entre C e N) [70, 71]. Outros autores, observando duas sub-bandas que compõem a banda larga em 900-1700 $\mathrm{cm}^{-1}$, atribuíram a sub-banda em energias mais altas à aglomeração maior de anéis aromáticos de $\mathrm{C}\left(s p^{2}\right)$ [47, 72], ou aos modos stretching de anéis aromáticos de piridina [73, 74], e outra sub-banda em energias mais baixas, à aglomeração menor de anéis aromáticos de $\mathrm{C}\left(s p^{2}\right)[47,72]$ ou ao modo stretching de $\mathrm{C}\left(s p^{2}\right)-\mathrm{N}$ em anilina $\left(\mathrm{C}_{6} \mathrm{H}_{7} \mathrm{~N}\right)$ [74]. O pico agudo em 1580-1600 $\mathrm{cm}^{-1}$ é observado exclusivamente em filmes de $\mathrm{C}$ hidrogenados, Ferrari et al. [13] e Pereira et al. [75] relacionaram este pico com os modos bending de $=\mathrm{N}-\mathrm{H}$ e $-\mathrm{NH}_{2}$ e outros autores atribuíram-no a ligações de $\mathrm{C}=\mathrm{C}$ em anéis aromáticos [76] ou a ligações de $\mathrm{C}=\mathrm{N}$ em aneís aromaticos e em cadeias [43].

Para identificar os sinais nos espectros do IR para os filmes de $\mathrm{CN}_{x}$, foram feitos por alguns autores estudos sobre a substituição isotópica de $\mathrm{H}$ por D e de ${ }^{14} \mathrm{~N}$ por ${ }^{15} \mathrm{~N}$. Entretanto, não foi detectado um deslocamento significativo no pico agudo nem na banda larga em 900-1700 cm ${ }^{-1}$, devido à substituição de H por D nas ligações de CH e NH. Nos estudos da substituição de ${ }^{14} \mathrm{~N}$ por ${ }^{15} \mathrm{~N}$, apesar de a diferença nas duas massas isotópicas ser pequena, foi confirmado que a banda em $2180 \mathrm{~cm}^{-1}$ refere-se às ligações de $\mathrm{C} \equiv \mathrm{N}$; porém, foi encontrado pouco deslocamento no sinal na região de $900-1700 \mathrm{~cm}^{-1}$. Esse fato indica que, mesmo que as ligações entre $\mathrm{C}$ e $\mathrm{N}$ criem dipolos elétricos, estas ligações não contribuem diretamente ao sinal na região de $900-1700 \mathrm{~cm}^{-1}$ dos espectros do IR para os filmes de $\mathrm{CN}_{x}$, mas ativam pela presença de $\mathrm{N}$ os modos vibracionais que estavam inativos. Observe-se nas Fig. 4.7-4.9 que a intensidade do pico em $1590 \mathrm{~cm}^{-1}$ cresce com o aumento de R(I/A), isto é, com o aumento do conteúdo de $\mathrm{N}$ no filme. 


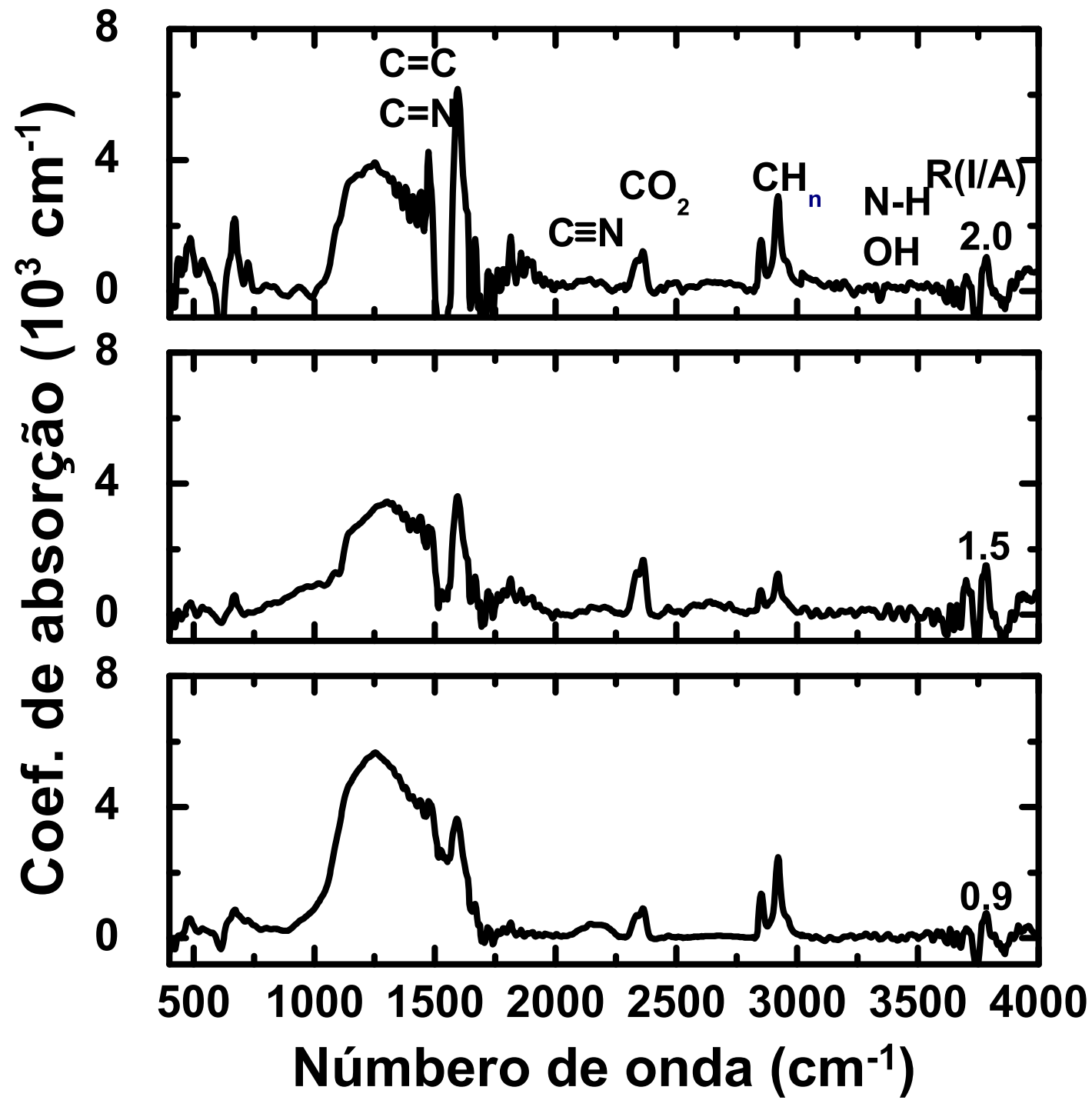

Figura 4.7: Espectros do IR para os filmes de $\mathrm{CN}_{x}$ depositados sobre os substratos de $\mathrm{Si}(100) \mathrm{em} 350^{\circ} \mathrm{C}$ com o feixe de íons de nitrogênio de $E=200 \mathrm{eV}$. 


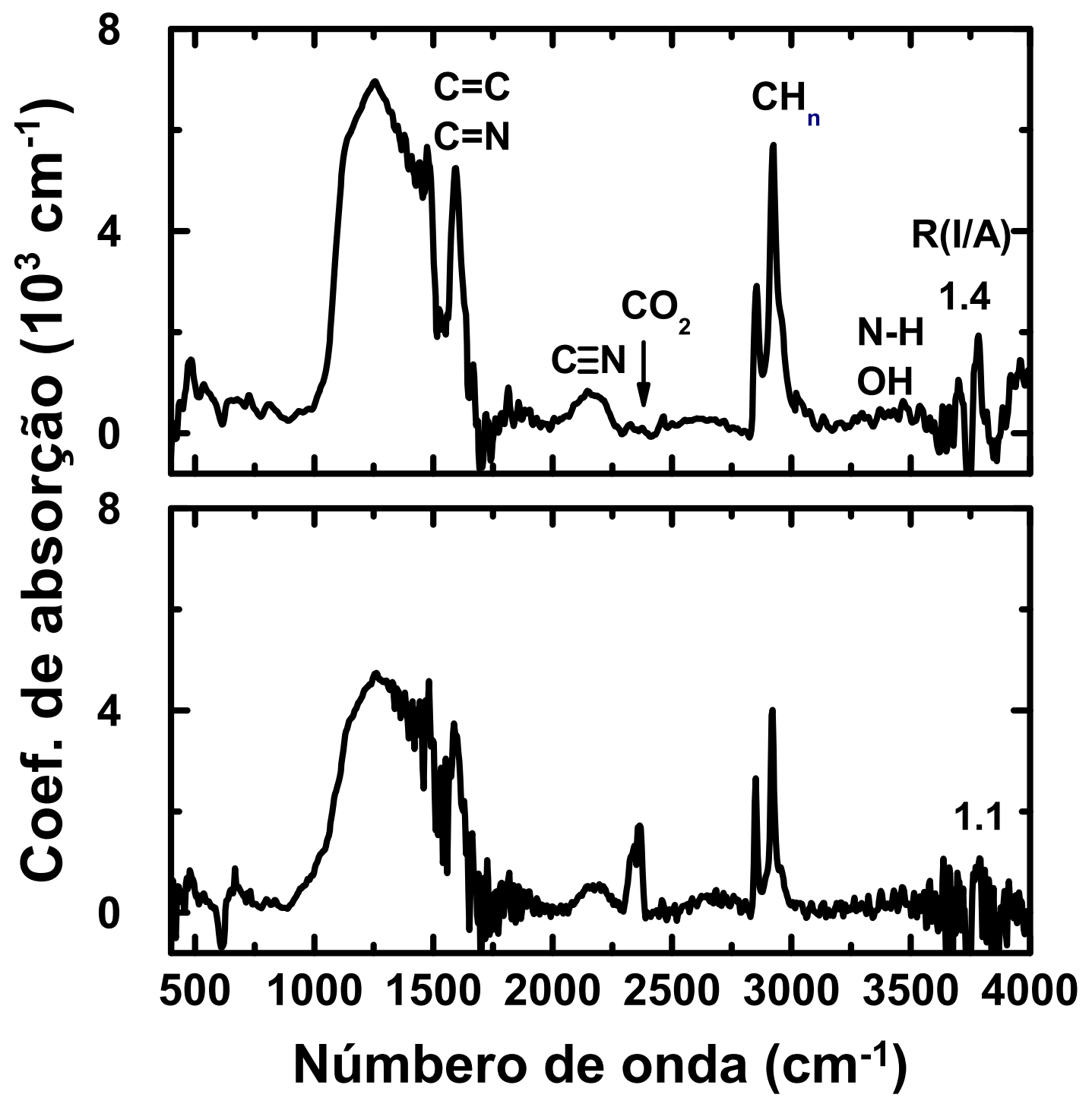

Figura 4.8: Espectros do IR para os filmes de $\mathrm{CN}_{x}$ depositados sobre os substratos de $\mathrm{Si}(100) \mathrm{em} 350^{\circ} \mathrm{C}$ com o feixe de íns de nitrogênio de $E=400 \mathrm{eV}$. 


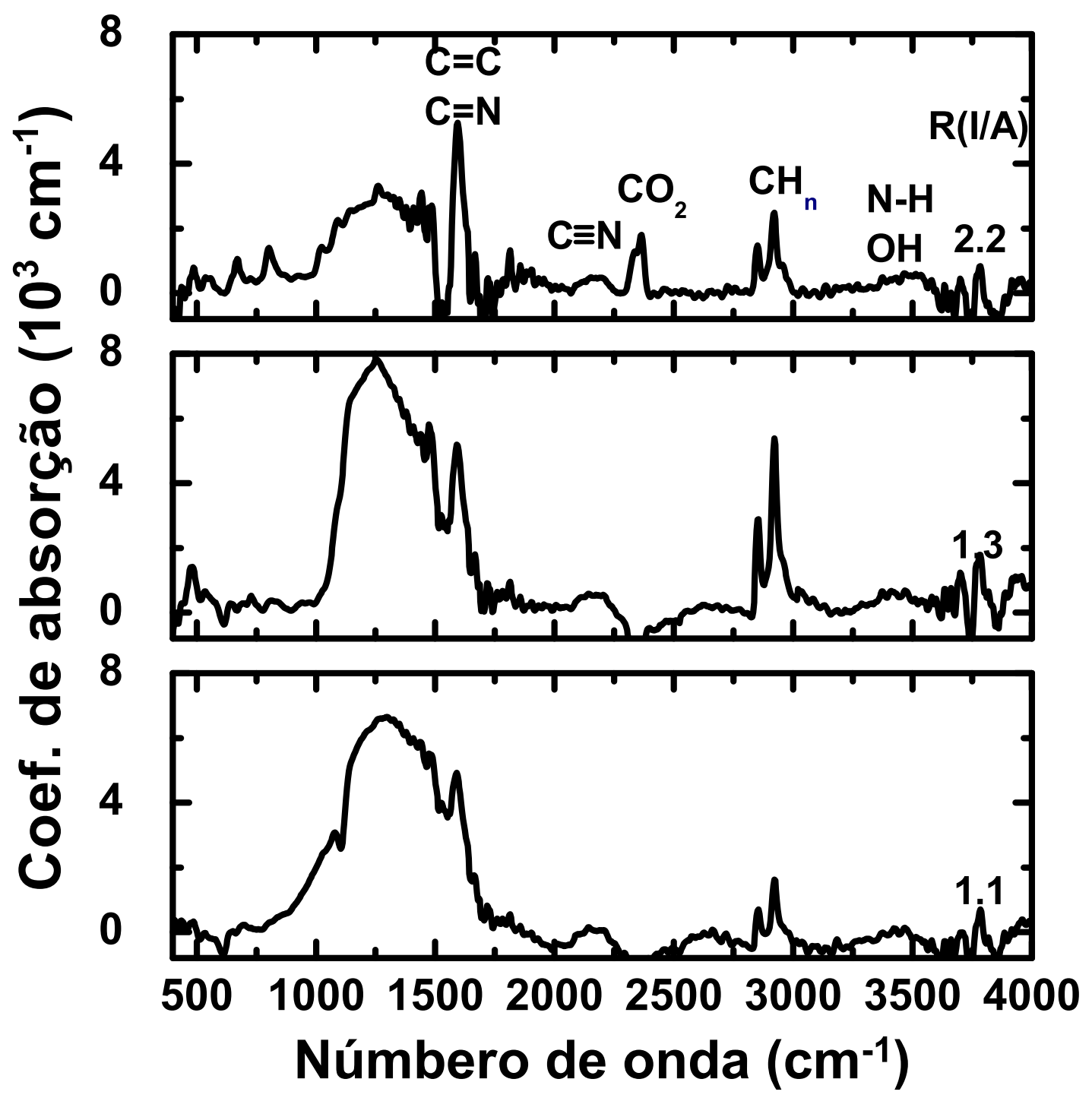

Figura 4.9: Espectros do IR para os filmes de $\mathrm{CN}_{x}$ depositados sobre os substratos de $\mathrm{Si}(100) \mathrm{em} 350^{\circ} \mathrm{C}$ com o feixe de íons de nitrogênio de $E=600 \mathrm{eV}$. 


\subsubsection{Filmes depositados com o feixe de íons derivado de $\mathrm{Ar}-\mathrm{N}_{2}$}

Nas Figs. 4.10 e 4.11 mostram os espectros do IR para os filmes de $\mathrm{CN}_{x}$ depositados sobre os substratos de $\mathrm{Si}(100) \mathrm{em} 500^{\circ} \mathrm{C}$ com $\mathrm{E}=200 \mathrm{e} 400 \mathrm{eV}$, respectivamente. As Figs. $4.12 \mathrm{e} 4.13$ indicam os espectros do IR para os filmes de $\mathrm{CN}_{x}$ depositados sobre os substratos de $\operatorname{Si}(111)$ em $500^{\circ} \mathrm{C}$ com os respectivos valores de $\mathrm{E}=200 \mathrm{e} 400 \mathrm{eV}$. Os valores de $\mathrm{R}(\mathrm{I} / \mathrm{A})$ utilizados são apresentados nas figuras.

As diferenças entre os espectros do IR para os filmes de $\mathrm{CN}_{x}$ depositados com o feixe de íons de nitrogênio e para os filmes de $\mathrm{CN}_{x}$ formados com o feixe de íons derivado de Ar- $\mathrm{N}_{2}$ são as seguintes: (i) a banda de $\mathrm{OH}$ em $3400 \mathrm{~cm}^{-1}$ e o conjunto de picos relacionados com $\mathrm{CH}_{n}$ em 2800-3000 cm ${ }^{-1}$ aparecem com intensidade bem reduzida ou até praticamente nula para os filmes formados com o feixe de íons derivado de $\mathrm{Ar}-\mathrm{N}_{2}$; (ii) o pico agudo em $1590 \mathrm{~cm}^{-1}$ está isolado da banda larga de $900-1700 \mathrm{~cm}^{-1}$ para os filmes de $\mathrm{CN}_{x}$ depositados com o feixe de íons de nitrogênio, enquanto que, para os filmes de $\mathrm{CN}_{x}$ formados com o feixe derivado de Ar- $\mathrm{N}_{2}$, este pico está sobreposto à banda larga com o surgimento de um pico em $1535 \mathrm{~cm}^{-1}$ que é visto claramente na Fig. 4.13 e atribuído por Muhl et al. à estrutura de paracianogênio [24]; (iii) a banda de $\mathrm{C} \equiv \mathrm{N}$ em $2180 \mathrm{~cm}^{-1}$ cresce significativamente com o aumento de $\mathrm{R}(\mathrm{I} / \mathrm{A})$, exceto o filme depositado sobre o $\mathrm{Si}(100)$ com $\mathrm{E}=200 \mathrm{eV}$. O crescimento da banda de $\mathrm{C} \equiv \mathrm{N}$ com o aumento de conteúdo de $\mathrm{N}$ está de acordo com a afirmação por Muhl et al..

A redução nas intensidades da banda e do pico associado com $\mathrm{H}$, mencionada acima no item (i), pode ser explicada por depleção de H induzida por íons incidentes de Ar [65], favorecendo a formação da ligação de $\mathrm{C} \equiv \mathrm{N}$. Com respeito ao item (ii), a redução na

intensidade do pico em $1590 \mathrm{~cm}^{-1}$ está de acordo com a afirmação de que o pico é observado 
exclusivamente em filmes de $\mathrm{C}$ hidrogenados [13, 43], entretanto, é difícil explicar as origens dos picos em 1535 e $1590 \mathrm{~cm}^{-1}$ e da banda larga em 900-1700 $\mathrm{cm}^{-1}$, usando os resultados disponíveis na literatura e dados obtidos neste trabalho, necessitando de mais investigação para esclarecê-las.

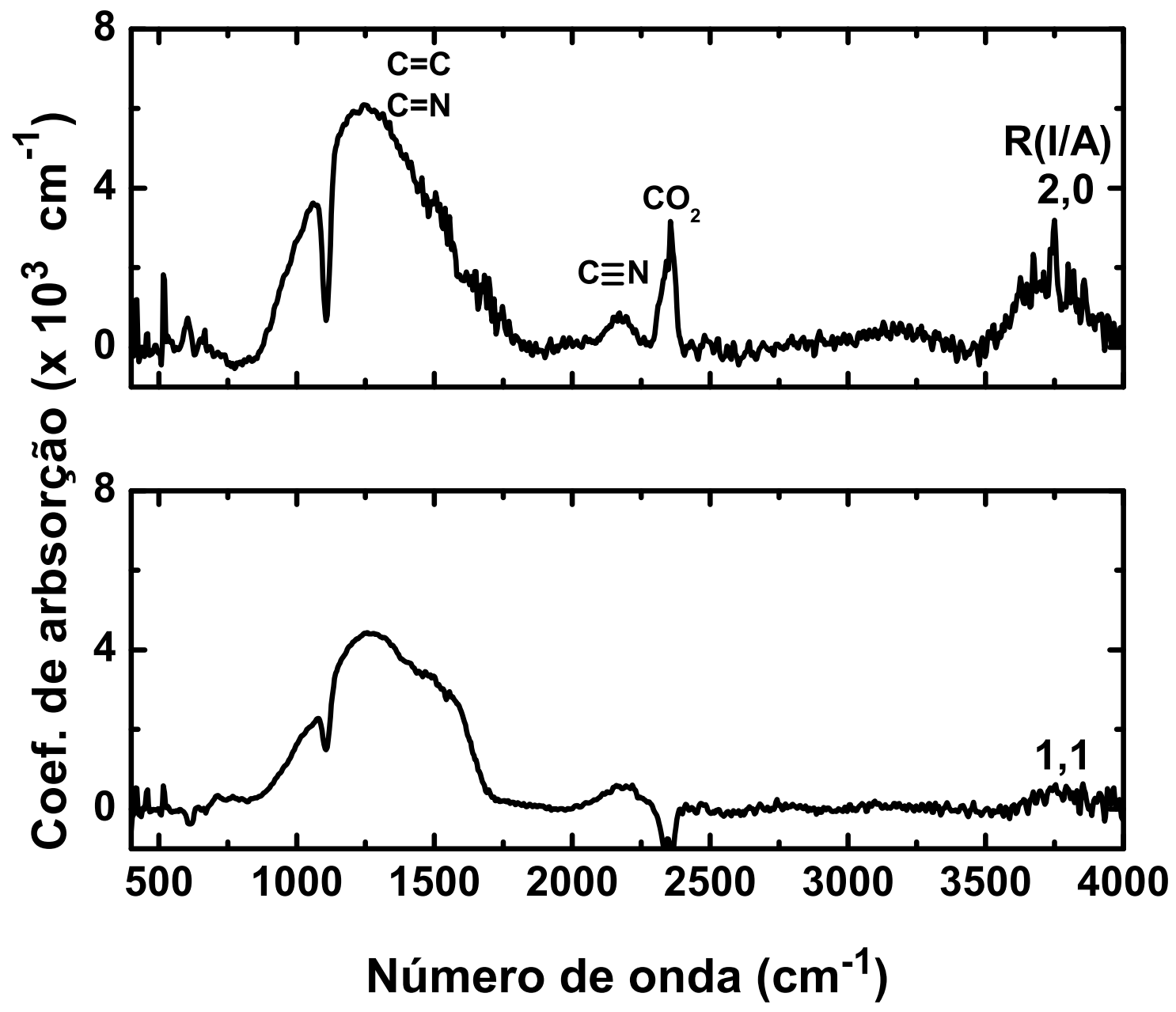

Figura 4.10: Espectros do IR para os filmes de $\mathrm{CN}_{x}$ depositados sobre os substratos de $\mathrm{Si}(100) \mathrm{em} 500^{\circ} \mathrm{C}$ com o feixe de íons derivado de $A r-N_{2}$ de $E=200 \mathrm{eV}$. 


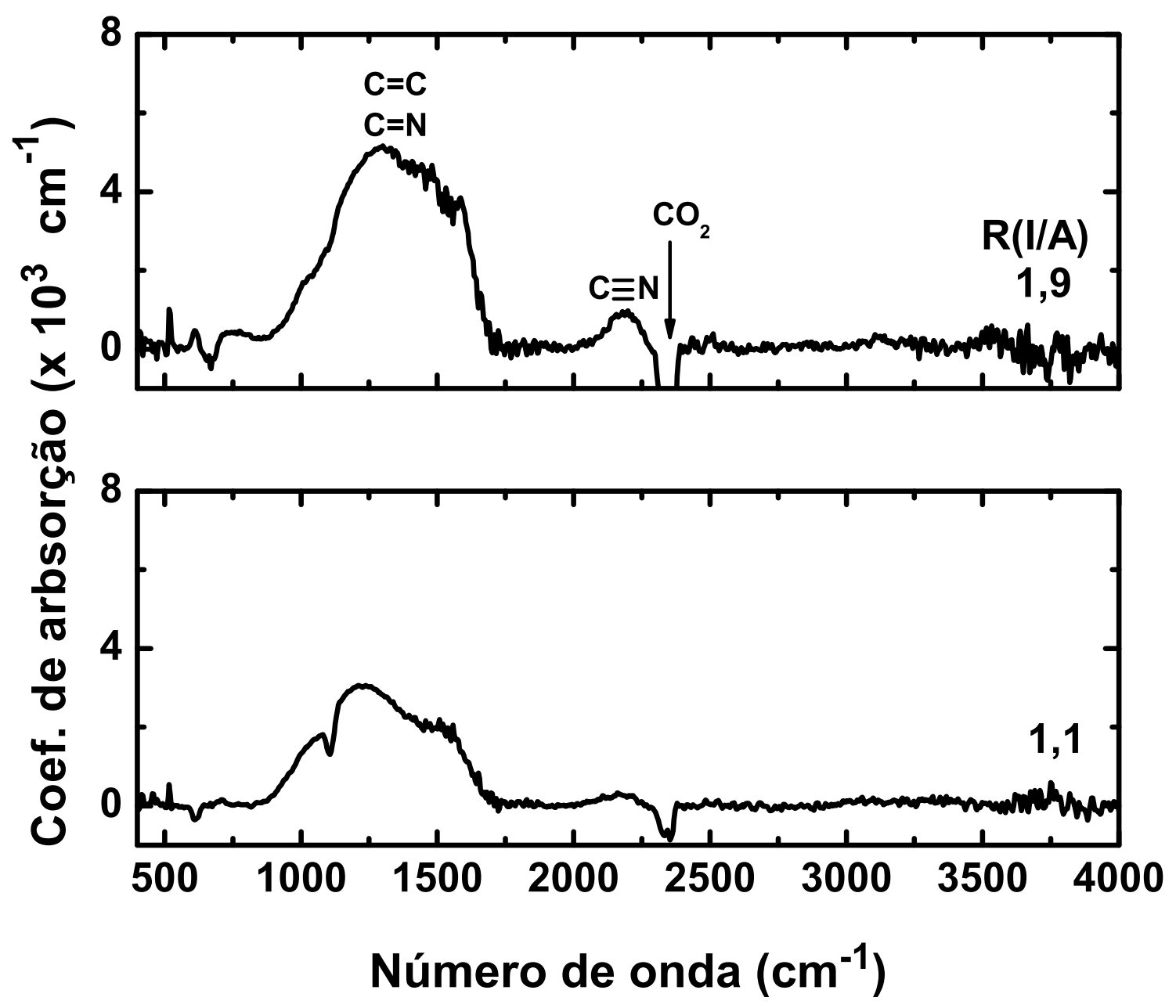

Figura 4.11: Espectros do IR para os filmes de $\mathrm{CN}_{x}$ depositados sobre os substratos de $\mathrm{Si}(100) \mathrm{em} 500^{\circ} \mathrm{C}$ com o feixe de íons derivado de $\mathrm{Ar}-\mathrm{N}_{2}$ de $E=400 \mathrm{eV}$. 


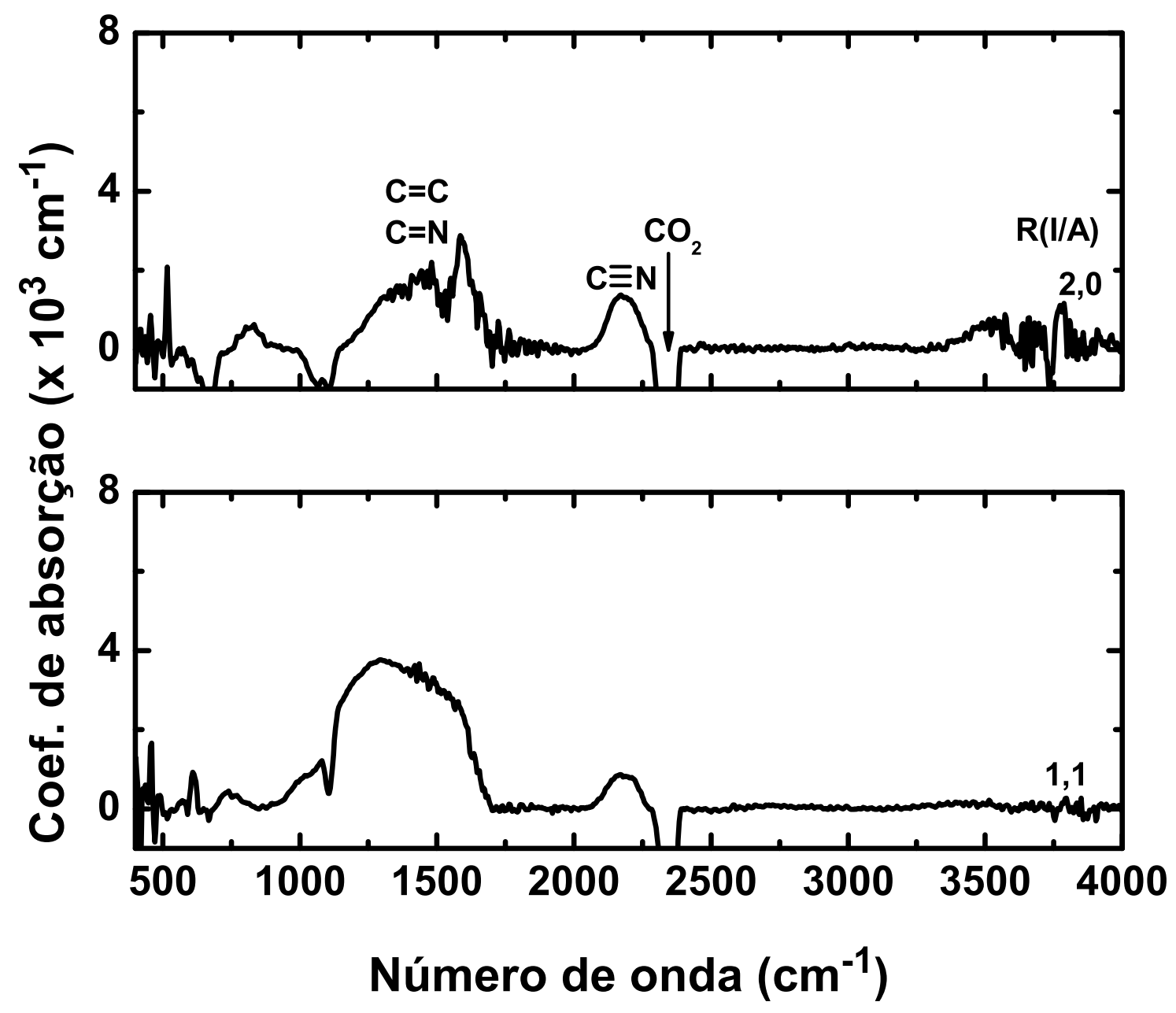

Figura 4.12: Espectros do IR para os filmes de $\mathrm{CN}_{x}$ depositados sobre os substratos de $\mathrm{Si}(111) \mathrm{em} 500^{\circ} \mathrm{C}$ com o feixe de íons derivado de $\operatorname{Ar}-N_{2}$ de $E=200 \mathrm{eV}$. 


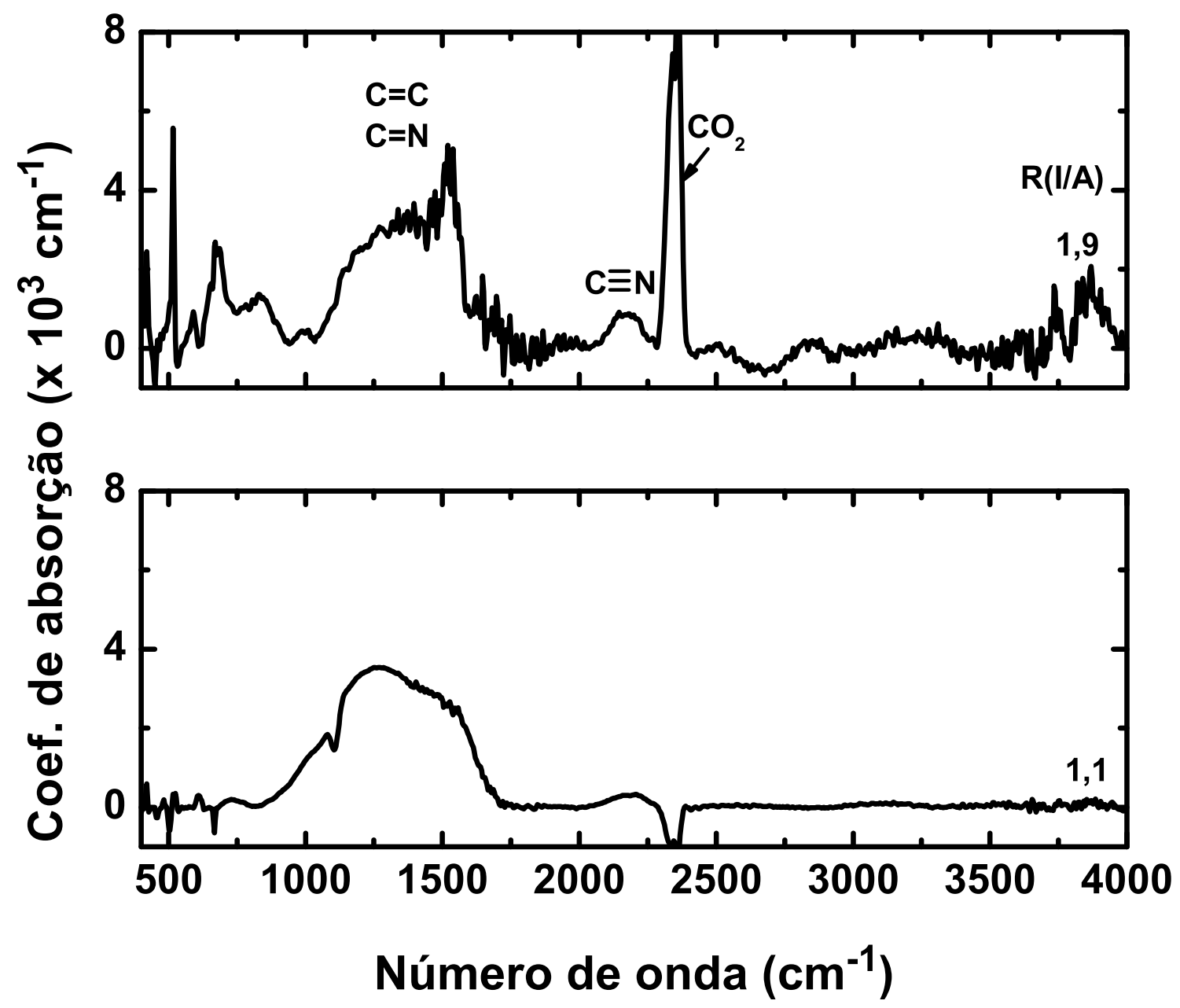

Figura 4.13: Espectros do IR para os filmes de $\mathrm{CN}_{x}$ depositados sobre os substratos de $\mathrm{Si}(111) \mathrm{em} 500^{\circ} \mathrm{C}$ com o feixe de íons derivado de $A r-N_{2}$ de $E=400 \mathrm{eV}$. 
As Figs. 4.14 e 4.15 mostram o efeito da temperatura do substrato nos espectros do IR para os filmes depositados sobre os respectivos substratos de $\mathrm{Si}(100)$ e de $\mathrm{Si}(111)$, com $\mathrm{E}=200 \mathrm{eV}$ e $\mathrm{R}(\mathrm{I} / \mathrm{A}) \cong 1,1$. Em ambas as figuras, observa-se o deslocamento da posição da banda larga em $900-1700 \mathrm{~cm}^{-1}$ para energias mais baixas com o aumento da temperatura do substrato. Usando a sugestão sobre a identificação de duas sub-bandas na banda larga em 900-1700 cm cm $^{-1}$ feita por Kaufman et al. [47] e Ng et al. [72] e mencionado na seção 4.3.1, esse deslocamento significa que a sub-banda em baixas energias cresce à custo da outra sub-banda com o aumento da temperatura do substrato. Porém, essa sugestão não explica o resultado das análises dos espectros Raman que será mencionado na seção 4.4.2.

As Fig. 4.16(a)-(c) apresentam os espectros do IR para os filmes depositados sobre os substratos de $\operatorname{Si}(100)$ em $400^{\circ} \mathrm{C}$ com $\mathrm{R}(\mathrm{I} / \mathrm{A})=1,0$ e $\mathrm{E}=400,200$ e $150 \mathrm{eV}$, respectivamente. Observa-se nas figuras que: o pico em $1535 \mathrm{~cm}^{-1}$ aparece nitidamente para $\mathrm{E}=400 \mathrm{eV}$ e não há outro efeito significativo da energia de íons. O resultado das análises dos espectros Raman, que será apresentado na seção 4.4.2, não apresenta dependência significativa da energia de íons nos espectros Raman. 


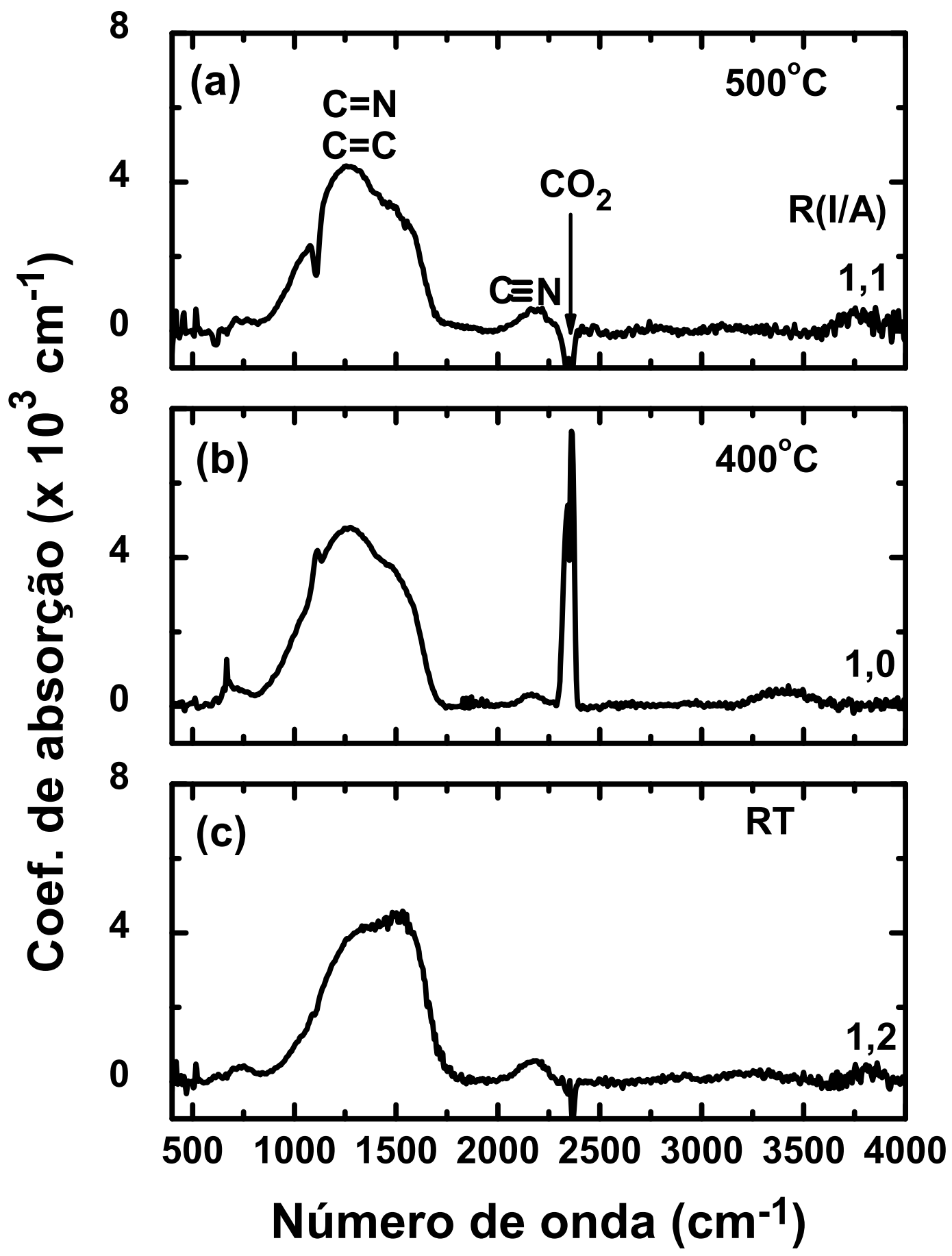

Figura 4.14: Espectros do IR para os filmes de $C N_{x}$ depositados sobre os substratos de Si(100) em (a) $500^{\circ} \mathrm{C}$, (b) $400^{\circ} \mathrm{C}$ e (c) $R T$ com o feixe de íons derivado de Ar- $N_{2}$ de $E=200 \mathrm{eV}$. 


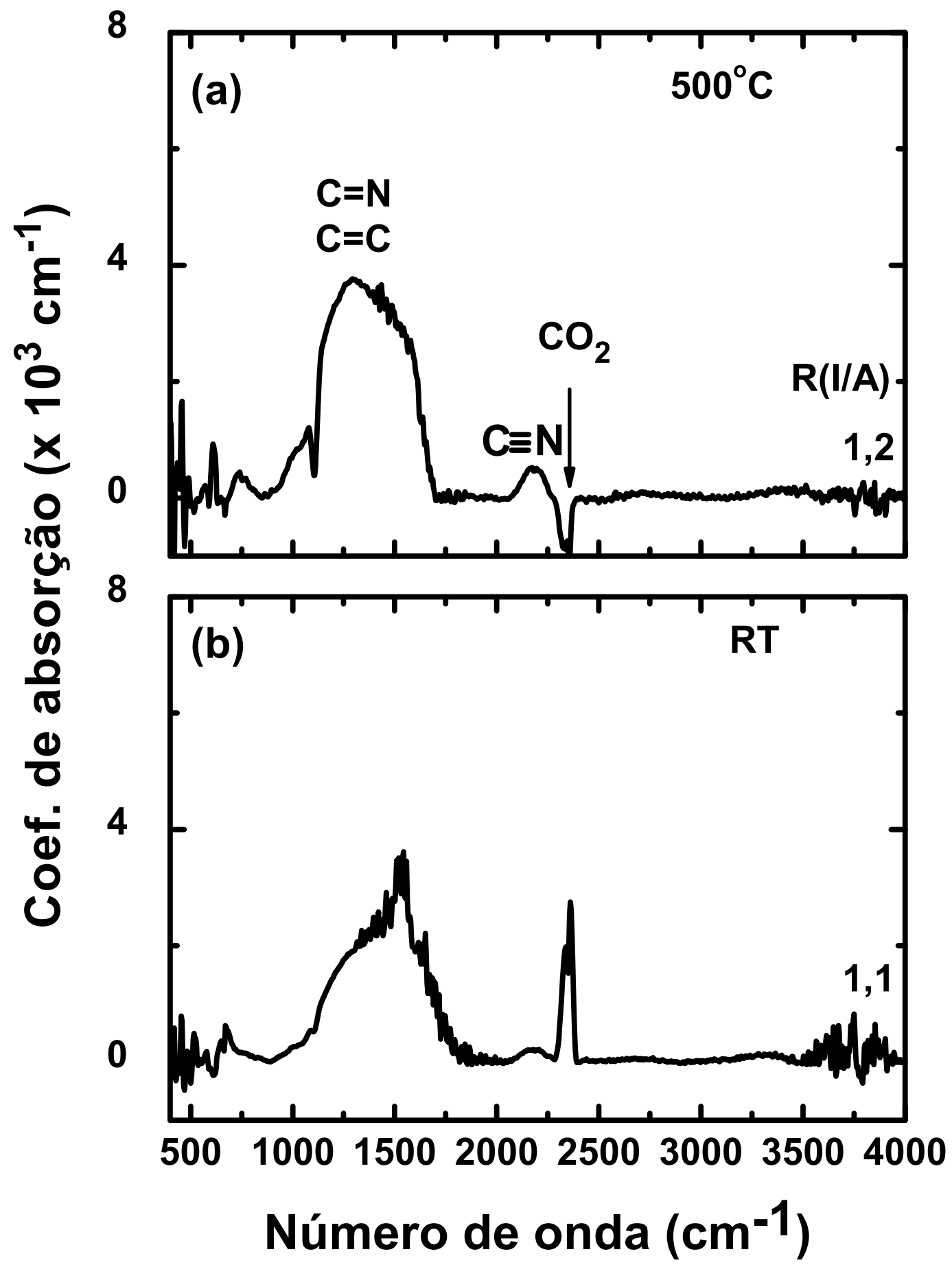

Figura 4.15: Espectros do IR para os filmes de $C N_{x}$ depositados sobre os substratos de $\operatorname{Si}(111)$ em (a) $500^{\circ} \mathrm{C}$ e (b) $R T$ com o feixe de íons derivado de $A r-N_{2}$ de $E=200 \mathrm{eV}$. 


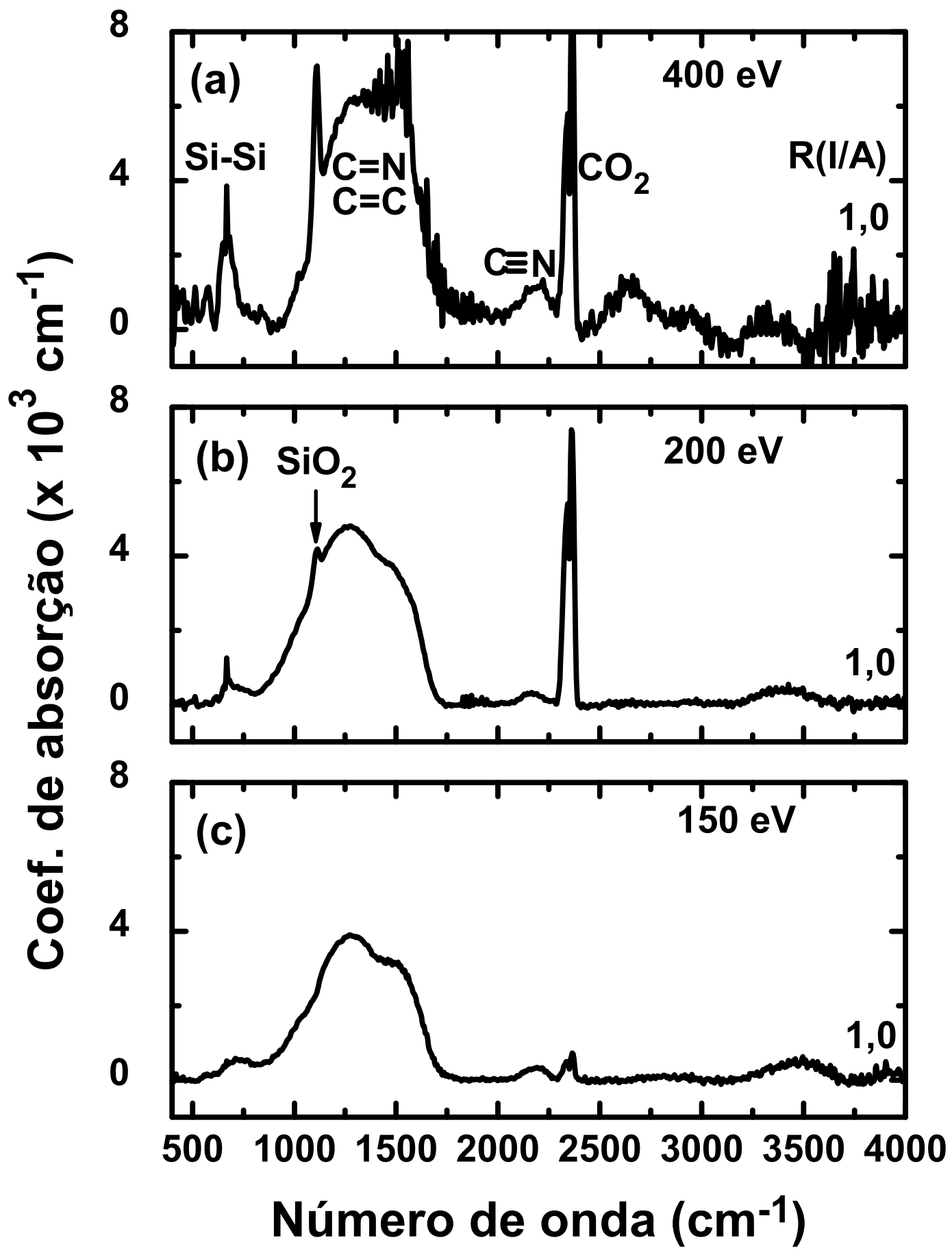

Figura 4.16: Espectros do IR para os filmes de $\mathrm{CN}_{x}$ depositados sobre os substratos de $\mathrm{Si}(100) \mathrm{em} 400^{\circ} \mathrm{C}$ com o feixe de íons derivado de Ar-N $N_{2}$ de (a) $E=400 \mathrm{eV}$, (b) $200 \mathrm{eV}$ e (c) $150 \mathrm{eV}$. 


\subsection{Espectros Raman dos filmes de $\mathrm{CN}_{x}$}

\subsubsection{Filmes depositados com o feixe de íons de nitrogênio}

A Fig. 4.17(a) mostra os espectros Raman do filme de $\mathrm{CN}_{x}$ depositados sobre os substratos de $\mathrm{Si}(100) \mathrm{em} 350^{\circ} \mathrm{C}$ com o feixe de íons de nitrogênio de $\mathrm{E}=400 \mathrm{eV}$ e $\mathrm{R}(\mathrm{I} / \mathrm{A})=1,1$. São observadas quatro bandas no espectro: uma banda pequena perto de $700 \mathrm{~cm}^{-1}$ que é atribuída por alguns autores $[38,43]$ à rotação planar de anéis hexagonais em câmadas grafíticas; uma banda quadrada em aproximadamente $980 \mathrm{~cm}^{-1}$ devida às vibrações de $\mathrm{Si}-\mathrm{Si}$ do substrato de $\mathrm{Si}$; uma banda dominante, composta por ao menos dois picos, na região de $900-2000 \mathrm{~cm}^{-1}$, e uma fraca perto de $2200 \mathrm{~cm}^{-1}$ atribuída às configurações $\mathrm{N} \equiv \mathrm{C}(s p)$. As Fig. 4.17(b) e (c) mostram os espectros Raman do filme de $a$ C depositado sobre o substrato de $\operatorname{Si}(100)$ em RT com o feixe de íons de Ar e E $=200 \mathrm{eV}$ e do filme de $a$-C depositado sobre o substrato de $\operatorname{Si}(100)$ em $400^{\circ} \mathrm{C}$ sem nenhuma irradiação por feixe de íons. Para comparação, os espectros Raman da grafite monocristalina e do diamente, extraídos da Ref. [50], são mostrados nas Fig. 4.17(d) e (e). Nota-se que: o diamante apresenta um unico pico no espectro Raman centrado em $1332 \mathrm{~cm}^{-1}[13,50]$ e a grafite monocristalina também apresenta um único pico em aproximadamente $1580 \mathrm{~cm}^{-1}$ [50-52]. Dois picos em aproximadamente $1360 \mathrm{~cm}^{-1}$ e $1580 \mathrm{~cm}^{-1}$ observados nos espectros Raman para $a$-C e $\mathrm{CN}_{x}$ são chamados do pico $\mathrm{D}$ e do pico $\mathrm{G}$, respectivamente.

A banda em $900-2000 \mathrm{~cm}^{-1}$ foi deconvoluída com uma função BWF para o pico G e uma Lorenziana para o pico D, como mostrada nas Figs. 4.17(a)-(c). Esta maneira de ajuste está sendo usada amplamente para análises quantitativas para os picos G e D nas estruturas de carbono [15, 43-45]. Foi usado um programa de computador (GNUPLOT) implementado com o algoritmo Marquardt-Levenberg de mínimos quadrados não linear. 


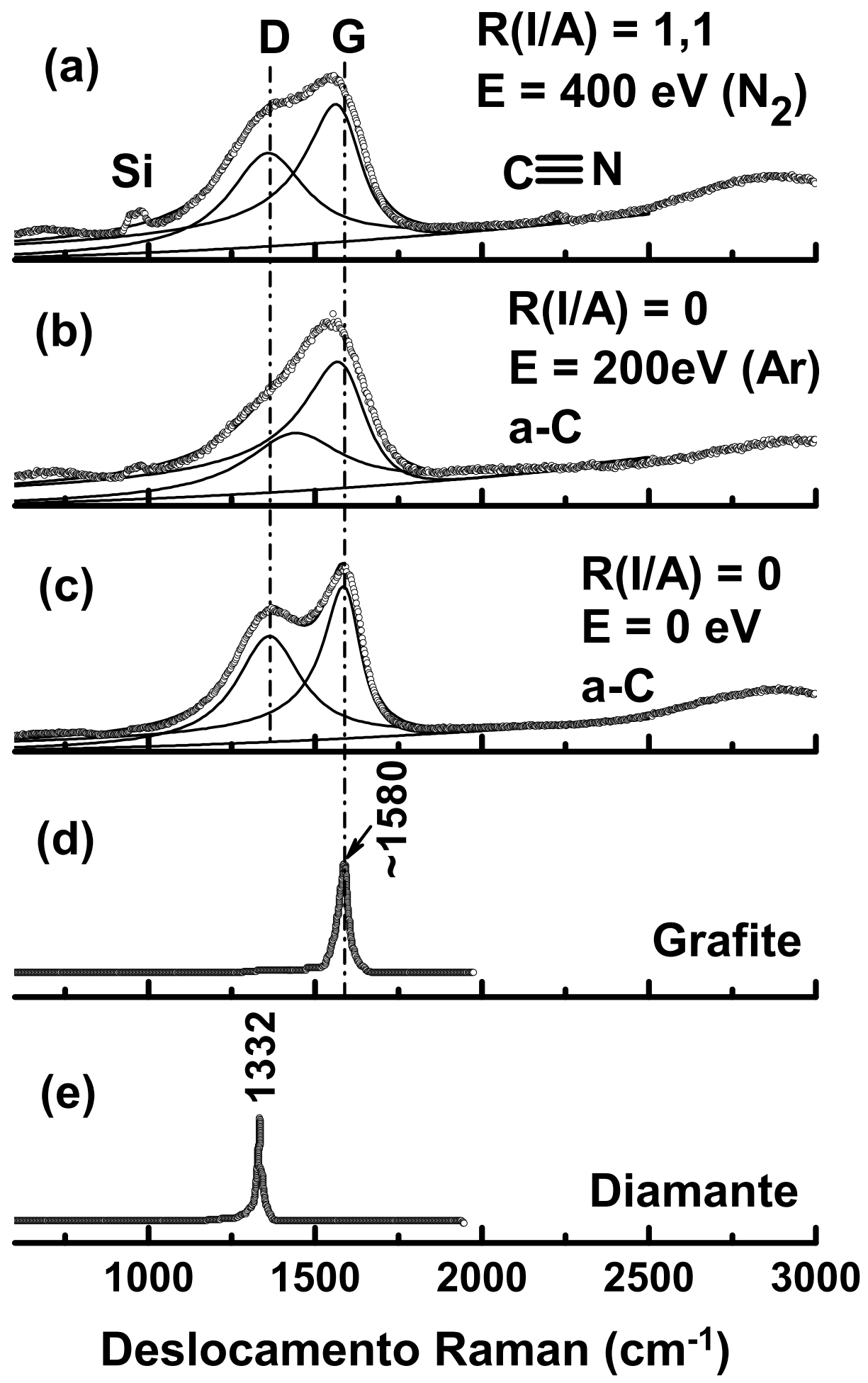

Figura 4.17: Os espectros Raman: (a) filme de $\mathrm{CN}_{x}$ depositado sobre o substrato de $\mathrm{Si}(100) \mathrm{em} 350^{\circ} \mathrm{C}$ com o feixe de íons de nitrogênio de $E=400 \mathrm{eV}$ e $R(I / A)=1,1$; (b) filme de a-C depositado sobre o substrato de Si(100) em RT com o feixe de ions de $\operatorname{Ar}$ de $E=200 \mathrm{eV}$ e $R(I / A)=0$; (c) filme de a-C depositado sobre o substrato de Si(100) em $400^{\circ} \mathrm{C}$ sem nenhuma irradiação, (d) da grafite e (e) do diamante. 
Os parâmetros obtidos, tais como a posição do pico $G$, a largura do pico $G(\Gamma)$ e a razão da intensidade do pico $\mathrm{D}$ relativa à do pico $\mathrm{G}\left(\mathrm{I}_{D} / \mathrm{I}_{G}\right)$ são mostrados em função de R(I/A) nas Figs. 4.18(a)-(c), respectivamente. Nota-se nas figuras que o círculo cheio e o triângulo cheio em $\mathrm{R}(\mathrm{I} / \mathrm{A})=0$ representam o filme de $a$-C depositado sobre o substrato de $\operatorname{Si}(100)$ em $400^{\circ} \mathrm{C}$ sem nenhuma irradiação pelo feixe de íons e o filme de $a$-C depositado sobre o substrato de $\mathrm{Si}(100)$ em RT com o feixe de íons de $\mathrm{Ar}$ de $\mathrm{E}=200 \mathrm{eV}$, respectivamente.

Primeiramente consideram-se os valores dos parâmetros Raman obtidos para os dois filmes de $a$-C. O filme de $a$-C depositado sem nenhuma irradiação (círculo preto na Fig. 4.18) mostra a posição do pico $\mathrm{G}$ em $1583 \mathrm{~cm}^{-1}$, que é um poco maior do que a da grafite $\left(1580 \mathrm{~cm}^{-1}\right)$, e a razão $\mathrm{I}_{D} / \mathrm{I}_{G}$ de $0,72 \mathrm{e}$, portanto, este filme está no estágio $\mathbf{1}$, no modelo fenomenológico, mencionado na seção 3.5, em que começa a redução progressiva do tamanho de grãos em camadas grafíticas ordenadas. O tamanho de grãos pode ser estimado com a equação (3.9) e é encontrado igual a $6,1 \mathrm{~nm}$. Por outro lado, a largura do pico $G, \Gamma$, fornece informação importante sobre a cristalinidade de filmes. $O$ valor de $\Gamma$ do filme é o mais baixo de todos os filmes obtidos neste trabalho, significando que este filme é o mais ordenado [16].

O filme de $a$-C formado usando só o feixe de Ar (triângulo cheio na Fig. 4.18) deve estar no estágio 2 que corresponde à desordem topológica de camadas grafíticas e à perda da ligação aromática, considerando-se a posição do pico $\mathrm{G} \mathrm{em} 1565 \mathrm{~cm}^{-1}$ e valor da razão de $\mathrm{I}_{D} / \mathrm{I}_{G}$ igual a 0,49 . Este filme indica o menor valor da razão $\mathrm{I}_{D} / \mathrm{I}_{G}$ e um valor de $\Gamma$ relativamente alto, significando que o filme é mais desordenado do que o filme $a$-C produzido sem irradiação [58]. O tamanho de grãos estimado com a equação (3.10) é igual a $0,9 \mathrm{~nm}$ e menor do que o tamanho de grãos do filme de $a$-C produzido sem irradiação 


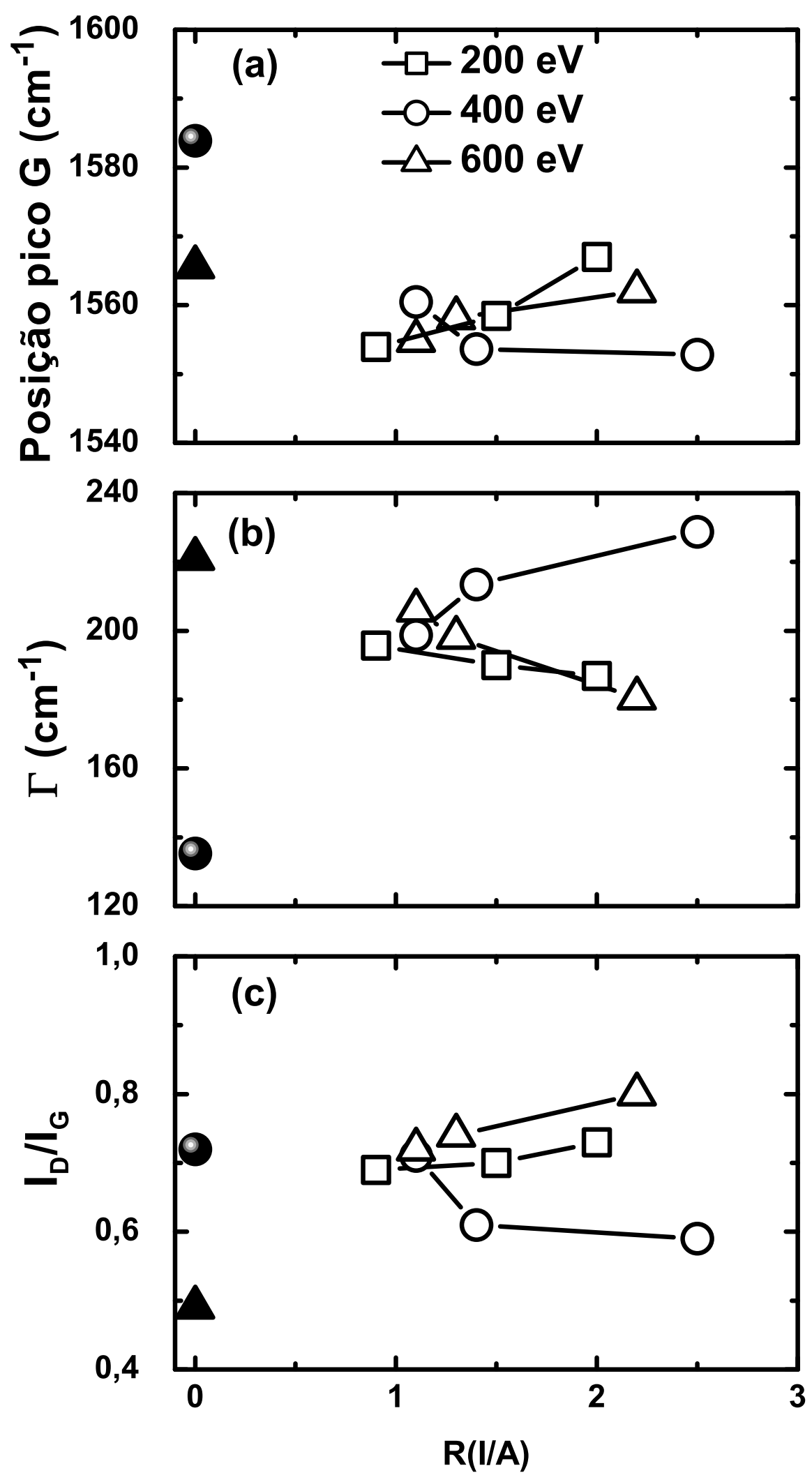

Figura 4.18: Parâmetros Raman: (a) posição do pico $G$, (b) $\Gamma$ e (c) $I_{D} / I_{G}$ em função de $R(I / A)$ para os filmes de $\mathrm{CN}_{x}$ depositados sobre os substratos de Si(100) em $350^{\circ} \mathrm{C}$ com o feixe de íons de nitrogênio. 
(6,1 nm) [77], este fato concorda com a afirmação acima sobre a desordem do filme, em conseqüência da submissão do filme à irradiação por íons. No espectro Raman exibido na Fig. 4.17(b) para o filme de $a$-C formado com o feixe de íons de Ar, vale salientar que: a posição do pico D está em $1440 \mathrm{~cm}^{-1}$, enquanto que a posição do pico D para o filme de a-C produzido sem irradiação e todos os filmes de $\mathrm{CN}_{x}$ depositados neste trabalho está na faixa de 1350-1370 $\mathrm{cm}^{-1}$; esta posição de $1440 \mathrm{~cm}^{-1}$ é próxima à posição do pico observado em materiais com a estrutura de fulereno $\left(1450 \mathrm{~cm}^{-1}\right)$, que é atribuído ao modo breathing de anéis pentagonais [78, 81]. Este ponto será discutido na seção 4.5 (difração de raios-X).

A incorporação de átomos de $\mathrm{N}$ em camadas grafíticas ordenadas apresenta os seguintes efeitos: mudança no comprimento e/ou no ângulo de ligações (efeito 1) [16, 45]; promoção de ordem topológica nas camadas, através da aglomeração de anéis aromáticos (efeito 2) [23, 43, 45]; indução de enrugamento de camadas grafíticas planas em conseqüência da presença de anéis pentagonais, causando ligações intercamadas (efeito 3) $[15,17]$; formação da configuração terminal $(\mathrm{C} \equiv \mathrm{N})$, impedindo o crescimento de camadas através da aglomeração de anéis aromáticos (efeito 4) [24, 45].

A Fig. 4.18(a) mostra que a posição do pico $\mathrm{G}$ para os filmes de $\mathrm{CN}_{x}$ está na faixa de $1553-1567 \mathrm{~cm}^{-1}$ e a razão $\mathrm{I}_{D} / \mathrm{I}_{G}$, em $0,59-0,78$; portanto, todos os filmes de $\mathrm{CN}_{x}$ depositados neste trabalho se encontram no estágio 2. As discrepâncias entre esses valores e os valores correspondentes para o filme de $a$-C depositado sem irradiação são atribuídas ao efeito 1.

Observe-se na Fig. 4.18 que há dois comportamentos opostos dos parâmetros em função de R(I/A); um para os filmes depositados com $\mathrm{E}=200$ ou $600 \mathrm{eV}$ e o outro para os filmes formados com $\mathrm{E}=400 \mathrm{eV}$. Para os filmes do primeiro grupo, a posição do pico $\mathrm{G}$ se desloca de modo ascendente, a razão $\mathrm{I}_{D} / \mathrm{I}_{G}$ aumenta e a largura $\Gamma$ diminui, com o aumento 
de R(I/A). Os filmes do segundo grupo mostram o comportamento completamente oposto. Como todos os filmes estão no estágio 2, o incremento da posição do pico G e o da razão $\mathrm{I}_{D} / \mathrm{I}_{G}$ com o aumento de $\mathrm{R}(\mathrm{I} / \mathrm{A})$, indicados pelos filmes do primeiro grupo, significam promoção da ordem topológica (efeito 2), conseqüentemente resultando na diminuição da largura $\Gamma$.

Por outro lado, os filmes do segundo grupo mostram a promoção da desordem com o aumento de R(I/A). Roy et al. atribuíram o a redução da posição do pico G ao aumento no conteúdo de anéis pentagonais (efeito 3) [15]. É conhecido que a eficiência do efeito 3 depende do conteúdo de $\mathrm{N}$ e da temperatura de deposição, como mostrado a seguir:

Hellgren et al. descreveram as seguintes três fases distintas de acordo com a tempertura de deposição e o conteúdo de N: a fase amorfa é formada abaixo de $150^{\circ} \mathrm{C}$ e, a fase característica de grafite e a de fulereno são formadas acima de $150^{\circ} \mathrm{C}$; a transição da fase característica de grafite à de fulereno é observada na faixa de concentração de $\mathrm{N}$ de 5-15\% atômica [16]. Além disso, Santos e Alvarez revelaram teoricamente que: a camada formada pela aglomeração de anéis é plana até 17\% atômica de N (efeito 2); acima dessa concentração, alguns átomos de $\mathrm{N}$ relaxam-se e ficam à posição de $0,07 \mathrm{~nm}$ acima ou abaixo da camada, formando-se enrugamento da camada [82] (efeito 3). Sabendo na seção 4.2 que: a concentração de $\mathrm{N}$ nos filmes do primeiro grupo é de 17-40\% atômica (28-40 e 17-37\% atômica, para os filmes formados com E = 200 e 600 eV, respectivamente) e a concentração dos filmes do segundo grupo de 37-47\% atômica. Supondo que a concentração da transição de fase esteja em $40 \%$ atômica no presente trabalho, é possível explicar o comportamento dos parâmetros para os filmes do segundo grupo.

Há possibilidade de $\mathrm{H}$ incorporado nos filmes contribuir para a redução da posição do pico $\mathrm{G}$, alterando ligações $\mathrm{C}-\mathrm{C}$ e $\mathrm{C}=\mathrm{C}$ com a formação de grupos de $\mathrm{CH}_{n}$ e, con- 
seqüêntemente, causando redução no tamanho de aglomerados [44]. Porém, esta possibilidade será descartada neste trabalho, pois, não se observa tendência crescente ou decrescente na intensidade dos picos de $\mathrm{CH}_{n}$ nos espectros de IR mostrados nas Figs. 4.7 e 4.9 em função de $R(I / A)$.

$\mathrm{Na}$ seção 4.3.1, foi mencionado que as freqüências vibracionais de $\mathrm{C}=\mathrm{N}$ são bastante próximas às freqüências dos modos vibracionais de $\mathrm{C}=\mathrm{C}$. Desta forma, os modos Raman D e G podem ficar ativos com base na semelhança entre os dois espectros do IR e Raman. Porém, como mostra a Fig. 4.17, essa similaridade não é seguida por todos os filmes de $\mathrm{CN}_{x}$.

\subsubsection{Filmes depositados com o feixe de íons derivado de $\mathrm{Ar}-\mathrm{N}_{2}$}

As Figs. 4.19 e 4.20 apresentam os efeitos de R(I/A) nos parâmetros Raman para os filmes de $\mathrm{CN}_{x}$ depositados sobre os substratos de $\mathrm{Si}(100)$ e $\mathrm{Si}(111)$ em $500^{\circ} \mathrm{C}$, respectivamente, com o feixe de íons derivado de $\mathrm{Ar}-\mathrm{N}_{2}$; o círculo cheio e o triângulo cheio nas figuras têm os mesmos significados usados na seção anterior. Como a posição do pico G de cada filme é mais baixa do que $1580 \mathrm{~cm}^{-1}$, a posição típica do monocristal da grafite, e a razão $\mathrm{I}_{D} / \mathrm{I}_{G}$ é em $0,5-0,9$, os filmes de $\mathrm{CN}_{x}$ estão no estágio 2 .

Observa-se na Fig. 4.19 os dois comportamentos opostos dos parâmetros com o aumento de $\mathrm{R}(\mathrm{I} / \mathrm{A})$, como já vistos na Fig. 4.18, para os filmes depositados com $\mathrm{E}=$ 200 eV e para os filmes formados com E = 400 e 600 eV. Com a argumentação utilizada na discussão da Fig. 4.18, os filmes do primeiro grupo mostram a promoção de ordem e os filmes do segundo grupo, a promoção de desordem. No entanto, comparando o filme formado com o feixe de íons derivado de $\mathrm{Ar}-\mathrm{N}_{2}$ de $\mathrm{E}=600 \mathrm{eV}$ e $\mathrm{R}(\mathrm{I} / \mathrm{A})=2,1$, com o filme depositado com o feixe de íons de nitrogênio e os mesmos valores dos parâmetros de 
deposição (Fig. 4.18), o primeiro filme é o mais desordenado do que o segundo, indicando o efeito de irradiação por íons de $\mathrm{Ar}$ e/ou o da concentração maior de $\mathrm{N}$ no primeiro filme. Esta afirmação concorda com a observação feita por Gago et al. de que os filmes depositados com o método IBAD usando o feixe de íons derivado de $\mathrm{Ar}-\mathrm{N}_{2}$, a razão do fluxo de Ar gasoso relativa ao de $\mathrm{N}_{2}$ gasoso $<1$ e $\mathrm{E}=360 \mathrm{eV}$, são mais desordenados, sendo comparados com os filmes depositados com o feixe de íons de nitrogênio [58]. Infelizmente, as medidas do conteúdo de $\mathrm{N}$ nesses filmes ainda não foram efetuadas.

Todos os filmes mostrados na Fig. 4.20 indicam a promoção de desordem e o filme depositado com $\mathrm{E}=600 \mathrm{eV}$ e $\mathrm{R}(\mathrm{I} / \mathrm{A})=2,1$ neste caso, também, é o mais desordenado. Vêse nas Figs. 4.10 e 4.12 que a intensidade da banda de $\mathrm{C} \equiv \mathrm{N}$, para os filmes formados nos substratos de $\mathrm{Si}(100)$ com $\mathrm{E}=200 \mathrm{eV}$, é praticamente independente de $\mathrm{R}(\mathrm{I} / \mathrm{A})$, enquanto que esta intensidade para os filmes depositados nos substratos de $\mathrm{Si}(111)$ com o mesmo valor de E cresce com o aumento de R(I/A) e, portanto, os filmes depositados nos Si(111) podem estar mais desordenados em conseqüência do efeito 4, indicado na seção 4.4.1. Esta observação está coerente com o resultado obtido na Fig. 4.20. A orientação cristalina do substrato é fundamental no processo de formação dos filmes de $\mathrm{CN}_{x}$. Os filmes preparados sobre os substratos de $\mathrm{Si}(111)$ são mais desordenados que os filmes depositados sobre os substratos de $\mathrm{Si}(100)$. Será necessário estudo mais detalhado para compreender a influência da orientação cristalina do substrato na deposição do filme.

A Fig. 4.21 mostra o efeito da temperatura do substrato nos parâmetros Raman para os filmes de $\mathrm{CN}_{x}$ formados nos substratos de $\mathrm{Si}(100)$ e de $\mathrm{Si}(111)$ com $\mathrm{E}=200$ $\mathrm{eV}$ e $\mathrm{R}(\mathrm{I} / \mathrm{A})=1,0$. A mudança da temperatura de substrato de $\mathrm{RT}$ a $400^{\circ} \mathrm{C}$ favorece a aglomeração de anéis aromáticos $[23,45,77,83]$, no entanto, de $400^{\circ} \mathrm{C}$ a $500^{\circ} \mathrm{C}$, não se observa este favorecimento [45]. Este fenômeno pode ser explicado usando o modelo de 
três fases, sugerido por Hellgrem et al. mencionado na seção anterior, de que a fase amorfa é formada abaixo de $150^{\circ} \mathrm{C}$ e, acima desta temperatura é formada a fase característica de grafite [16].

A Fig. 4.22 apresenta o efeito da energia de íons nos parâmetros Raman para os filmes $\mathrm{CN}_{x}$ preparados nos substratos de $\mathrm{Si}(100)$ em $400^{\circ} \mathrm{C}$ em $\mathrm{R}(\mathrm{I} / \mathrm{A})=1,0$. Note-se nesta figura que o ponto experimental em $\mathrm{E}=0$ corresponde ao filme de $a$-C formado sobre o substrato de $\operatorname{Si}(100)$ em $400^{\circ} \mathrm{C}$ sem irradiação por íons. Consideram-se os parâmetros Raman mostrados na figura independentes da energia de íons de 150-600 eV. 


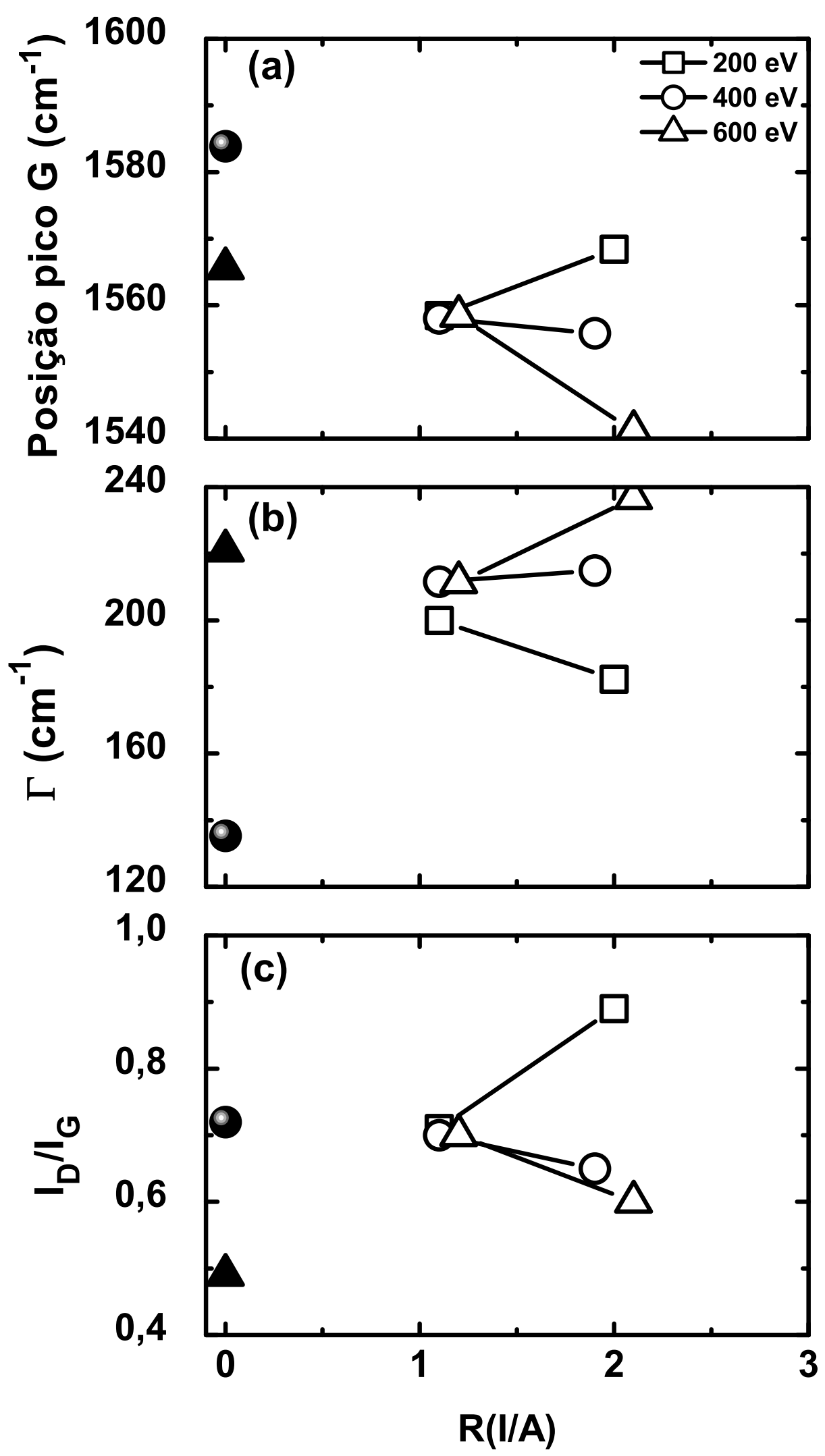

Figura 4.19: Parâmetros Raman: (a) posição do pico $G$, (b) $\Gamma$ e (c) $I_{D} / I_{G}$ em função de $R(I / A)$ para os filmes de $\mathrm{CN}_{x}$ depositados sobre os substratos de $\mathrm{Si}(100) \mathrm{em} 500^{\circ} \mathrm{C} \mathrm{com}$ o feixe de íons derivado de $\operatorname{Ar}-N_{2}$. 

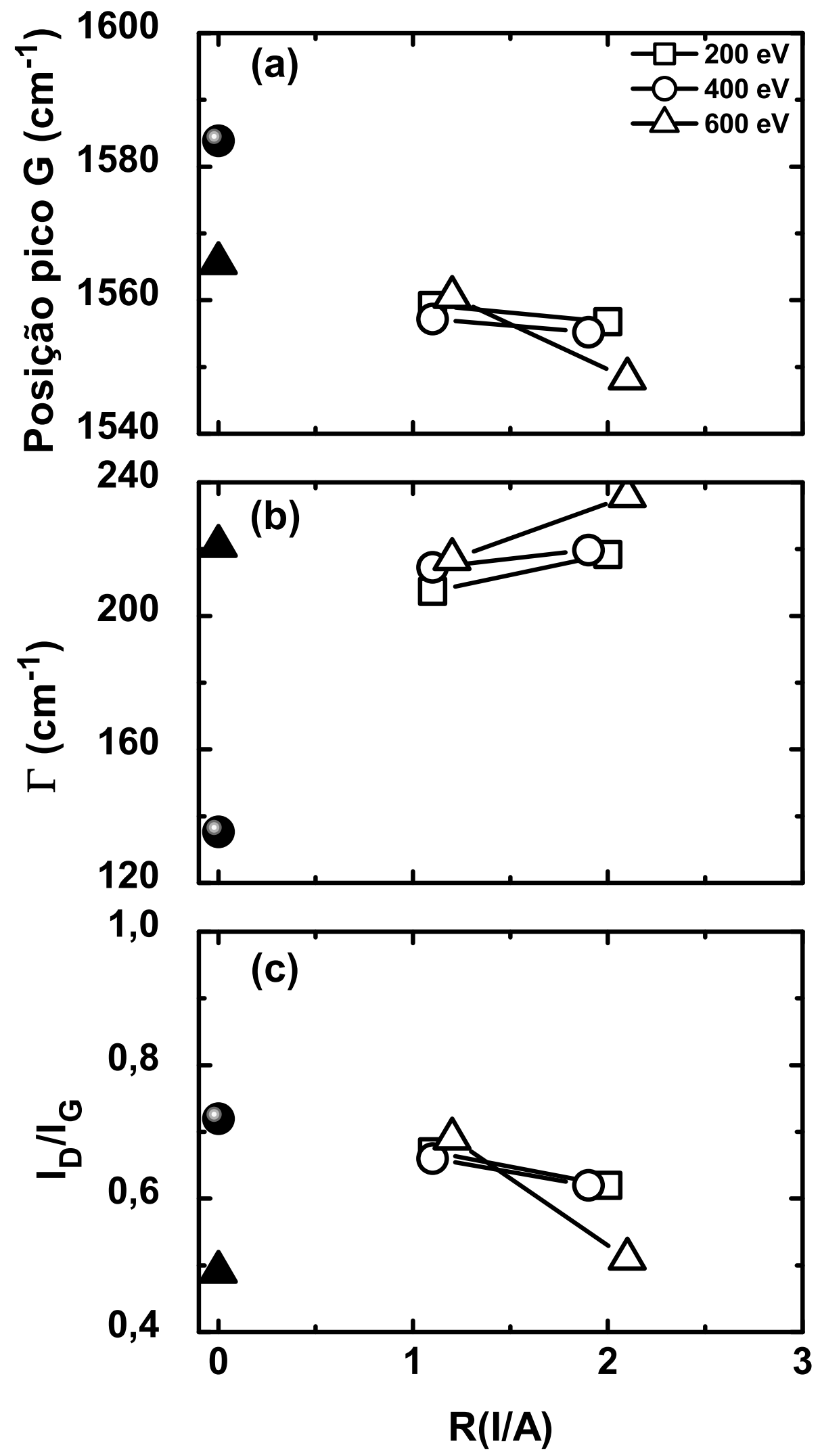

Figura 4.20: Parâmetros Raman: (a) posição do pico $G$, (b) $\Gamma$ e (c) $I_{D} / I_{G}$ em função de $R(I / A)$ para os filmes de $\mathrm{CN}_{x}$ depositados sobre os substratos de Si(111) em $500^{\circ} \mathrm{C}$ com o feixe de íons derivado de $\operatorname{Ar}-N_{2}$. 


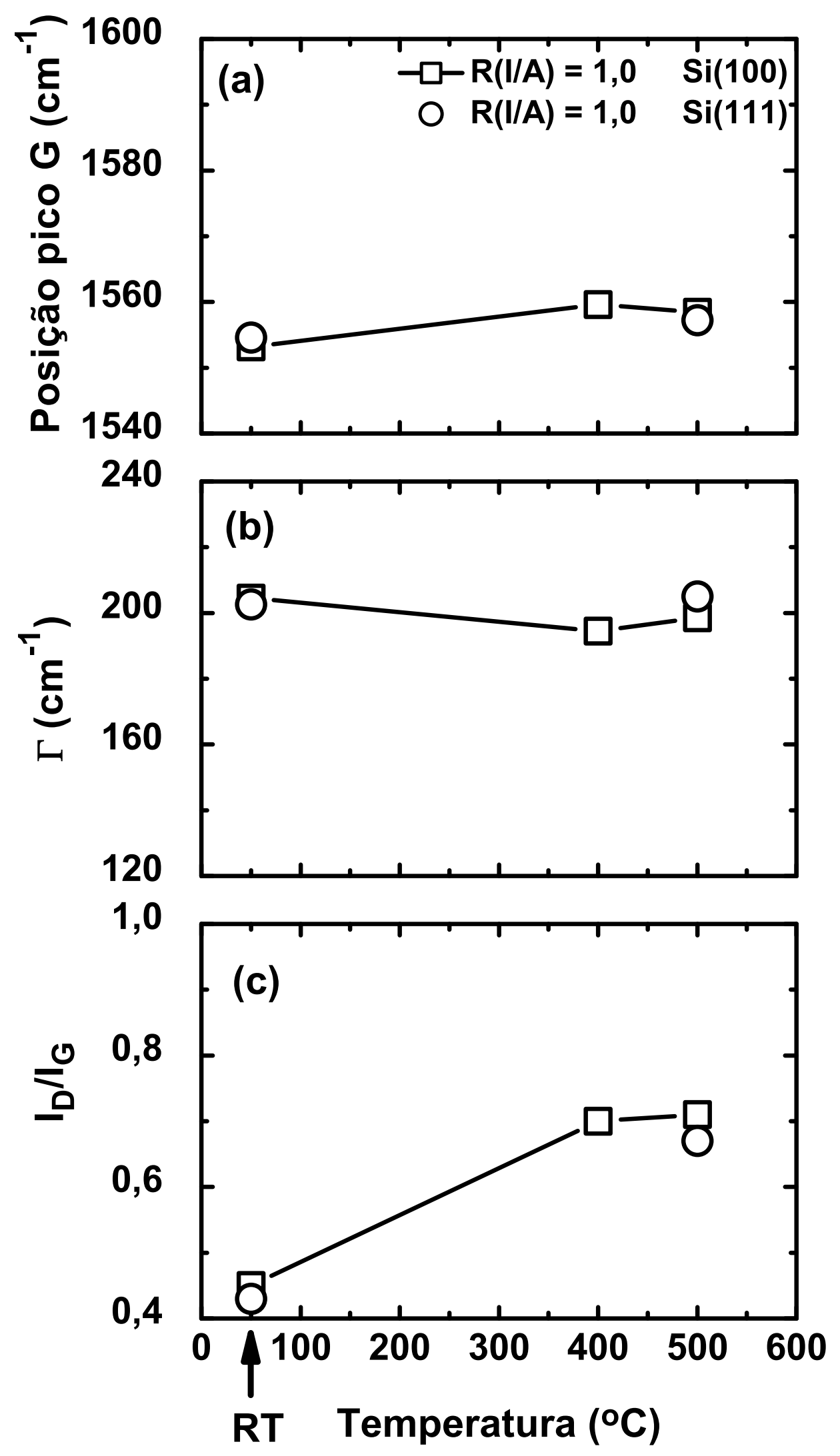

Figura 4.21: Parâmetros Raman: (a) posição do pico G, (b) $\Gamma$ e (c) $I_{D} / I_{G}$ em função da temperatura para os filmes de $C N_{x}$ depositados sobre os substratos de Si(100) ou Si(111) com o feixe de íons derivado de $\operatorname{Ar}-N_{2}$ de $E=200 \mathrm{eV}$ e $R(I / A) \approx 1$. 

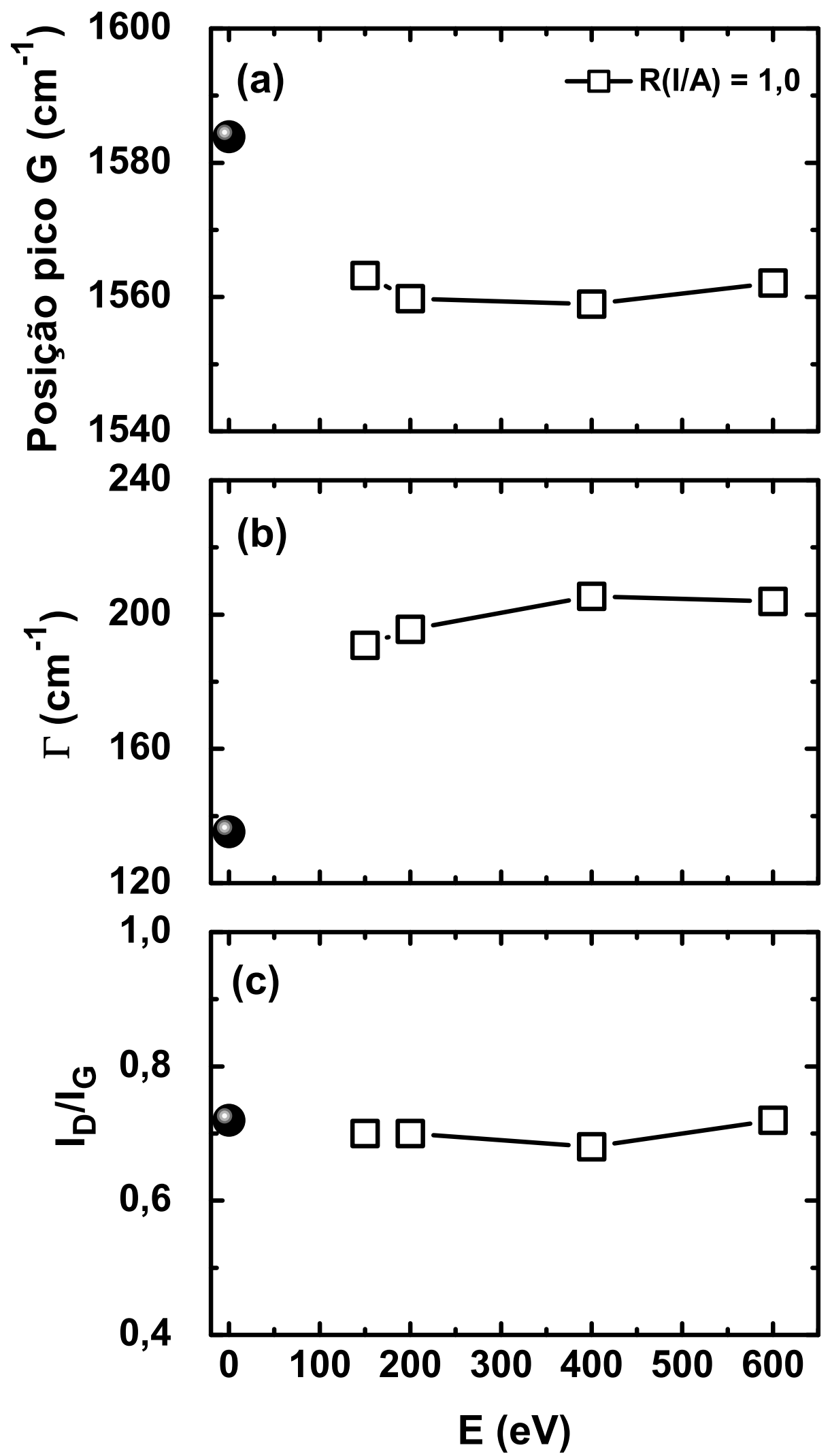

Figura 4.22: Parâmetros Raman: (a) posição do pico $G$, (b) $\Gamma$ e (c) $I_{D} / I_{G}$ em função de $E$ para os filmes de $\mathrm{CN}_{x}$ depositados sobre os substratos de $\mathrm{Si}(100) \mathrm{em} 400^{\circ} \mathrm{C}$ com o feixe de íons derivado de $\mathrm{Ar}-\mathrm{N}_{2}$. 


\subsection{Difração de raios $\mathrm{X}$}

Nos estudos de difração de raios X e de elétrons não há evidência concreta para a cristalização de nitreto de carbono, como tendo possibilidade de formar o diamante desordenado politípico na presença de N [18]. Nesta seção tenta-se identificar os picos observados nos difratogramas para alguns filmes estudados no presente trabalho, usando as informações disponíveis na literatura.

A Fig. 4.23(a) apresenta o difratograma de raios $\mathrm{X}$ medido com o método $\theta-2 \theta$ para o filme de $a$-C formado sobre o substrato de $\mathrm{Si}(100)$ em RT com o feixe de íons de $\mathrm{Ar}$ de $200 \mathrm{eV}$, e as Figs. 4.23(b)-(d), para os filmes de $\mathrm{CN}_{x}$ depositados sobre os substratos de $\operatorname{Si}(100)$ em $350^{\circ} \mathrm{C}$ com o feixe de íons de nitrogênio de: $\mathrm{E}=400 \mathrm{eV}$ e $\mathrm{R}(\mathrm{I} / \mathrm{A})=1,1 ; 400$ $\mathrm{eV}$ e 1,$4 ; 600 \mathrm{eV}$ e 2,2 , respectivamente. O pico observado em torno de $2 \theta=32,9^{\circ}$ para os filmes é identificado como o do substrato de $\operatorname{Si}(400)$ cristalino $\operatorname{com} \lambda / 2$.

Na Fig. 4.23(a) são observados alguns picos de reflexão em $16,6^{\circ}, 21,7^{\circ}, 22,6^{\circ}$, $37,9^{\circ}, 43,7^{\circ}, 44,5^{\circ}$ e $45,9^{\circ}$. Os picos em $16,6^{\circ}$ e $22,6^{\circ}$ podem ser atribuídos, respectivamente, aos planos (220) e (222) de fulereno ou aos planos (210) e (310) de nanotubo de C com parede simples (Single-Wall Nanotube, SWNT) [79, 80], respectivamente. Os respectivos picos em $21,7^{\circ}, 37,9^{\circ}$ e $45,9^{\circ}$ podem estar relacionados com os planos (311), (531) e (711) de fulereno [81, 84-86], e os picos em $43,7^{\circ}$ e $44,5^{\circ}$ podem ser associados, respectivamente, ao plano (111) do diamente $[\mathrm{D}(111)]$ e ao plano (101) da grafite $[\mathrm{G}(101)][87,88]$.

O difratograma do filme de $\mathrm{CN}_{x}$ formado com $\mathrm{E}=600 \mathrm{eV}$ é similar ao difratograma do filme de $a$-C, exceto as variações nas intensidades dos picos. Na região de $21^{\circ}-23^{\circ}$ no difratograma, pode se encontrar em $22,2^{\circ}$ o pico de reflexão do plano (100) de $\mathrm{C}_{3} \mathrm{~N}_{4}$ grafítico [84] e/ou do (210) de $\mathrm{CN}_{x}$ [89], além dos picos dos planos (311) e (222) de fulereno e do 
pico do plano (310) do SWNT [80]; na região de $43^{\circ}-47^{\circ}$, pode se encontrar o pico do plano (111) de $\beta-\mathrm{C}_{3} \mathrm{~N}_{4}$ em 44,6 $6^{\circ}[84,89]$, além do pico de $\mathrm{D}(111)$ e do pico de $\mathrm{G}(101)$. Nos difratogramas para os dois filmes de $\mathrm{CN}_{x}$ formados com $\mathrm{E}=400 \mathrm{eV}$, observa-se um pico em $38,4^{\circ}$ que pode ser atribuído ao plano (101) de $\beta-\mathrm{C}_{3} \mathrm{~N}_{4}$ [89]. O aumento na intensidade do sinal em $21^{\circ}-23^{\circ}$ nos difratogramas (c) e (d) com o aumento de R(I/A) de 1,1 a 1,4 pode ser um indício da existência do SWNT.

A Fig. 4.24(a) apresenta o difratograma de raios X para o filme de $a$-C formado sobre o substrato de $\mathrm{Si}(100)$ em RT com o feixe de íons de Ar de 1000 eV. As Figs. 4.24(b) e (c) mostram os difratogramas para os filmes de $\mathrm{CN}_{x}$ depositados sobre os substratos de $\mathrm{Si}(100)$ com feixe de íons derivados de $\operatorname{Ar}-\mathrm{N}_{2}$ : (b) em $500^{\circ} \mathrm{C}, \mathrm{E}=400 \mathrm{eV}$ e R(I/A) $=1,1$; (c) em RT, $\mathrm{E}=200 \mathrm{eV}$ e R(I/A) = 1,2. As Figs. 4.24(d) e (e) para os filmes de $\mathrm{CN}_{x}$ depositados sobre os substratos de $\mathrm{Si}(111)$ com feixe de íons derivados de $\mathrm{Ar}-\mathrm{N}_{2}$ : (d) em $500^{\circ} \mathrm{C}, \mathrm{E}=400 \mathrm{eV}$ e $\mathrm{R}(\mathrm{I} / \mathrm{A})=1,1$; (c) em $\mathrm{RT}, \mathrm{E}=200 \mathrm{eV}$ e $\mathrm{R}(\mathrm{I} / \mathrm{A})=1,2$. Um pico observado em torno de $2 \theta=28,5^{\circ}$ nas Figs. 4.24(d) e (e) é devido à reflexão do plano (111) do substrato de Si.

Os filmes depositados em $\mathrm{Si}(100)$ [Figs. 4.24(a)-(c)] são amorfos, enquanto que os filmes depositados em $\mathrm{Si}(111)$ apresentam um pico em 20,9 [Fig. 4.24(d)] ou outro em 26,6 $6^{\circ}$ [Fig. 4.24(e)]; o primeiro pico pode ser atribuído ao plano (311) de fulereno e/ou ao plano (220) do SWNT, e o segundo, ao plano (003) de grafite e/ou ao plano (002) de MWNT (Multi-Wall Nanotube) [90]. 


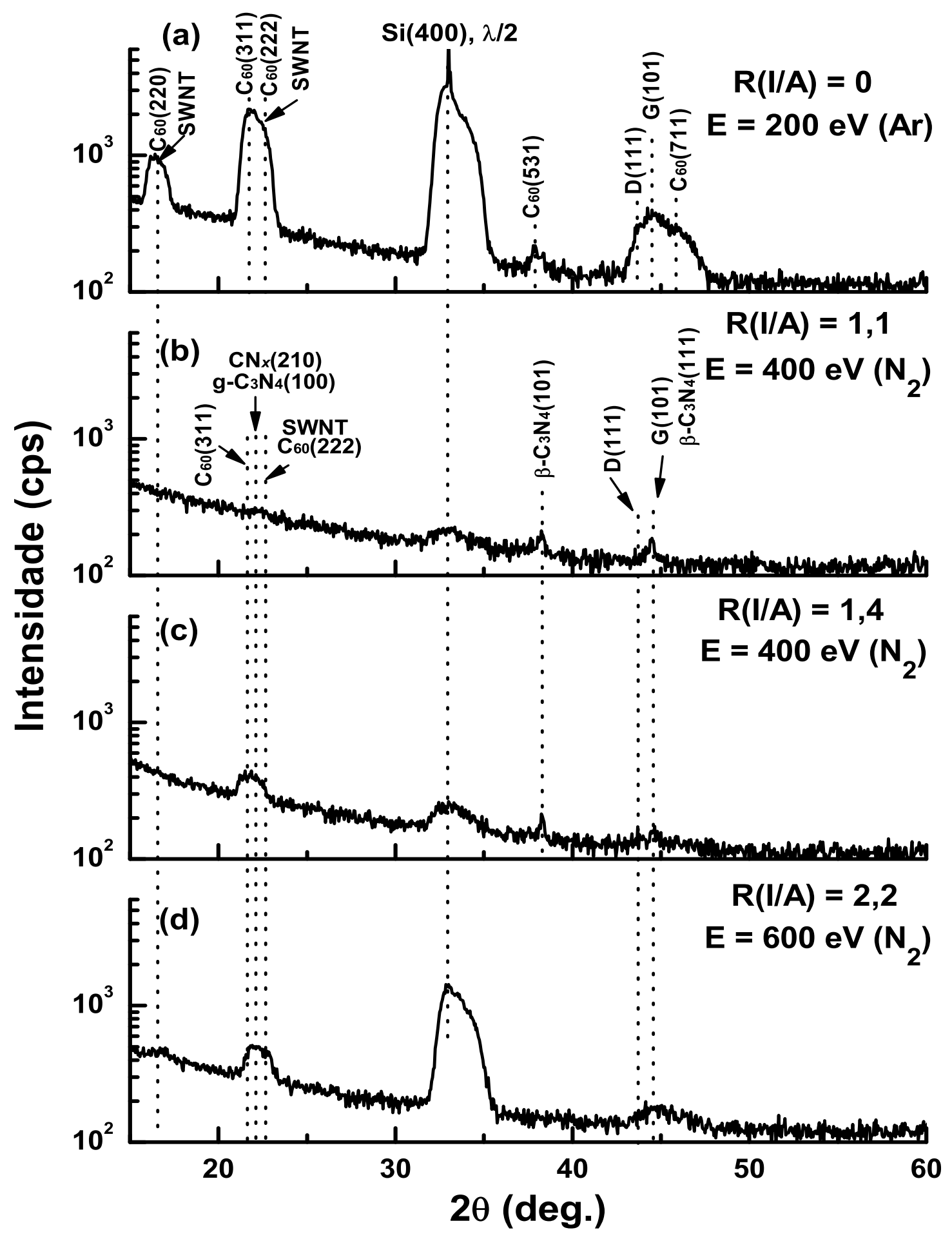

Figura 4.23: Difratogramas de raios $X$. (a) filme de a-C depositado sobre o substrato de $\mathrm{Si}(100)$ em $R T$ com o feixe de íons de $\operatorname{Ar}$ de $E=200 \mathrm{eV}$. Filmes de $C N_{x}$ depositados sobre os substratos de $\mathrm{Si}(100) \mathrm{em}$ $350^{\circ} \mathrm{C}$ com o feixe de íons de nitrogênio de: (b) $E=400 \mathrm{eV}$ e $R(I / A)=1,1$; (c) $E=400 \mathrm{eV}$ e $R(I / A)=$ 1,$4 ;(d) E=600$ eV e $R(I / A)=2,2$. 


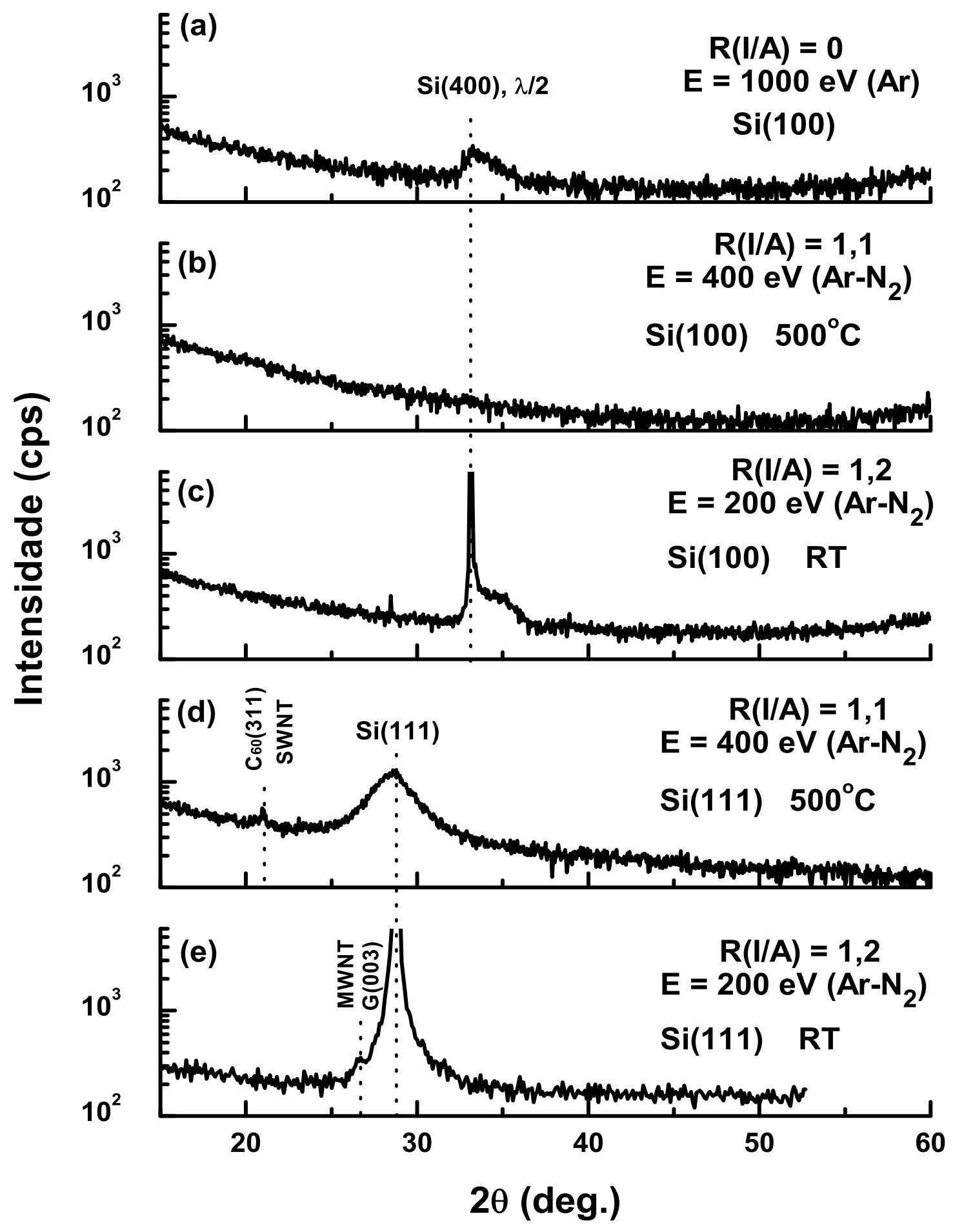

Figura 4.24: Difratogramas de raios $X$. (a) filme de a-C depositado sobre o substrato de $\operatorname{Si}(100)$ em $R T$ com o feixe de íons de Ar de $E=1000 \mathrm{eV}$. Filmes de $C N_{x}$ depositados sobre os substratos de Si(100) em (b) $500^{\circ} \mathrm{C}$ e (c) $R T$ com o feixe de íons derivados de $A r-N_{2}$ de: $E=400 \mathrm{eV}$ e $R(\mathrm{I} / \mathrm{A})=1,1 ; 200 \mathrm{eV}$ e 1,2, respectivamente. Filmes de $C N_{x}$ depositados sobre os substratos de $\operatorname{Si}(111)$ em (d) $500^{\circ} \mathrm{C}$ e (e) $R T$ com o feixe de íons derivados de $A r-N_{2}$ de: $E=400$ eV e $R(I / A)=1,1 ; 200$ eV e 1,2, respectivamente. 


\subsection{Comparação com filmes de $\mathrm{CN}_{x}$ preparados com}

\section{o método RF magnetron sputtering reativo}

Foram analisados, com as técnicas de Raman e de XPS, os filmes $\mathrm{CN}_{x}$ preparados previamente com o método RF magnetron sputtering reativo, para comparação. Estes filmes foram formados sobre os substratos de $\mathrm{Si}(100)$ mantidos em $90^{\circ} \mathrm{C}$ usando um alvo de grafite (99,9999\% de pureza) em descargas de $\mathrm{N}_{2}$ e Ar. Uma série de deposição foi feita com a potência de descarga de $350 \mathrm{~W}$ na posição do alvo, variando o fluxo relativo de $\mathrm{N}_{2}$ gasoso em relação ao de Ar gasoso, FR, de 50, 60, 70, 80, 90 e 100\%, e a pressão de trabalho na câmara de deposição foi de 0,4 Pa.

A Fig. 4.25 mostra os parâmetros Raman obtidos para estes filmes: a posição do pico $G$, a largura do pico $G(\Gamma)$ e a razão $I_{D} / I_{G}$, em função de $F$. Esta figura mostra que a posição do pico $\mathrm{G}$ está na faixa de $1553-1566 \mathrm{~cm}^{-1}$ e a razão $\mathrm{I}_{D} / \mathrm{I}_{G}$, em $0,53-0,88$; portanto, todos os filmes se encontram no estágio 2 do modelo proposto por Ferrari et al. [13]. Observa-se nesta figura que os parâmetros obtidos para o filme formado com FR = $80 \%$ são bem distintos dos parâmetros para os outros filmes. Como se viu na seção 4.4.1, conclui-se que: a diminuição da posição do pico $\mathrm{G}$, a da razão $\mathrm{I}_{D} / \mathrm{I}_{G}$ e o aumento da $\Gamma$ em FR $=80 \%$ indicam promoção da desordem topológica em camadas grafíticas; isto sugere a formação de enrugamento da camada induzido pela incorporação de N, cuja concentração é superior à concentração de transição da fase característica de grafite à de fulereno, apesar de a temperatura de deposição de $90^{\circ} \mathrm{C}$ deste estudo ser inferior à temperatura da transição de fase em $150^{\circ} \mathrm{C}$ observada por Hellgren et al. [16].

Geralmente, os espectros de N 1s, que são mais sensíveis a mudanças estruturais nos filmes do que os espectros de C 1s, estão sendo deconvoluídos em três ou quatro 

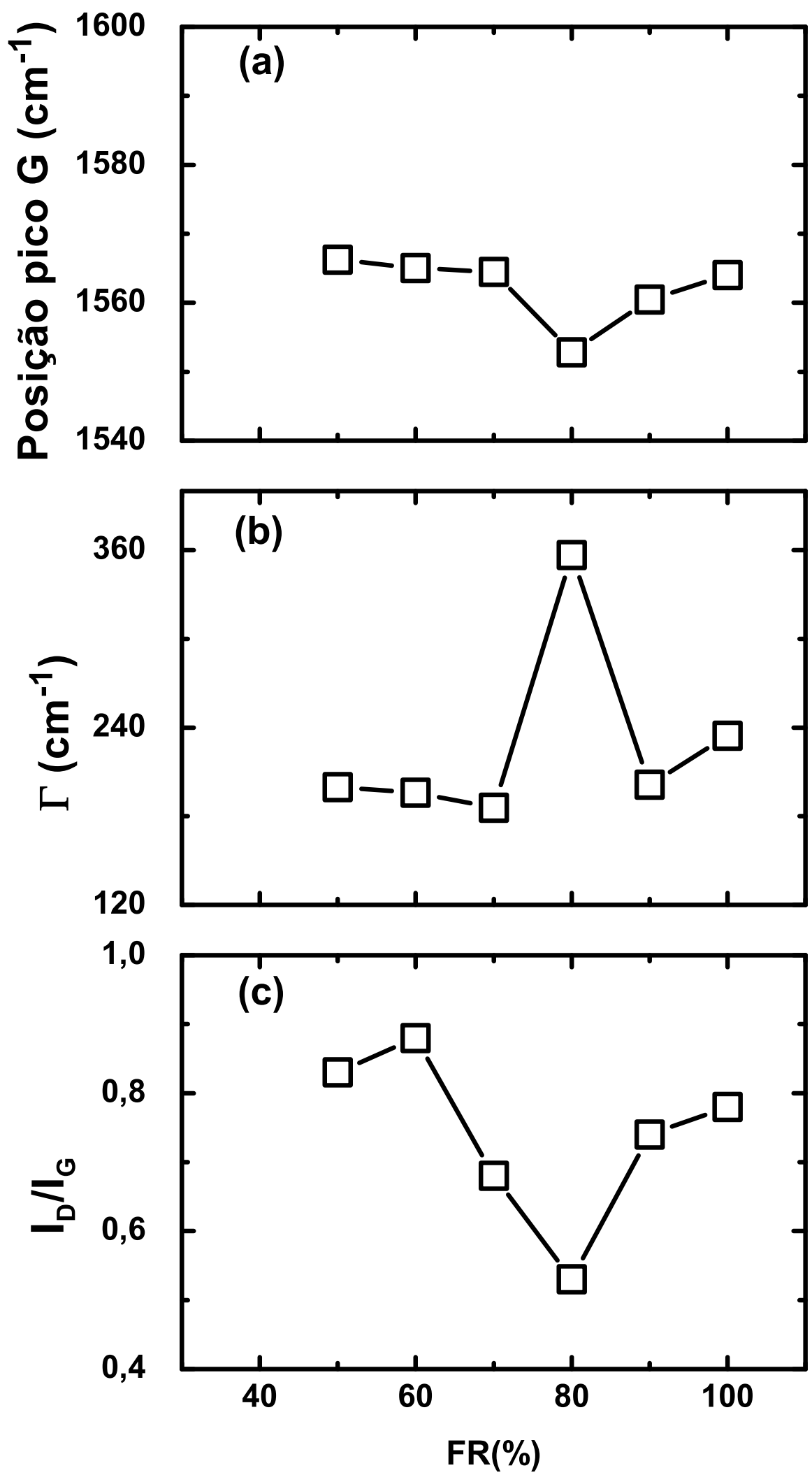

Figura 4.25: Parâmetros Raman: (a) posição do pico $G$, (b) $\Gamma$ e (c) $I_{D} / I_{G}$ em função de $F R$. 
picos baseados em moléculas orgânicas e polímeros de energias de ligações bem conhecidas. Muitos autores usaram três picos nas regiões de 398,0-398,6 (N1), 400,0-400,7 (N2) [16, 37, 83, 91] e em aproximadamente $402 \mathrm{eV}$ (N3). O consenso da identificação dos picos é que o pico N3 é atribuído a ligações entre $\mathrm{N}$ e $\mathrm{O}, \mathrm{N}$ e $\mathrm{N}$, ou N e C $[16,83]$.

A maioria de autores atribuiu os picos situados abaixo de $400 \mathrm{eV}(\mathrm{N} 1)$ e os picos acima de $400 \mathrm{eV}(\mathrm{N} 2)$, respectivamente, à ligação $\mathrm{N}-\mathrm{C}\left(s p^{3}\right)$ na estrutura de $\beta-\mathrm{C}_{3} \mathrm{~N}_{4}$ e à ligação $\mathrm{N}-\mathrm{C}\left(s p^{2}\right)$, com base nos valores de energia de ligação para urotropina $\left[\mathrm{N}-\mathrm{C}\left(s p^{3}\right)\right] \mathrm{em}$ 399,4 eV e piridina [N-C( $\left.\left.s p^{2}\right)\right]$ em 399,8 eV [92, 93]. Porém, este esquema de identificação não está aceito completamente por alguns autores. Por exemplo, Ronning et al. [37] e Kohzaki et al. [83] associaram os picos $\mathrm{N} 1$ e $\mathrm{N} 2$, respectivamente, a $\mathrm{N}-\mathrm{C}\left(s p^{2}\right)$ e $\mathrm{N}-\mathrm{C}\left(s p^{3}\right)$, enquanto que Ripalda et al. atribuíram os picos $\mathrm{N} 1$ e $\mathrm{N} 2$ a $\mathrm{N}\left(s p^{2}\right)-\mathrm{C}\left(s p^{2}\right)$ nas bordas da camada grafítica e N substituinte na estrutura grafítica, respectivamente [94].

A interpretação dos espectros de C 1s é mais controverso e não definitivo até o momento. Os espectros são geralmente analisados em termos de quatro contribuições na região de 284,2-284,6 (C1), 285,6-286,4 (C2), 287,0-287,9 (C3), 288,2-290,0 eV (C4) $[37,92,93]$. O primeiro e último picos estão atribuídos às ligações da grafite e CO, respectivamente [92, 93]. Muitos pesquisadores atribuíram os picos C2 e C3 às ligações de $\mathrm{C}\left(s p^{2}\right)-\mathrm{N}$ e $\mathrm{C}\left(s p^{3}\right)-\mathrm{N}$ na estruturas de $\beta-\mathrm{C}_{3} \mathrm{~N}_{4}$, respectivamente, referindo-se aos valores de piridina $(285,5 \mathrm{eV})$ e urotropina $(286,9 \mathrm{eV})[92,93]$. Entretanto, este esquema não tem apoio por Ronning et al. [37]. Considerando quatro picos cujas energias de ligação de 284,7, 285,6, 286,8 e 288,1 eV , estes autores sugeriram a seguinte relação: o pico em 284,7 eV é associado a átomos de $\mathrm{C}$ no ambiente de $\mathrm{C}$ puro; o pico de $285,6 \mathrm{eV}$, a $\mathrm{C}\left(s p^{3}\right)$ ligado a um átomo de $\mathrm{N}$; o pico de $286,8 \mathrm{eV}$, a $\mathrm{C}\left(s p^{3}\right)$ ligado a dois átomos de $\mathrm{N}$. Além disso, eles propuseram que o átomo de $\mathrm{C}\left(s p^{3}\right)$ na estrutura de $\beta-\mathrm{C}_{3} \mathrm{~N}_{4}$ deve estar em $288,1 \mathrm{eV}$ : 
porém este pico não foi observado nos espectros deles.
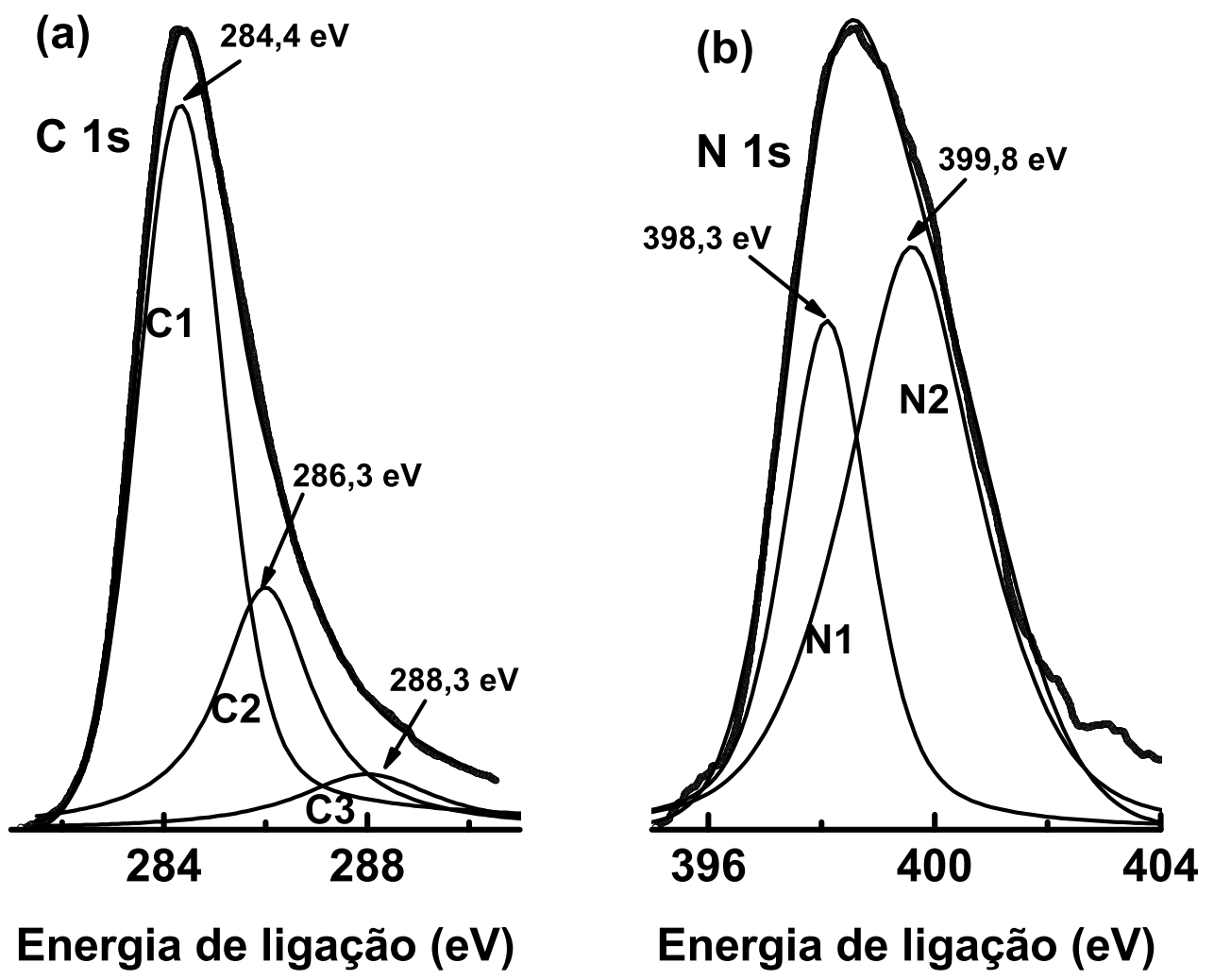

Figura 4.26: Espectros de XPS de C 1s (a) e $N$ 1s (b) para o filme depositado com o $F R=100 \%$.

A Fig. 4.26 apresenta dois espectros típicos de XPS de C 1s e $\mathrm{N}$ 1s para o filme formado com $\mathrm{FR}=100 \%$. Os espectros de $\mathrm{C}$ 1s e $\mathrm{N}$ 1s neste trabalho foram ajustados com a função Doniach-Šunjić [37], sendo considerados os dois picos principais N1 e N2 para os espectros de $\mathrm{N}$ 1s, e três picos principais $\mathrm{C} 1-\mathrm{C} 3$ para os espectros de C 1s. Os resultados da deconvolução são mostrados, também, na Fig. 4.26 e os valores dos parâmetros de ajuste, na tabela 4.2.

A composição química do filme, $\mathrm{C}(\mathrm{N} / \mathrm{C})$, foi estimada pela razão $\mathrm{A}(\mathrm{C}) / \mathrm{A}(\mathrm{N})$, onde $\mathrm{A}(\mathrm{C})$ e $\mathrm{A}(\mathrm{N})$ são as áreas sobre os respectivos espectros de C 1s e N 1s, depois da correção com os fatores de sensibilidade relativos, devido à transmissão de analisador e seção de 
Tabela 4.2: Os valores das energias de ligação para os picos deconvoluídos.

\begin{tabular}{lcc}
\hline \hline Espectros & Picos & $\begin{array}{c}\text { Posição do pico } \\
(\mathrm{eV})\end{array}$ \\
\hline C 1s & $\mathrm{C} 1$ & $284,4 \pm 0,2$ \\
& $\mathrm{C} 2$ & $286,3 \pm 0,2$ \\
& $\mathrm{C} 3$ & $288,3 \pm 0,3$ \\
\hline N 1s & $\mathrm{N} 1$ & $398,3 \pm 0,1$ \\
& $\mathrm{~N} 2$ & $399,8 \pm 0,1$ \\
\hline \hline
\end{tabular}

choque de fotoionização. A Fig. 4.27(a) apresenta a C(N/C) em função de FR. O valor máximo de $\mathrm{C}(\mathrm{N} / \mathrm{C})$, igual a 0,37 que corresponde a $27 \%$ atômica de $\mathrm{N}$, ocorre quando $\mathrm{FR}$ $=80 \%$; as concentrações de $\mathrm{N}$ nos outros filmes são de 19 a $21 \%$ atômica. Na mesma figura são indicadas a razão da área do pico $\mathrm{N} 2$ relativa à área do pico $\mathrm{N} 1$ no espectro de $\mathrm{N}$ 1s, $\mathrm{A}(\mathrm{N} 2) / \mathrm{A}(\mathrm{N} 1)$, e a razão da área do pico $\mathrm{C} 2$ relativa à área do pico $\mathrm{C} 3$ no espectro de $\mathrm{C}$ 1s, $\mathrm{A}(\mathrm{C} 2) / \mathrm{A}(\mathrm{C} 3)$. Observe-se que as duas razões mostram seus máximos em $\mathrm{FR}=80 \%$. Se atribuir os picos $\mathrm{N} 2$ e $\mathrm{C} 2$ às ligações de $\mathrm{C}\left(s p^{3}\right)-\mathrm{N}$ e os picos $\mathrm{N} 1$ e $\mathrm{C} 3$ às ligações de $\mathrm{C}\left(s p^{2}\right)-\mathrm{N}$ [37, 83], este fato significa que: os primeiros átomos de $\mathrm{N}$ situam-se substitucionalmente em sítios de camadas grafíticas de $\mathrm{C}\left(s p^{2}\right)$; quando mais $\mathrm{N}$ for incorporado no filme, o $\mathrm{N}$ ligar-se-á com o $\mathrm{C}\left(s p^{3}\right)$, como mencionado na seção 4.4.1. Este fenômeno foi observado por Hellgren et al. [16] e Souto et al. [91]. Os resultados de Raman indicam a desordem incrementada em FR $=80 \%$, acompanhada pelo aumento da dureza medida com o método Knoop [Fig. 4.27(b)]. 


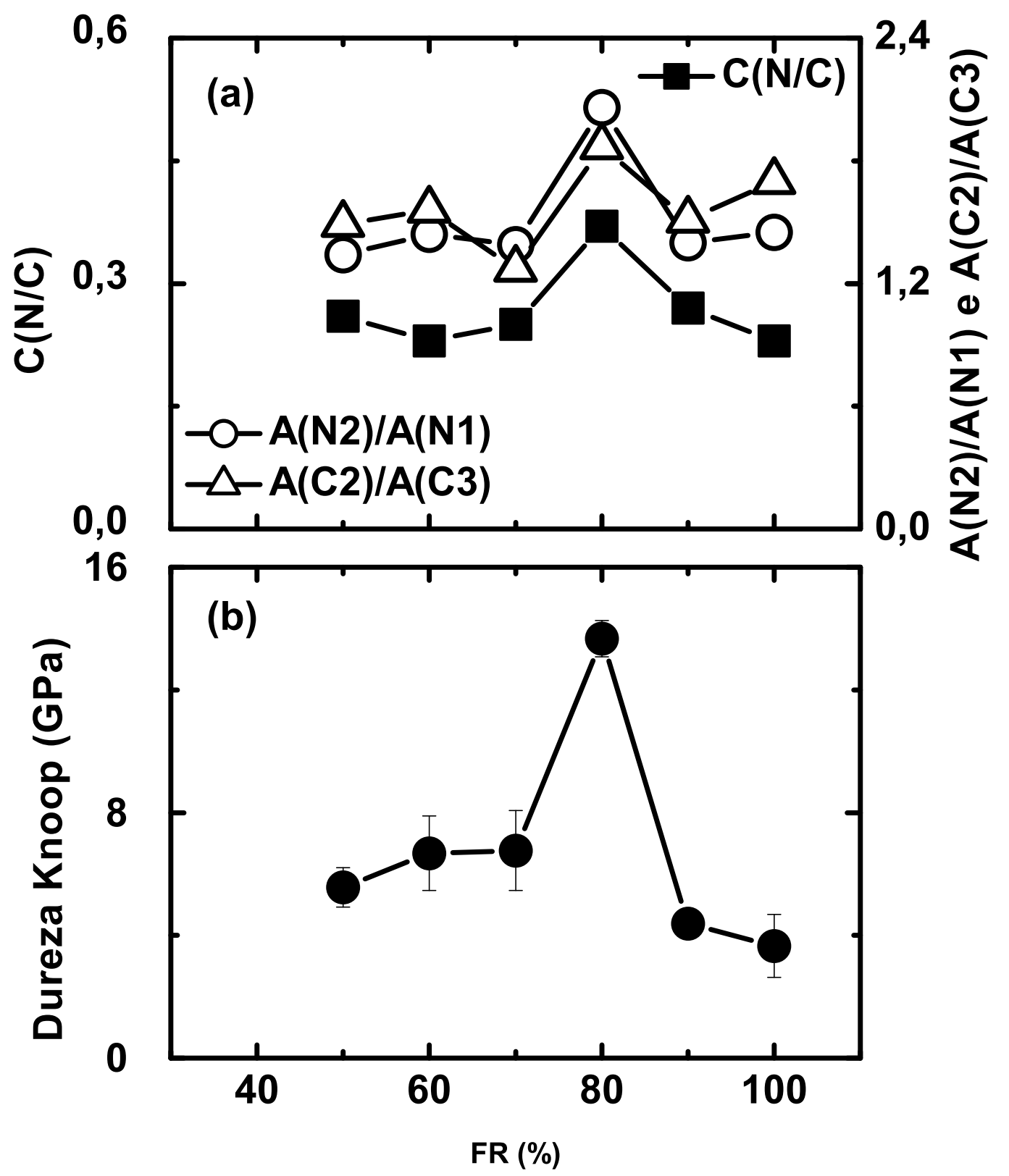

Figura 4.27: (a) $C(N / C)$ e as razões das áreas dos picos $A(N 2) / A(N 1)$ e $A(C 2) / A(C 3)$ e (b) dureza Knoop em função de $F R$. 


\section{Capítulo 5}

\section{Conclusões}

O presente trabalho é composto de: (a) formações dos filmes de $a$-C e de $\mathrm{CN}_{x}$ sobre os substratos de Si usando o método IBAD, em termos de: energia de íons, razão de chegada $[\mathrm{R}(\mathrm{I} / \mathrm{A})]$ e temperatura de substrato; (b) estudos das propriedades dos filmes acima formados e do mecanismo envolvido no processo de deposição dos filmes. Foram utilizadas as seguintes técnicas de análise dos filmes: perfilometria, espectrocopia do IR, espectroscopia Raman, ERDA e XRD, e (c) analises dos filmes de $\mathrm{CN}_{x}$ previamente depositados com o método RF magnetron sputtering reativo usando as técnicas de caracterização de XPS, espectroscopia Raman e a dureza Knoop.

Era foco deste trabalho realizar medidas de XPS e de dureza Knoop para os filmes depositados com o método IBAD a fim de viabilizar a comparação destes resultados com os resultados previamente mencionados no item (c). Para isso, entrou-se em contato com vários laboratórios para a realização das respectivas medidas. Infelizmente, não recebemos os resultados de XPS antes da redação da tese e, as mesmas não estão aqui descritas, pois, devido a dificuldades operacionais como, a dificuldade em medir-se a dureza para o filme com espessura menor que $71 \mathrm{~nm}$, os resultados e sua devida interpretação serão publicados 
posteriormente.

Os resultados obtidos foram os seguintes:

\subsection{Taxa de deposição}

A taxa de deposição, para os filmes depositados com o feixe de íons de Ar, é determinada pelo sputtering físico que é dependente da energia de íons, enquanto que a taxa de deposição para os filmes de $\mathrm{CN}_{x}$, depositados com o feixe de íons de nitrogênio ou com o feixe de íons derivado de $\mathrm{Ar}-\mathrm{N}_{2}$, é governado pelo sputtering químico. O sputtering químico por íons de nitrogênio é praticamente independente da energia de íons utilizada neste estudo (200-600 eV) e mais eficiente do que o sputtering físico nesta região de energia. Para o feixe de íons derivado de $A r-\mathrm{N}_{2}$, o rendimento do sputtering não é dado pela soma do sputtering físico por íons de Ar com o originado pelos íons de nitrogênio, mas por efeito multiplicativo. Isto é, íons de Ar incidentes rompem nas cascatas de colisões ligações de compostos e as rupturas de ligações resultando são instantaneamente passivadas por átomos de $\mathrm{N}$, produzindo mais compostos voláteis difundidos e liberados através da superfície do filme. Neste caso o rendimento do sputtering químico é dependente da energia de íons e de $\mathrm{R}(\mathrm{I} / \mathrm{A})$.

\subsection{Espectroscopia do IR}

As origens da banda larga de $900-1700 \mathrm{~cm}^{-1}$ e os picos em 1535 e $1590 \mathrm{~cm}^{-1}$ observados nos espectros do IR continuam sendo indefinidas, apesar de os espectros do IR terem sido analisados neste trabalho para os filmes de $a$ - $\mathrm{C}$ e de $\mathrm{CN}_{x}$. Quando se utilizou o feixe de íons derivado de $\mathrm{Ar}-\mathrm{N}_{2}$ na deposição de filme, observaram-se a redução 
nas intensidades dos sinais relacionados com $\mathrm{H}$ e $\mathrm{O}$, e o aumento na intensidade do sinal associado à ligação de $\mathrm{C} \equiv \mathrm{N}$, no espectro do IR do filme, em conseqüência da depleção de $\mathrm{H}$ e $\mathrm{O}$ por íons de Ar incidentes que favorece a formação da ligação de $\mathrm{C} \equiv \mathrm{N}$.

\subsection{Espectroscopia Raman}

Os espectros Raman medidos para todos os filmes obtidos neste trabalho foram analisados em termos de: posição do pico $G$, largura do pico $G(\Gamma)$ e razão $I_{D} / I_{G}$. Os comportamentos destes parâmetros Raman obtidos em função de R(I/A) foram explicados razoalvelmente através do modelo de três estágios, sugerido por Ferrari et al., e da sugestão sobre a transição da fase característica da grafite à de fulereno, na qual a incorporação de $\mathrm{N}$ em camadas grafíticas promove a formação de anéis pentagonais que podem induzir o enrugamento em camadas, facilitando ligações entre as camadas através de átomos de C hibridizados de $s p^{3}$. A occorrência desta transição depende fortemente da concentração de $\mathrm{N}$ no filme.

Foram analisados, para comparação, os espectros Raman e de XPS de N 1s e de $\mathrm{C}$ 1s para os filmes de $\mathrm{CN}_{x}$ depositados previamente com o método $\mathrm{RF}$ magnetron sputtering reativo. Os espectros XPS de $\mathrm{N}$ 1s foram deconvoluídos em dois picos, N1 e N2, respectivamente, em 398,3 e 399,8 eV, e os espectros de XPS de C 1s, em três picos, C1-C3, em 284,4, 286,3 e 288,3 eV, respectivamente. Atribuindo-se os picos N2 e C2 às ligações de $\mathrm{C}\left(s p^{2}\right)-\mathrm{N}$ e os picos $\mathrm{N} 1$ e $\mathrm{C} 3$ às ligações de $\mathrm{C}\left(s p^{3}\right)-\mathrm{N}$, os comportamentos dos três parâmetros Raman foram explicados consistentemente, levando-se em consideração a concentração de N nos filmes. 


\subsection{Difração de raios X}

Observou-se uma possibilidade da existência do SWNT nos difratogramas de raios-

X para os filmes que indicaram, nas análises dos comportamentos dos três parâmetros Raman, a transição da fase característica da grafite à de fulereno.

Finalizando este capítulo, sugere-se a realização de:

- Complementar os resultados dos parâmetros Raman na região de $\mathrm{R}(\mathrm{I} / \mathrm{A})<1$, formando filmes de $\mathrm{CN}_{x}$ nesta região de $\mathrm{R}(\mathrm{I} / \mathrm{A})$ e medindo seus espectros Raman;

- medir os filmes depositados neste trabalho com a técnica de microscópia eletrônica de transmissão (Transmission Electron Microscopy TEM) para observar o SWNT e com a técnica de XPS para concretizar a idéia da atribuição dos picos observados nos espectros de XPS de N 1s e de C 1s. 


\section{Bibliografia}

[1] E. Vainonen; Hidrogen migration in diamond-like carbon film; J. Appl. Phys. 82 (1997) $3791-3796$.

[2] D.Y. Lee, Y.H. Kim; The effects of substrates on carbon nitride thin films prepared by direct dual ion beam deposition; Thin Solid Films 355-356 (1999) 239-245.

[3] J. Kikuma, K. Yoneyama; Surface analysis of CVD carbon using NEXAFS, XPS and TEM; J. Elect. Spectrosc. 88-91 (1998) 919-925.

[4] T. Malkow; Critical observations in the research of carbon nitride; Mater. Sci. Eng. A 292 (2000) 112-124.

[5] A.Y. Liu and M.L. Cohen; Structural properties and electronic structure of lowcompressibility materials: $\beta-\mathrm{Si}_{3} \mathrm{~N}_{4}$ and hypothetical $\beta-\mathrm{C}_{3} \mathrm{~N}_{4}$; Phys. Rev. B 41 (1990) 1072710734 .

[6] A.Y. Liu, R.M. Wentzcovitch; Stability of carbon nitride solids; Phys. Rev. B 50 (1994) 10362-10365.

[7] D.M. Teter and R.J. Hemley; Low-Compressibility Carbon Nitride; Sci. 271 (1996) 53-55.

[8] M.L. Cohen; Calculation of bulk moduli of diamond and zinc-blende solids; Phys. Rev. B 32 (1985) 7988-7991.

[9] S. Fahy and S.G. Louie; High-pressure structural and electronic properties of carbon; Phys. Rev. B 36 (1987) 3373-3385.

[10] S. Muhl, J.M. Méndez; A review of the preparation of carbon nitride films; Diam. Rel. Mater. 8 (1999) 1809-1830.

[11] J. J. Sakurai; Modern Quantum Mechanics; Addison-Wesley, Los Angeles, (1994), p. 350.

[12] R. Saito; Physical Properties of Carbon Nanotubes; Imperial College Press, (1998).

[13] A. C. Ferrari, S. E. Rodil e J. Robertson; Interpretation of infrared and Raman spectra of amorphous carbon nitrides; Phys. Rev. B 67 (2003) 155306-1-155306-20.

[14] J. Robertson; A.C. Davis; Nitrogen doping of tetrahedral amorphous carbon; Diamond Relat. Mater. 4 (1995) 441-444.

[15] D. Roy; M. Chhowalla; N. Hellgren; T.W. Clyne; G.A.J. Amaratunga; Probing carbon nanoparticles in $C N_{x}$ thin films using Raman spectroscopy; Phy. Rev. B 70 (2004) 035406-1-5. 
[16] N. Hellgren; M. P. Johansson; E. Broitman; L. Hultman; J.E. Sundgren; Role of nitrogen in the formation of hard and elastic $C N_{x}$ thin films by reactive magnetron sputtering; Phys. Rev. B 59 (1999) 5162-5168.

[17] H. Sjöström; S. Stafström; M. Boman; J.E. Sundgren; Superhard and Elastic Carbon Nitride Thin Films Having Fullerenelike Microstructure; Phys. Rev. Lett. 75 (1995) 1336-1339.

[18] S. Matsumoto, E.Q. Xie; On the validity of the formation of crystalline carbon nitride, $C_{3} N_{4}$; Diamond Rel. Mater. 8 (1999) 1175-1182.

[19] W. Dawei; F. Dejun; G. Huaixi; Z. Zhihong; M. Xianquan; F. Xiangjun; Structure and characteristics of $C_{3} N_{4}$ thin films prepared by rf plasma-enhanced chemical vapor deposition; Phys. Rev. B 56 (1997) 4949-4954.

[20] W.C. Chan, M.K. Fung; Nitrogenated amorphous carbon films synthesized by electron cyclotron resonance plasma enhanced chemical vapor deposition; Diam. Rel. Mater. 8 (1999) 1732-1736.

[21] Z. Zhang, H. Guo, G. Zhong, F. Yu, Q. Xiong, X. Fan; Formation of cubic $C_{3} N_{4}$ thin films by plasma enhanced chemical vapor deposition; Thin Solid Films 346 (1999) 96-99.

[22] H.K. Jang; G. Kim; Y.S. Lee; S.W. Whangbo; C.N. Whang; Hydrogenated amorphous carbon nitride films on Si(100) deposited by direct current saddle-field plasma-enhances chemical vapor deposition; J. Vac. Sci. Technol. A 17 (1999) 2607-2611.

[23] R. Gago; J. Neidhardt; M. Vinnichenko; U. kreissig; Zs. Czigány; A. Kolitsch; L. Hultman; W. Möller; Synthesis of carbon nitride thin films by low-energy ion beam assisted evaporation: on the mechanisms for fullerene-like microstructure formation; Thin Solid Films 483 (2005) 89-94.

[24] S. Muhl, A.G. Couto; Production and characterisation of carbon nitride thin films produced by a graphite hollow cathode system; Thin Solid Films 308-309 (1997) 228-232.

[25] X.C. Wang; P. Wu; Z.Q. Li; E.Y. Jiang; H.L. Bai; Microstructure of amorphous carbon nitride films fabricated by facing-target reactive magnetron sputtering; J. Phys. D 37 (2004) 2127-2134.

[26] K.M. Yu, M.L. Cohen; Observation of crystalline $C_{3} N_{4}$; Phys. Rev. B 49 (1994) 5034-5037.

[27] R.A. Castro; Caracterização de filmes finos de nitreto de carbono produzidos por RF magnetron sputtering reativo; defensa de mestrado, IFUSP, 2002.

[28] T.R. Lu, C.T. Kuo; Preparation of a novel target material for carbon nitride film deposition; Thin Solid Films 308-309 (1997) 126-129.

[29] Y. Aoi; K. Ono; E. Kamijo; Preparation of amorphous $C N_{x}$ thin films by pulsed laser deposition using a radio frequency radical beam source; J. Appl. Phys. 86 (1999) 2318-2322.

[30] A.A. Veovodin; J.G. Jones; J.S. Zabinski; Zs. Czigány; L. Hultman; Growth and structure of fullerene-like $C N_{x}$ thin films produced by pulsed laser ablation of graphite in nitrogen; J. Appl. Phys. 92 (2002) 4980-4985.

[31] C. Niu; Y.Z. Lu; C.M. Lieber; Experimental realization of the covalent solid carbon nitride; Science, 261, (1993) 334-337. 
[32] J.F.D. Chubaci, K. Ogata; Formation of carbon nitride - a novel hard coating; Nucl. Instr. and Math. B 116 (1996) 452-456.

[33] J.F.D. Chubaci; Formação e caracterização de filmes de finos de nitreto de carbono; Dissertação (Doutorado) IFUSP, (1996).

[34] H.W. Song, F.Z. Cui; Carbon nitride films synthesized by $\mathrm{NH}_{3}$-ion-beam-assisted deposition; J. Phys.: Condens. Matter 6 (1994) 6125-6129.

[35] X.W. Su, H.W. Song, F.Z. Cui, W.Z.Li, H.D. Li; Formation of $\beta-C_{3} N_{4}$ grains by nitrogenion-beam-assisted deposition; Surf. Coat. Techn. 84 (1996) 388-391.

[36] Y.H. Cheng et al; Deposition of carbon nitride films by filtered cathodic vacuum arc combined with radio frequency ion beam source; Diam. Rel. Mater. 9 (2000) 2010-2018.

[37] C. Ronning, H. Feldermann; Carbon nitride deposited using energetic species: A review on XPS studies; Phys. Rev. B 58 (1998) 2207-2215.

[38] W. Sucasaire; M. Matsuoka, K.C. Lopes; J.C. Mittani, L.H. Avanci; J.F.D. Chubci; N. Added; V. Trava; E.J. Corat; Raman and Infrared Spectroscopy Studies of Carbon Nitride Films Preparation on Si(100) Substrates by Ion Beam Assisted Deposition; J. Braz. Chem. Soc. 17 (2006) 1163-1169.

[39] H.R. Kaufman, R.S. Robinson; Operation of Broad-Beam Sources; Commonwealth Scientific Corp, Alexandria, VA (1984).

[40] N. Added; J.F.D. Chubaci; M. Matsuoka; R.A. Castro; M. Radtke; E. Alonso; R. Liguori Neto; M.A. Rizzuto, M. Tabacniks; R.D. Mansano; Light element analysis using ERDA method with an ionization chamber; Nucl. Instr. and Meth. B 175-177 (2001) 787-790.

[41] P.K. Chu; L. Li; Characterization of amorphous and nanocrystalline carbon films; Mater.Chem. Phys. 96 (2006) 253-277.

[42] B. Kleinsorge; A.C. Ferrari; J. Robertson; W.I. Milne; Influence of nitrogen and temperature in the deposition of tetrahedrally bonded amorphous carbon; J. Appl. Phys. 88 (2000) 11491157.

[43] S.E. Rodil; A.C. Ferrari; J. Robertson; W.I. Milne; Raman and Infrared modes of hydrogenated amorphous carbon nitride; J. Appl. Phys. 89 (2001) 5425-5430.

[44] A. C. Ferrari, e J. Robertson; Interpretation of Raman spectra of disordered and amorphous carbon; Phys. Rev. B 61 (2000) 14095-14107.

[45] G. Abrasonis; R. Gago; M. Vinnichenko; U. Kreissig, A. Kolitsh; W. Möller; Sixfold ring clustering in $s p^{2}$-dominated carbon and carbon nitride thin films: A Raman spectroscopy study; Phy. Rev. 73 (2006) 125427-1-125427-13.

[46] N.M. Victoria; P. Hammer; M.C. dos Santos; F. Alvarez; Vibrational analysis of amorphous carbon-nitrogen alloys by ${ }^{1} 5 N$ and D isotopic substitution; Phys. Rev. B 61 (2000) 1083-1087.

[47] J.H. Kaufman; S. Metin; Symmetry breaking in nitrogen-doped amorphous carbon: Infrared observation of the Raman-active $G$ and D bands; Phys. Rev. B 39 (1989) 13053-13059.

[48] O. Sala; Fundamentos da espectroscopia Raman e no infravermelho; Unesp, São Paulo, (1995). 
[49] E.B. Wilson Jr.; J.C. Decius; P.C. Cross; Molecular Vibrations, The Theory of Infrared and Raman Vibrational Spectra; Dover Publications, Inc.: New York, (1980) pp 34.

[50] J. Robertson; Diamond-like amorphous carbon; Mater. Sci. Eng. R 37 (2002) 129-281.

[51] F. Tuinstra; J.L. Koenig; Raman Spectrum of Graphite; J. Chem. Phys. 53 (1970) 1126-1130.

[52] M.Y. Chen; D. Li; X. Lin; V.P. Dravid; Y.W. Chung; Analytical electron microscopy and Raman Spectroscopy studies of carbon nitride thin films; J. Vac. Sci. Technol. A 11 (1993) 521-524.

[53] J.M. Rubio; Espectroscopia infrarroja; Programa Regiomal de Desarrollo Científico y Tecnológico - OEA; Washinton, D.C. (1974).

[54] B. Dischler; A. Bubenzer; P. Koidl; Bonding in hydrogenated hard carbon studied by optical spectroscopy; Solid State Commun. 48 (1983) 105-108.

[55] R. McCann; S.S. Roy; P. Papakonstantinou; J.A. McLaughlin; Spectroscopic analysis of a-C and $a-C N_{x}$ films prepared by ultrafast high repetition rate pulsed laser deposition; J. Appl. Phys. 97 (2005) 073522-1-11.

[56] P. P. Nascente; Caracterização de Materiais por Técnicas de Análise de Superfícies; Departamento de Engenharia de Materiais - UFSC (1999).

[57] M. Ohring; The Materials Science of Thin Film; Academic Press, Inc., New York (1992).

[58] R. Gago; I. Jiménez; D. Cáceres; F. Agulló-Rueda; T. Sajavaara; J.M. Albella; A. ClimentFont; I. Vergara; J. Räisänen; E. Rauhala; Hardning mechanisms in graphitic carbon nitride films grown with $N_{2} /$ Ar ion assistance; Chem. Mater. 13 (2001) 129-135.

[59] http://www.srim.org/

[60] P. Hammer; M.A. Baker; C. Lenardi; W. Gissler; Ion beam deposited carbon nitride films: characterization and identification of chemical sputtering; Thin Solid Films 290-291 (1996) 107-111.

[61] P. Hammer; W. Gissel; Chemical sputtering of carbon films by low energy $N_{2}^{+}$ion bombardment; Diamond Relat. Mater. 5 (1996) 1152-1158.

[62] D Van Vechten, GK Hubler e EP Donovan; Characterization of a $3 \mathrm{~cm}$ Kaufman ion source with nitrogen feed gas Vacuum 36 11/12 841-845 1986.

[63] F. A. Smidt; Use of ion beam assisted deposition to modify the microstructure and properties of thin films.; International Mater. Rev. 35 (1990) 59-128.

[64] W. Jacob; C. Hopf; M. Schlüter; Chemical sputtering of carbon by nitrogen ions; Appl. Phys. Lett. 86 (2005) 204103-1-204103-2.

[65] C. Hopf; A. von Keudell; W. Jacobb; Chemical sputtering of hydrocarbon films; J. Appl. Phys. 94 (2003) 2373-2380.

[66] F. Alvarez; N.M. Victoria; P. Hammer; F.L. Freire, Jr; M.C. dos Santos; Infrared analysis of deuterated carbon-nitrogen films obtained by dual-ion-beam-assisted-deposition; Appl. Phys. Lett. 73 (1998) 1065-1067. 
[67] C. Popov; M.F. Plass; A. Bergmaier; W. Kulisch; synthesis of carbon nitride films by lowpower inductively coupled plasma-activated transport reactions from a solid carbon source; Appl. Phys. A69 (1999) 241-244.

[68] Wikipedia.org. S.v. "Delocalized electron" Retrieved March $12 \quad 2007$ from http://encyclopedia.thefreedictionary.com/Delocalized+electron

[69] N. Nakayama; Y. Tsuchiya; S. Tamada; K. Kosuge; Structural Properties of amorphous carbon nitride films prepared by reative RF-magnetron sputtering; Jpn. J. Appl. Phys. 32 (1993) L1465-L1468.

[70] F. Weich; J. Widany; Th. Frauenheim; Paracyanogen-like structures in high-density amorphous carbon nitride; carbon 37 (1999) 545-548.

[71] J.J. Cuomo; P.A. Leary; D. Yu; W. Reuter; M. Frish; Reactive sputtering of carbon and carbide targets in nitrogens; J. Vac. Sci. Technol. A 16 (1979) 299-302.

[72] Y.M. Ng; C.W. Ong; X.A. Zhao; C.L. Choy; Polymerization of dual ion beam deposited $C N_{x}$ films with increasing $N$ content; J. Vac. Sci. Technol. A 17 (1999) 584-591.

[73] P. Hammer; M.A. Baker; C. Lenardi; W. Gissler; Synthesis of carbon nitride films at low temperatures; J. Vac. Sci. Technol. A15 (1997) 107-112.

[74] Y. Taki; T. Kitagawa; O. Takai; Shielded arc ion plating and structural characterization of amorphous carbon nitride thin films; Thin Solid Films 304 (1997) 183-190.

[75] J. Pereira; I. Géraud-Grenier; V. Massereau-Guilbaud; A. Plain; V. Fernandez; Characterization of a-CN $\mathrm{N}_{x} \mathrm{H}$ particles and coatings prepared in a $\mathrm{CH}_{4} / \mathrm{N}_{2}$ r.f. plasma; Surf. Coat. Technol. 200 (2006) 6414-6419.

[76] A. Champi; F.C. Marques; Structural changes in amorphous carbon nitride films due to bias voltage; Thin Solid Films 501 (2006) 362-365.

[77] H. Nakazawa; T. Mikami; Y. Enta; M. Suemitsu, M. Mashita; Structure chemical bonding and these thermal stabilities of diamond-like carbon (DLC) films by RF magnetron sputtering; Jpn. J. Appl. Phys. 42 (2003) L676-L679.

[78] V.D. Blank; S.G. Buga; N.R. Serebryanaya; V.N. Denisov; Ultrahard and superhard carbon phases produced from $C_{60}$ by heating at high pressure: structural and Raman studies; Phys. Lett. A 205 (1995) 208-216.

[79] A.S. Claye; J.E. Fischer; C.B. Huffman; A.G. Rinzler; R.E. Smalley; Solid-State Electrochemistry of the Li Single Wall Carbon Nanotube System; J. Electrochem. Soc. 147 (2000) $2845-2852$.

[80] S. Kawasaki; K. Komatsu; F. Okino; H. Touhara; H. Kataura; Fluorination of open- and closed-end single-walled carbon nanotubes; Phys. Chem. Chem. Phys. 6 (2004) 1769-1772.

[81] J.H. Rhee; D. Singh; Y. Li; S.C. Sharma; Crystal structure of $C_{60}$ following compresion under 31,1 GPa in diamond anvil cell at room temperature; Solid State Commun. 127 (2003) 295297.

[82] M.C. Santos; F. Alvarez; Nitrogen substitution of carbon in graphite: Structure evolution toward molecular forms; Phys. Rev. B 58 (1998) 13918-13924. 
[83] M. Kohzaki; A. Matsumuro; T. Hayashi; M. Muramatsu; K. Yamaguchi; Preparation of carbon nitride thin films by ion beam assisted deposition and their mechanical properties; Thin Solid Films 308-309 (1997) 239-244.

[84] W. Hu; N. Xu; Y.Q. Sheng; T.W. Zhang; J. Sun; J.D. Wu; Z.F. Ying; Synthesis of nanocrystalline carbon nitride films by glow discharge plasma beam deposition; Mater. Sci. Eng. A 432 (2006) 142-148.

[85] K.L. Narayanan; N. Kojima; K. Yamaguchi; N. Ishikawa; W. Yamaguchi; Arsenic ion implantation induced structural affects in $C_{60}$ films; J. Mater. Sci. 34 (1999) 5227-5231.

[86] B.M. Ginzburg; Sh. Tuichiev; S.Kh. Tabarov; A.A. Shepelevskii; L.A. Shibaev; X-ray diffraction analysis of $C_{60}$ fullerene powder and fullerene soot; Tech. Phys. 50 (2005) 1458-1461.

[87] A.L.D. Skury; G.S. Bobrovnitchii, S.N. Monteiro; Effect of the graphite perfection on the $\mathrm{HP}-\mathrm{HT}$ diamond synthesis in a Ni-Mn-C system; Diamond Relat. Mater. 13 (2004) 17251730.

[88] S. Endo; N. Idani; R. Oshima; K.J. Takano; M. Wakatsuki; X-ray diffraction and transmission-electron microscopy of natural polycrystalline grafite recovered from high pressure; Phys. Rev. B 49 (1994) 22-27.

[89] X. Yan; T. Xu; G. Chen; S. Yang; H. Liu; Preparation and characterization of electrochemically deposited carbon nitride films on silicon substrate; J. Phys. D 37 (2004) 907-913.

[90] T.M. Keller; S.B. Qadri; C.A. Little; Carbon nanotube formation in situ during carbonization in shaped bulk solid cobalt nanoparticle compositions; J. Mater. Chem. 14 (2004) 3063-3070.

[91] S. Souto; M. Pickholz, M.C. dos Santos; F. Alvarez; Electronic structure of nitride-carbon alloys $\left(a-C N_{x}\right)$ determined by photoelectron spectroscopy; Phys. Rev. B 57 (1998) 2536-2540.

[92] D. Marton; K.J. Boyd; A.H. Al-Bayati; S.S. Todorov; J.W. Rabalais; Carbon nitride deposited using energetic species: a two-phase system; Phys. Rev. Lett. 73 (1994) 118-121.

[93] Z. Wu; Y. Yu; X. Liu; Characteristics of carbon nitride films synthesized by single-source ion beam enhanced deposition system; Appl. Phys. Lett. 68 (1996) 1291-1293.

[94] J. M. Ripalda; E. Román; N. Díaz; L. Galán; I. Montero; G. Comelli; A. Baraldi; S. Lizzit; A. Goldoni; G. Paolucci; Correlation of $x$-ray absorption and $x$-ray photoemission spectroscopies in amorphous carbon nitride; J. Phys.Rev. B 60 (1999) R3705-R3708.

[95] W. Hwanga; Y.K. Kim; M. E. Rudd; New model for electron-impact ionization cross sections of molecules; J. Chem. Phys. 104 (1996) 2956-2966.

[96] R. Rejoub; B.G. Lindsay; R.F. Stebbings; Determination of the absolute partial and total cross sections for electron-impact ionization of the rare gases; PHys. Rev. A65 (2002) 0427131-042713-8.

[97] H.C. Straub; P. Renault; B.G. Lindsay; K.A. Smith; R.F. Stebbings; Absolute partial cross sections for electron-impact ionization of $\mathrm{H}_{2}, \mathrm{~N}_{2}$, and $\mathrm{O}_{2}$ from threshold to $1000 \mathrm{eV}$; PHys. Rev. A54 (1996) 2146-2153.

[98] Brown, S.C.; Basic Data of Plasma Physics, 1966, MIT Press, Cambrige, MA, 1967, p. 67. 


\section{Apêndice A}

\section{Razão da Taxa de Chegada, R(I/A)}

\section{A.1 Cálculo de fluxo de íons de nitrogênio, I}

Os parâmetros de deposição fundamentais e importantes no método IBAD são a energia de íons e a $\mathrm{R}(\mathrm{I} / \mathrm{A})$. Para os filmes de $\mathrm{CN}_{x}$ depositados com o feixe de íons derivado de $A r-\mathrm{N}_{2}$ (o fluxo de gases total foi de 3,10 sccm; o fluxo relativo de argônio foi de $10 \%$ do fluxo total), a corrente do feixe de íons de nitrogênio foi considerado $90 \%$ de $\mathrm{I}_{T}$, devido ao fato de que o valor da seção de choque de ionização por colisão eletrônica para o gás de $\mathrm{N}_{2}$ e bem similar ao para o gás de $\operatorname{Ar}$ [95-97].

O cálculo de $\mathrm{R}(\mathrm{I} / \mathrm{A})$ baseia-se na corrente de íons de nitrogênio incidentes ao substrato e a taxa de deposição de carbono. Como o analisador de massa não está disponível na câmara de vácuo, a distribuição dos estados de cargas referentes aos íons de nitrogênio foi considerada de $11 \%$ de $\mathrm{N}^{+}$e $89 \%$ de $\mathrm{N}_{2}^{+}$na base dos dados publicados [58,62, 63]. Uma parte de íons é esperada sofrer colisões da transferência de cargas com o gás de nitrogênio ao longo da trajetória do feixe de $41 \mathrm{~cm}$ a partir de saída da fonte de íons até o substrato, tornando-se partículas neutras mantendo sua energia inicial. Conseqüentemente, é necessário corrigir a corrente de íons, que passa pelo copo de Faraday, medida com o 
amperímetro, usando a seguinte equação [98]:

$$
i=i_{0} e^{-p_{0} P_{c}(v) x}
$$

onde $i$ e $i_{0}$ são a corrente final e a corrente inicial, respectivamente; $p_{0}=273 p / T$ é a pressão reduzida; $P_{c}(v)$ é a probabilidade de colisão dependendo da velocidade de íons $v$, e $x$, a distância recorrida dos íons.

A concentração de moléculas de gás por $\mathrm{cm}^{3}$ é dada por $\frac{N}{V}=3,53 \times 10^{16} p_{0}$. A $P_{c}(v)$ é também chamada de seção de colisão efetiva $\mathrm{Q}_{c}$. A seção de colisão efetiva para um íon $q$ é encontrada dividindo $\mathrm{Q}_{c}$ pelo número de moléculas por $\mathrm{cm}^{3}$ em $0^{\circ} \mathrm{C}$ e 1 Torr de pressão.

$$
q=\frac{Q_{c}}{N / V}
$$

Substituindo a equação (A.2) na equação (A.1), a corrente de íons é dada por:

$$
i=i_{0} \exp \left(-3,53 \times 10^{16} p_{0} q x\right)
$$

A leitura da corrente do feixe de íons, $I_{T}$, que passa pelo copo de Faraday de 2" de diâmetro e medida com o amperímetro, é a soma das correntes de $i\left(N^{+}\right)$e $i\left(N_{2}^{+}\right)$, isto é:

$$
I_{T}=i\left(N^{+}\right)+i\left(N_{2}^{+}\right)
$$

As correntes são dadas por:

$$
i\left(N^{+}\right)=i_{0}\left(N^{+}\right) \exp \left(-3,53 \times 10^{16} p q_{1} x\right)
$$

e

$$
i\left(N_{2}^{+}\right)=i_{0}\left(N_{2}^{+}\right) \exp \left(-3,53 \times 10^{16} p q_{2} x\right)
$$

onde $q_{1}$ e $q_{2}$ são as seções de colisão efetiva para $\mathrm{N}^{+}$e $\mathrm{N}_{2}^{+}$, respectivamente. $p$ é a pressão de deposição e $x$, a distânça entre a fonte de íons e o substrato. 
A relação entre as correntes iniciais $i_{0}\left(N_{2}^{+}\right)$e $i_{0}\left(N^{+}\right)$é dada pela expressão [62]:

$$
i_{0}\left(N_{2}^{+}\right)=8 i_{0}\left(N^{+}\right)
$$

Substituindo as equações (A.5), (A.6) e (A.7) na equação (A.4) resulta:

$$
i_{0}\left(N^{+}\right)=\frac{I_{T}}{\exp \left(-3,53 \times 10^{16} p q_{1} x\right)+8 \exp \left(-3,53 \times 10^{16} p q_{2} x\right)}
$$

Então, a corrente de íons corrigida para nitrogênio $I_{c}$ é dada por:

$$
\begin{gathered}
I_{c}=i_{0}\left(N_{2}^{+}\right)+i_{0}\left(N^{+}\right)=9 i_{0}\left(N^{+}\right) \\
I_{c}=\frac{9 I_{T}}{\exp \left(-3,53 \times 10^{16} p q_{1} x\right)+8 \exp \left(-3,53 \times 10^{16} p q_{2} x\right)}
\end{gathered}
$$

A referência [98] dá os gráficos de $q_{1}$ e $q_{2}$ para a energia de 0 a 2000 eV. Os valores

\begin{tabular}{|c|c|c|c|c|c|}
\hline $\mathrm{N}^{+}$ & Energia & $q_{1} \times 10^{-16}$ & $\mathrm{~N}_{2}^{+}$ & Energia & $q_{2} \times 10^{-16}$ \\
\hline & $(\mathrm{eV})$ & $\left(\mathrm{cm}^{2}\right)$ & & $(\mathrm{eV})$ & $\left(\mathrm{cm}^{2}\right)$ \\
\hline & 1000 & 5,18 & & 1000 & 22,96 \\
\hline & 800 & 4,98 & & 800 & 23,52 \\
\hline & 600 & 4,79 & & 600 & 24,23 \\
\hline & 400 & 4,57 & & 400 & 25,24 \\
\hline & 200 & 4,46 & & 200 & 26,96 \\
\hline
\end{tabular}
de $q_{1}$ e $q_{2}$ para a energia de íons de 200, 400, 600, 800 e 1000 eV são indicados na tabela A.1.

Tabela A.1: Valores de $q_{1}$ e $q_{2}$ para algumas energias do feixe de íons de nitrogênio [98].

São mostradas abaixo algumas fórmulas úties para calcular o fluxo de íons de nitrogênio (I).

A corrente de íons corrigida: $I_{c}(\mathrm{~mA})$

A densidade de corrente: $\rho=\frac{I c}{\pi(2,5)^{2}} \mathrm{~mA} / \mathrm{cm}^{2}$ 
O fluxo de íons de nitrogênio é dada por:

$$
I=\frac{I_{c} \times 10^{-3}}{\pi(2,5)^{2} \times 1,602 \times 10^{-19}}=0,318 \times 10^{15} \times I_{c} \quad \text { ions } /\left(\mathrm{cm}^{2} \mathrm{~s}\right)
$$

\section{A.2 Cálculo de fluxo de átomos de carbono evapora- dos, A}

O fluxo de átomos de carbono evaporados $A$ pode ser calculado a partir da taxa de deposição $T_{d}(\AA / s)$. Em baixo são mostradas algumas fórmulas para calcular a $A$.

A taxa de deposição: $T_{d} \times 10^{-8}(\mathrm{~cm} / \mathrm{s})$

A massa atômico do carbono: $M=12,011 \mathrm{~g}$

A densidade do grafite: $\rho=2,25 \mathrm{~g} / \mathrm{cm}^{3}$

O número de Avogadro: $N_{a}=6,022 \times 10^{23}$ átomos $/ \mathrm{mol}$

O $A$ é dado pela seguinte expressão:

$$
A=\frac{T_{d} \times 10^{-8} \times \rho}{M} N_{a}=1,128 \times T_{d} \times 10^{15} \quad \text { atomos } /\left(\mathrm{cm}^{2} \mathrm{~s}\right)
$$

\section{A.3 Cálculo de R(I/A)}

A R(I/A) é dada pela equação (A.11) dividida pela (A.12), isto é:

$$
\mathrm{R}(\mathrm{I} / \mathrm{A})=0,28 \frac{I_{c}}{T_{d}}
$$




\section{Apêndice B}

\section{Participação em congressos}

Montagem e caracterização do sistema de deposição assistida por feixe de íons.

K.C. Lopes; M. Matsuoka; W. Sucasaire; J.C. Mittani; C.C. Perego; A.C. Tromba;

O.B. de Morais; A.O.R. Meira

USP, Instituto de Física, C.P. 66318, 05315-970, São Paulo, SP

XXVI Congresso Brasileiro de Aplicações de Vácuo na Indústria e na Ciência Londrina - PR, 30 de Julho, 2005.

Filmes finos de nitreto de carbono, nitreto de boro e nitreto de índio preparados com método de deposição assistida por feixe de íons.

M. Matsuoka; W. Sucasaire; K.C. Lopes; M. Pontes; J.F.D. Chubaci; L. Avanci; J.C. Mittani Instituto de Física, Universidade de São Paulo, C.P. 66318, 05315-970 - São Paulo - SP

XXVI Congresso Brasileiro de Aplicações de Vácuo na Indústria e na Ciência Londrina - PR, 30 de Julho, 2005.

Raman spectroscopy studies of carbon nitride films prepared on $\operatorname{Si}(100)$ substrate by ion beam assisted deposition.

Wilmer Sucasaire, ${ }^{a}$ Masao Matsuoka, ${ }^{a}$ Karina C. Lopes,${ }^{a}$ Juan C. R. Mittani, ${ }^{a}$ Luis H. Avanci, ${ }^{a}$ Jose F. D. Chubaci, ${ }^{a}$ Nemitala Added, ${ }^{a}$ Vladimir Trava ${ }^{b}$ and Evaldo J. Corat ${ }^{b}$

${ }^{a}$ Instituto de Física, Universidade de São Paulo, CP 66318, 05315-970 São Paulo-SP, Brazil

${ }^{b}$ Instituto Nacional de Pesquisas Espaciais, 12227-010 São José dos Campos-SP, Brazil

III Congresso Brasileiro de Carbono - Carbono 2005

Rio de Janeiro - RJ, de 07 à 11 de novembro, 2005 


\title{
Apêndice C
}

\section{Artigos publicados}

\author{
Journal of the Brazilian Chemical Society \\ Print ISSN 0103-5053 \\ J. Braz. Chem. Soc. vol.17 no.6 São Paulo Sept./Oct. 2006
}

Raman and infrared spectroscopy studies of carbon nitride films prepared on Si (100) substrates by ion beam assisted deposition

Wilmer Sucasaire $^{I}$; Masao Matsuoka ${ }^{I}$; Karina C. Lopes ${ }^{I}$; Juan C. R. Mittani ${ }^{I}$; Luis H. Avanci $^{I}$; Jose F. D. Chubaci ${ }^{I}$; Nemitala Added ${ }^{I}$; Vladimir Trava ${ }^{I I}$; Evaldo J. Corat ${ }^{I I}$

${ }^{I}$ Instituto de Física, Universidade de São Paulo, CP 66318, 05315-970 São Paulo-SP, Brazil

${ }^{I I}$ Instituto Nacional de Pesquisas Espaciais, 12227-010 São José dos Campos-SP, Brazil 